$11-2013$

\title{
The relationships among heritage language proficiency, ethnic identity, and self-esteem
}

Shu-Chun Yu

Follow this and additional works at: https://via.library.depaul.edu/soe_etd

Part of the Bilingual, Multilingual, and Multicultural Education Commons

\section{Recommended Citation}

$\mathrm{Yu}$, Shu-Chun, "The relationships among heritage language proficiency, ethnic identity, and self-esteem" (2013). College of Education Theses and Dissertations. 136.

https://via.library.depaul.edu/soe_etd/136

This Dissertation is brought to you for free and open access by the College of Education at Digital Commons@DePaul. It has been accepted for inclusion in College of Education Theses and Dissertations by an authorized administrator of Digital Commons@DePaul. For more information, please contact digitalservices@depaul.edu. 
DePaul University

College of Education

\section{THE RELATIONSHIPS AMONG HERITAGE LANGUAGE PROFICIENCY, ETHNIC IDENTITY, AND SELF-ESTEEM}

A Dissertation in Education

with a Concentration in Curriculum Studies

by

Shu-Chun $\mathrm{Yu}$

(C) 2013 Shu-Chun $\mathrm{Yu}$

Submitted in Partial Fulfillment

of the Requirements

for the Degree of

Doctor of Education

November 2013 
UMI Number: 3577929

All rights reserved

INFORMATION TO ALL USERS

The quality of this reproduction is dependent upon the quality of the copy submitted.

In the unlikely event that the author did not send a complete manuscript and there are missing pages, these will be noted. Also, if material had to be removed, a note will indicate the deletion.

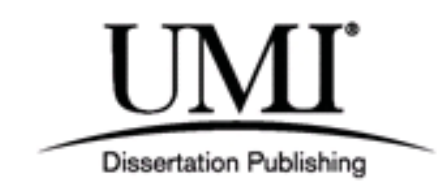

UMI 3577929

Published by ProQuest LLC (2014). Copyright in the Dissertation held by the Author.

Microform Edition (C) ProQuest LLC.

All rights reserved. This work is protected against unauthorized copying under Title 17, United States Code

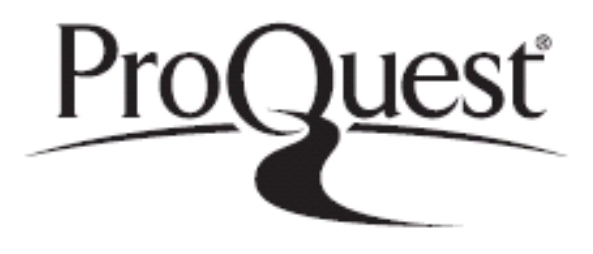

ProQuest LLC.

789 East Eisenhower Parkway

P.O. Box 1346

Ann Arbor, MI 48106 - 1346 
We approve the dissertation of Shu-Chun Yu.

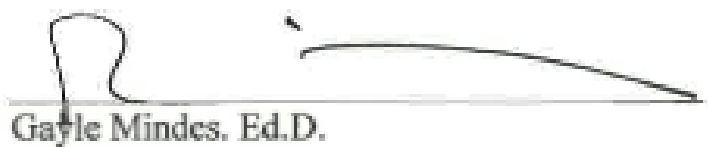

Gayle Mindes. Ed.D.

Professor of Education

Quly 2, 2013

Dissertation Advisor

Committee Chair

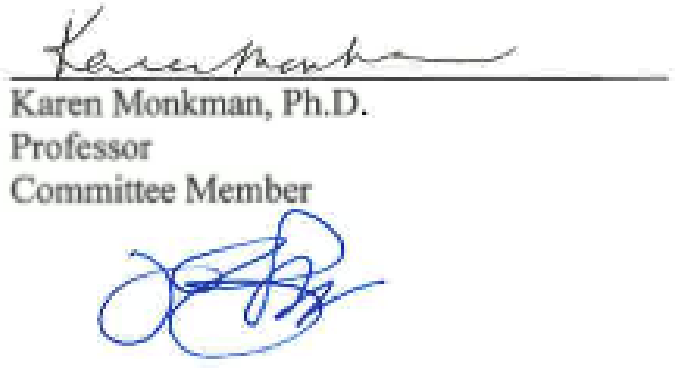

Jason Goulah, Ph.D.

$7-2-2013$

Date

Associate Professor

Committee Member

$\frac{7.2 \cdot 20 / 3}{\text { Date }}$




\begin{abstract}
Language plays an important role in linking with the past, with national origins; it is an indispensable tool for communication. With the trend toward globalization and the continual change of the ethnic composition of the U.S. population, there is increasing awareness in the U.S. that not every child is raised in an English-only family. The purpose of this research was to explore the relationships among heritage language proficiency, ethnic identity, and self-esteem in the American-born Chinese (ABC) children who went to the Chinese language schools for Chinese language learning on weekends. There were three research questions to be answered in this study: (1) What is the relationship between Chinese heritage language proficiency and ethnic identity, (2) Is there any connection between heritage language proficiency and self-esteem, and (3) How does ethnic identity associate with self-esteem? A total of 63 students and their 56 parents were surveyed with the Children's Self-Perception of Chinese Language Learning Survey and the Parents' Demographic Questionnaire, respectively. Results showed that there were positive relationships between Chinese heritage language proficiency and ethnic identity, language proficiency and self-esteem, and ethnic identity and self-esteem. There was a significant group difference on the ethnic identity by Chinese language proficiency across the two subgroups: at least one parent from Taiwan and at least one parent from Mandarin-speaking countries other than Taiwan. However, no group difference was found on the self-esteem by Chinese language proficiency. Limitations and implications were discussed.
\end{abstract}

Keywords: heritage language proficiency, ethnic identity, and self-esteem. 


\section{TABLE OF CONTENTS}

List of Tables..................................................................

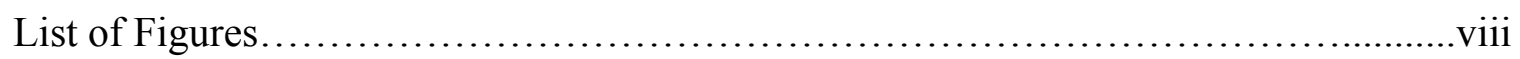

Acknowledgements........................................................

Chapter One: Introduction..................................................

Statement of the Problem................................................... 2

The Debate Between English-Only and Bilingual Education..............

The Problem of Language Shift .................................

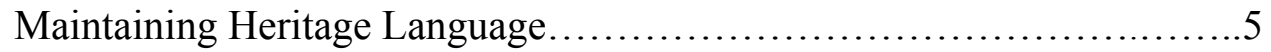

The Functions of Community-Based Chinese Heritage Language Schools6

Statement of Purpose .....................................................

Significance of the Study........................................... 10

Definition of Terms............................................... 11

Design of the Research Presentation..................................... 13

Chapter Two: Literature Review............................................14

The History of Chinese Immigration to the United States...................... 14

The First Era: The Gold Rush Era..................................15

The Second Era: A Series of Chinese Exclusion Policies................16

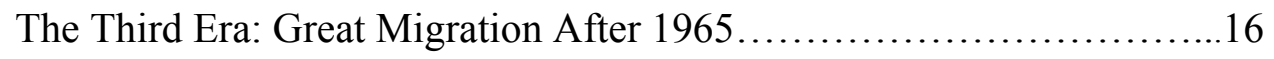

Acculturation: Learning a Second Culture............................... 17

The Controversy of Assimilation in Education.........................18

Bilingual Education in the United States...........................21

Learning Chinese Heritage Language in Chinese Language Schools ............24 
The Crisis of Heritage Language Loss.................................25

Why Maintain Chinese Heritage Language.............................27

The History of Chinese Language Schools...........................29

The Importance of Chinese Heritage Language Schools. .................32

Heritage Language Proficiency, Ethnic Identity, and Self-Esteem.................34

Ethnic Identity ................................................... 34

Self-Esteem...........................................................

Research on Heritage Language Proficiency, Ethnic Identity, and Self-

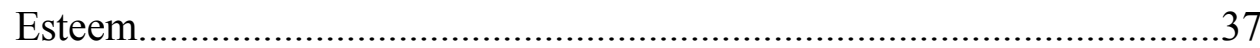

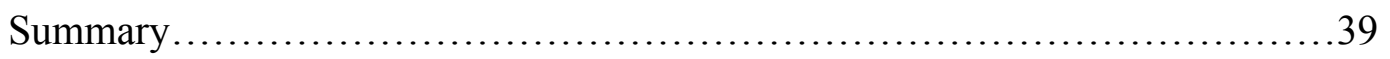

Chapter Three: Methodology.......................................................42

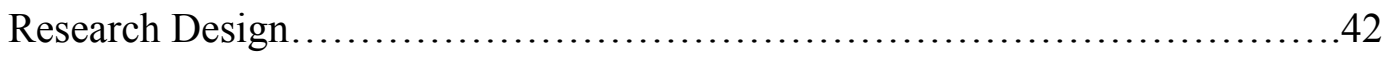

Parents' Demographic Questionnaire. ..................................43

Demographic Questionnaire. .....................................43

Self-Evaluated Chinese Language Fluency Questionnaire (CLFQ).........43

Twelve-item Multigroup Ethnic Identity Measure (MEIM)...............45

Rosenberg's Self-Esteem Scale (RSE). ...............................46

Selection of Study Participants..........................................48

Sampling Participants............................................... 49

Background of the Chinese schools..................................51

Data Sources............................................................ 54

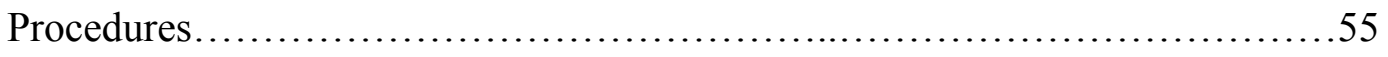

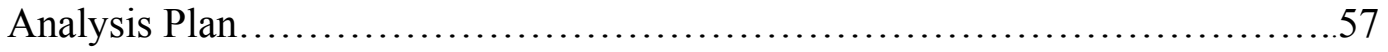




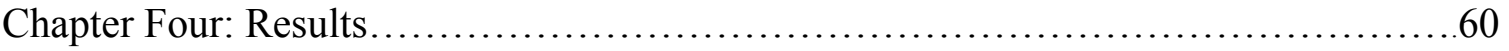

Descriptive Statistics of Sample and Demographic Information..................60

Internal Reliabilities of Measures..............................................69

Analysis of Research Questions and Hypotheses................................71

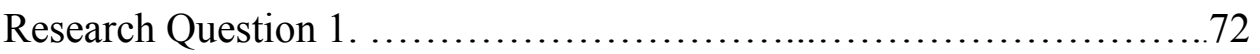

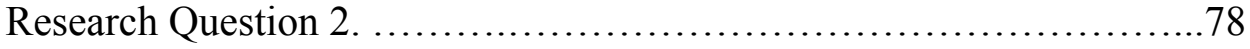

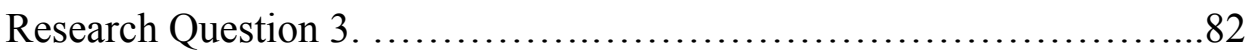

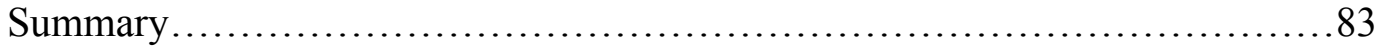

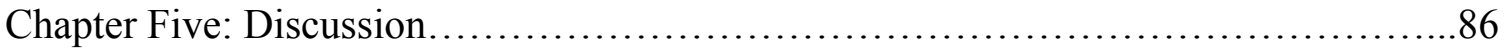

Summary and Interpretation of the Research Findings.........................86

The Relationship between Chinese Heritage Language Proficiency and

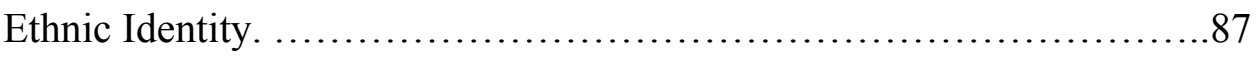

The Connection between Chinese Heritage Language Proficiency and

Self-Esteem. .......................................................... 88

The Association between Ethnic Identity and Self-Esteem................89

Additional Findings in the Present Study. .............................90

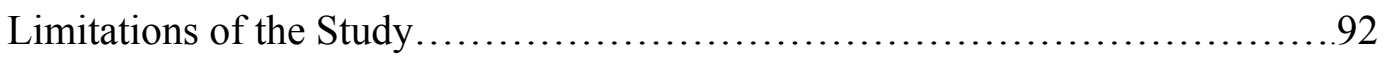

Implications for Education and Future Research..............................93

Implications for the Chinese Language Schools and Parents...............94

Implications for the $\mathrm{K}-12$ Educators and Policymakers...................96

Implications for Future Research.....................................99

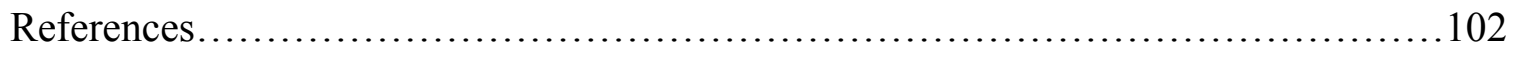




\section{LIST OF TABLES}

Table 1 The Distribution of Student Participants..................................51

Table 2 The Comparison of Mandarin Chinese: Characters and Phonetic Systems.......53

Table 3 Crosstabulation of Gender and School..................................61

Table 4 Crosstabulation of Gender and Grade....................................62

Table 5 Primary Language Use: Parents and Children............................63

Table 6 Descriptive Statistics of Chinese Language Proficiency Items...............65

Table 7 Distribution of Father and Mother's Highest Level of Education................68

Table 8 Reasons of Sending Child to Chinese Language School......................69

Table 9 Means, Standard Deviations, and Cronbach's Alphas for Measures.............70

Table 10 Correlations of Research Variables........................................ 73

Table 11 Subgroup by Chinese Language Proficiency on Ethnic Identity................75

Table 12 Subgroup by Subscale Understanding/Speaking on Ethnic Identity............76

Table 13 Subgroup by Subscale Reading/Writing on Ethnic Identity..................77

Table 14 Item Mean Scores by Subgroup....................................... 78

Table 15 Subgroup by Chinese Language Proficiency on Self-Esteem.................80

Table 16 Subgroup by Subscale Understanding/Speaking on Self-Esteem...............81

Table 17 Subgroup by Subscale Reading/Writing on Self-Esteem......................82 


\section{LIST OF FIGURES}

Figure 1 The procedure of survey distribution and collection.

Figure 2 Primary Language Use at Home and Child's Understanding/Speaking Abilities

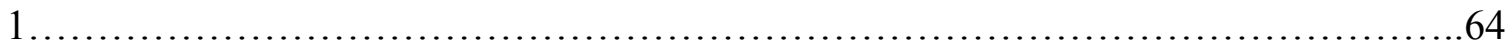

Figure 3 Primary Language Use at Home and Child's Understanding/Speaking Abilities

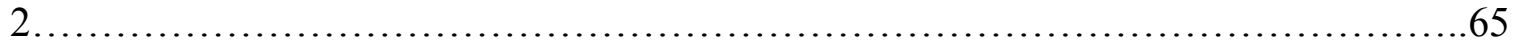

Figure 4 Primary Language Use at Home and Child's Understanding/Speaking Abilities

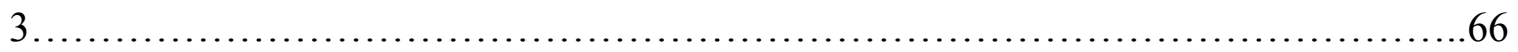

Figure 5 Self-Evaluated Chinese Language Proficiency............................67 


\section{ACKNOWLEDGEMENTS}

I would never have been able to finish my dissertation without the help and support of the kind people around me; to only some of whom it is possible to give particular mention here.

First and foremost, inexpressible thanks to my committee chair, Dr. Gayle Mindes, for providing me the encouragement, advice, and support from the very beginning when I had only a little knowledge of my topic to the final integration of this project. Whenever I need her, she is always there to help. Sincerely thanks go to other committee members, Dr. Karen Monkman and Dr. Jason Goulah, for their constructive feedback and encouraging words. And many thanks go to Drs. Barbara Radner and Darlene Unger for their support and thoughtful criticism of my preliminary research. It is sincerely a privilege to work under such a knowledgeable and caring committee of professionals who are truly dedicated to the success of their students.

At this time, I wish to thank all the principals, teachers, parents, and students of the Chinese language schools who cooperated with and involved in this study. This study would not have been possible without their participation.

To my family and friends in Taiwan, thank you for the support and care. To my classmates of the doctoral program at DePaul University, thank you for the help and encouragement. Last but not the least, my deepest gratitude goes to my husband, Calvin, for his support, patience, and love. When I was upset and almost gave up, he always listened to me and cheered me up. And to my son, Victor, thank you for your understanding when I was busy doing the research and could not stay with you. This research is dedicated to you. 


\section{Chapter One: Introduction}

In the contemporary globalized world, many people immigrate to other countries to pursue a better life, and the United States is one of the most popular countries for those immigrants. Portes and Rumbaut (2001) asserted that the motivations of immigrants converge in a different way as they reach the United States shores: to survive in any manner possible and then to move ahead, seeking all the attainable support mechanisms, the open and hidden avenues for mobility that a complex and advanced society makes available. Immigrants who migrate to the United States come from all over the world. As the latest census shows, the total 2010 U. S. population consists of $63.7 \%$ White, $16.3 \%$ Hispanic/Latino, $12.2 \%$ Black/African-American, 4.7\% Asian, and 3.1\% others (U.S. Census Bureau, 2010, http://factfinder2.census.gov/faces/nav/jsf/pages/index.xhtml). When counting the U.S. population growth over the last decade (i.e., from 2000 to 2010), newcomers plus births to all immigrants had shared $80.4 \%$ of the total U.S. population growth (Camarota, 2012). Among the population, Asian, which increased by $43.3 \%$ was the fastest growing group between 2000 and 2010 (Humes, Jones, \& Ramirez, 2011).

The primary reason for Asians crossing the ocean to the U.S. is to look for more economic opportunities (Suárez-Orozco, Suárez-Orozco, \& Qin, 2004). This phenomenon can be traced back to the first era of immigration, particularly Chinese immigrants, who in 1850s came here based on the demand of the U.S. for labor for gold mining and then railroad construction (Lai, 2004; Takaki, 1989). This pursuit of the "American Dream" resulted in the population of immigrants in the U.S. 
increasing rapidly for decades. Within the Asian population, Chinese-Americans, numbering 3,347,229 including one third native-born and two-thirds foreign-born immigrants, made up the largest group in 2010 (U.S. Census Bureau, 2010). In addition, among these foreign-born Chinese immigrants age 5 and over, 91.7 percent reported speaking languages other than English at home, and 60.6 percent reported speaking English less than “very well” (U.S. Census Bureau, 2010).

\section{Statement of the Problem}

In the process of such geographical relocations, immigrant families are faced with two salient issues: first, whether they should maintain their language and culture of origin or assimilate to the host country (Portes \& Rumbaut, 2001); second, if they choose to keep their heritage, how to maintain children's heritage language in an English-dominant environment and develop their bilingual skills (Zhang, 2008). In addition, a challenge associated with educating linguistically diverse students comes out in educational systems as well, especially regarding which language should be used for instruction (Garcia, 2002).

The debate between English-only and bilingual education. Controversy over educational policies for newcomers exists between English-only and bilingual education (Yearwood, 2008). One line of thinking holds that assimilation and monolingual, English in this case, education speeds a minority student's transit into the majority culture and improves his or her chances of competing in the mainstream society by replacing the student's heritage language with the dominant language (Portes \& Rumbaut, 2006). However, other researchers argue that the development of the home language is necessary for the development of the second 
language in school (Garcia, 2002). Furthermore, they suggest that schools should create an environment that embraces as well as enhances the cultural diversity of immigrant groups (Garcia, 2002). There is no doubt that there is a tendency toward cultural pluralism in the U.S. and more and more educators encourage the use of the minority languages in terms of cultural pluralism (Bankston \& Zhou, 1995).

Although the ideology of English only has continued to exist in the educational system, opponents have resisted English monolingualism and suggested bilingual education for ethnic minority students (Cheatham, Santos, \& Ro, 2007). With the trend toward globalization and the continual change of the ethnic composition of the U.S. population, Americans ought to be able to accept linguistic pluralism (Zhang, 2008).

Federal support of bilingual education in 1968 had shown a national commitment for an important change in the educational policy, that is, it values the assets of a people with a heritage language other than English (Rodriguez, 1968). The Bilingual Education Act in 1968 officially advanced the development of bilingual education programs across the nation, which, in other words, acknowledged the failure of English-only school policies (Ryan \& Carranza, 1977). In fact, when the population of the United States became more and more diverse since the 1970s, the ideology of English monolingualism changed (Bankston \& Zhou, 1995). However, even though the Federal government passed the law to promote bilingual education, the debate between English-only and bilingual education is still on going (Ovando, 2003). In some states, such as Florida and New York, educators have pursued language maintenance policies, which are the retention of one's heritage language 
other than English and programs in order to enable students to be bilingual (Ambert \& Melendez, 1985). On the other hand, some states still legislate to make English the only language to teach language minority students, for example, the passage of Propositions 227 and 203 in California and Arizona, and the passage of the Massachusetts version of the Unz initiative (Hornberger, 2004). In brief, the two language policies, English only and bilingualism, have alternated in American educational history (Zhang, 2008) and there are still the arguments that challenge contemporary education in the U. S (Ovando, 2003). However, language shift to English in the children of immigrants became a problem of heritage language loss and affected family relationship (Wong-Fillmore, 1991), which continues to the present (Tannenbaum, 2005; Zhang, 2008).

The problem of language shift. Language plays an important role in linking with the past, with national origins. It helps children to understand the world, to communicate with others (Joseph, 2004), as well as to identify ethnic or cultural identity (Fong, 2004). However, the language ideology of English hegemony over the children of immigrants' home languages, implicit at schools and in the mainstream society, can accelerate their pace of language shift and lead to the unwillingness to speak the home languages (Zhang, 2008). Once the children have mastered English, they make English their primary, preferred language, which is often achieved at the expense of heritage language loss (Veltman, 2000; Zhang, 2008). The situation is especially obvious in the second-generation immigrants who are native born (Maloof, Rubin, \& Niller, 2006; Portes, 2002; Zhang, 2008). In her study, Wong-Fillmore (1991) found that over 1,100 families' children from a 
number of language backgrounds (Korean, Chinese, Spanish, Khmer, and Vietnamese) shift to English shortly after entering English-language schools. With the overwhelming pressure on Chinese to assimilate, the language shift to English, particularly for the native-born children, is taking place at a fast rate in the community (Wong \& López, 2000). In addition, Portes and Rumbaut (2001), in their study of language assimilation on over 5,200 children of immigrants from 77 different nationalities attending eighth and ninth grades, concluded that no secondgeneration group is fluent (i.e., the ability to speak, listen, read, and write well) in its mother tongue by age 17. "What happens to familial relations when the language children give up happens to be the only language that parents speak? What is lost when children and parents cannot communicate easily to one another?" (WongFillmore, 1991, pp. 342-343). Ng (1999) asserted that with limited proficiency in the heritage language, it is hard for children to create a positive impact on the communication and on the relationship with their parents. In other words, bilingualism increases communication between immigrant youths and their parents and reduces the generational conflicts commonly found in families in which parents remain foreign monolinguals and the children have shifted entirely to English (Portes, 2002).

Maintaining heritage language. The population of the school-age (ages 5-17) children who spoke a language other than English at home rose from 4.7 million to 11.2 million, which grew $138.84 \%$ between 1980 and 2009 (The Condition of Education, 2011). This data reveals that heritage languages are important for immigrant children, especially for their communication at home. In order to help 
the preservation of heritage languages, Joseph (2004) suggested creating resources that help immigrant descendants to be bilingual in both heritage language and dominant language. Landry and Allard (1992) identified that family, school, and socio-institutional milieus are the most important social domains for bilingual development. Although there are many bilingual programs in the public schools nationwide, the majority of the programs play a transitional role, whose ultimate goal is to help English language learners achieve English proficiency, rather than maintain their heritage languages (Garcia, n. d), especially in recent years when support for full bilingual programs has been reduced or eliminated. The function of Chinese-English bilingual programs is no exception (Guthrie, 1985; Wong, 1980). Rossell (2003) found that in some Chinese bilingual-education classrooms, the English language learners of Chinese origin only receive a small part of instruction in Mandarin Chinese as a foreign language rather than as a heritage language. The subject matter and literacy are taught in English in these classrooms. Under the restrictive language policies in public education, the majority of school-age children of immigrants who learn their heritage languages do so at community-based heritage language schools (Chao, 1996; Douglas, 2005; Shin, 2005). As a result, heritage language schools as a community institution have become widespread and vigorous in providing supplemental heritage language support (Li, 2005).

\section{The functions of community-based Chinese heritage language schools.}

The community-based heritage language schools, which usually are organized and managed by groups of interested parents or by religious, cultural, and civic institutions (Lai, 2004), can provide the children opportunities to learn their own 
languages and, furthermore, decrease the crisis of heritage language loss (Maloof et al., 2006). Fishman (1985) found that minority language communities in the United Sates have been deeply committed to maintaining their community languages through the establishment of language programs where children are expected to develop existing heritage language proficiencies and cultural knowledge. Taking Chinese immigrants as an example, growing up with Confucian culture, which emphasizes respect for one's origin and ancestry, the first-generation Chinese parents take pride in their ethnicity, language, and culture (Zhang, 2008). They work hard with the communities to maintain the heritage language among their American-born children. Besides teaching the heritage language at home, many parents also send their children to the community-based weekend Chinese schools where provide more opportunities for the children to use and learn the home language (Zhang, 2008). A study conducted by Lu (2001) showed that new Chinese immigrants strongly hope their children will preserve the Chinese culture through learning Chinese language and participating in the communal activities and communication practices. Therefore, the maintenance of the Chinese heritage language among the second-generation children becomes an important topic for the Chinese community in the forms of weekend community-based Chinese language schools (Cheng, 2010; Zhang, 2008). The preservation of the Chinese culture that keeps family ties and maintains the Chinese identity is the main reason why parents send their children to the Chinese language schools (Lu, 2001).

Language is one of the most prominent factors in the formation of one's ethnic and cultural identity (Fong, 2004; Portes, 2002; Ryan \& Carranza, 1997; Zhang, 
2008) and self-esteem (Wright \& Taylor, 1995; Yearwood, 2008). Chinese immigrant parents value the cultural identity and pride in the second generation and seek to transmit the cultural identity by means of the Chinese language (Zhang, 2008); as some parents said in an interview conducted by Zhang (2008): "without the Chinese language, you are no longer a Chinese" (p. 110). Bankston and Zhou (1995) also proposed that heritage language learning and ethnic identity have twoway casual orders, that is, strong ethnic identity maintains and improves heritage language learning, and heritage language learning can reinforce the sense of ethnic identity as well. Heritage language learning also increases learners' self-esteem (LaFromboise, Coleman, \& Gerton, 1993; Wright \& Taylor, 1995; Yearwood, 2008). For example, Wright and Taylor (1995) conducted research on children from Inuit, White, and mixed-heritage who are educated in their heritage languages and found that early heritage language education can have a positive effect on the self-esteem of the minority language students.

Briefly speaking, these empirical studies, as aforementioned, support that heritage language learning strengthens family relationship (Lu, 2001; Portes, 2002), helps develop ethnic identity (Bosher, 1997; Lu, 2001; Portes, 2002) and selfesteem (Wright \& Taylor, 1995; Yearwood, 2008), and betters academic achievement (Bosher, 1997; Yearwood, 2008). Ultimately, "heritage language development can help promote a healthy sense of multiculturalism, an acceptance not only of both the majority and the heritage culture, but a deeper understanding of the human condition" (Krashen, 1998, p. 9). Immigrant parents and educators who care about this topic and know the value of learning heritage language can 
encourage the children of immigrants to learn their own heritage languages. Even policymakers should re-think the importance of heritage language learning in the public school settings as the student population has become more diverse and students have brought different cultures to the classroom.

\section{Statement of Purpose}

In this current study, I planed to explore the relationships among heritage language proficiency, ethnic identity, and self-esteem of the American-born Chinese (ABC) children who went to the Chinese language schools for Chinese language learning on weekends. Regarding children's heritage language learning, some researchers argue that only having basic communication skills (i.e., understanding and speaking) in the heritage language spoken at home may result in a negative impact on the relationship with one's parents and suggest emphasizing children's literacy ability (i.e., reading and writing) as well (Ng, 1999; Zhang, 2008). Therefore, heritage language proficiency, in this study, denoted the proficiency of Mandarin Chinese in understanding, speaking, reading, and writing. In addition, under the umbrella of the Chinese language, there are seven major dialect families: Mandarin (spoken by 70\% of the total Chinese speaking population), Wu (8.4\%), Xiang (5\%), Yue (5\%, loosely called Cantonese in the United States; Cantonese is a group of Yue dialects), Hakka (4\%), Gan (2.4\%), and Min (1.5\%) (Li \& Thompson, 1981). Since Mandarin is the language spoken by the majority of Chinese population, Mandarin Chinese learning was targeted in the current study.

By conducting this current research, I, on the one hand, aimed at providing meaningful information to the Chinese language school students, parents, teachers, 
and administrators of Chinese teaching and learning. On the other hand, I hoped to shed some light on the useful resources the community-based heritage language schools can bring to the K-12 school system in terms of the heritage language development and maintenance and second language acquisition. Although the small areas covered in this research could not be a representative sample of the Chinese across the nation, I hoped that the current study could help parents, educators, policymakers, and bilingualism supporters who are interested in heritage language learning gain insight into the importance of heritage language retention to the children of immigrants in this particular location at a particular time.

\section{Significance of the Study}

There are many studies investigating how heritage language learning positively affects students' ethnic identity, school effort, and mental health (e.g., Bankston \& Zhou, 1995; Lu, 2001; Portes, 2002; Ryan \& Carranza, 1997; Yearwood, 2008). Yet, only a few studies focused on the Chinese population (Ng, 1999). During the last decade, the population of Asians in the United States had increased by $43.3 \%$, which became the fastest growing group in the U.S. (Humes et al., 2011). In addition, Chinese, the largest Asian group in the nation, accounted for $1.1 \%$ of the U.S. total population in the 2010 censes (U.S. Census Bureau, 2010). With the dramatically increasing population in the U.S., Asians, especially Chinese, have become an important minority group in need of investigation today. Moreover, a majority of studies on heritage language learning focused on high school and college students in the traditional school settings (Bankston \& Zhou, 1995; Bosher, 1997; Cho, Cho, \& Tse, 1997; Feuerverger, 1991; Jo, 2001; Kim \& Chao, 2009). Research on the same 
topic but targeting children who go to the community-based language schools and investigating the relationships between both ethnic identity and self-esteem is scarce, which made the current research more salient.

By examining the relationships among heritage language proficiency (i.e., understanding, speaking, reading, and writing), ethnic identity, and self-esteem, I attempted to investigate how the second generation of Chinese immigrants who attended a Chinese heritage language school and developed their heritage language fluency sensed with regard to ethnic identity and self-esteem. The results might inform the Chinese language schools, parents, educators, and policymakers about the value of heritage language learning and the effects provided by the Chinese language schools. There were three research questions to be answered in this study: (1) What is the relationship between Chinese heritage language proficiency and ethnic identity, (2) Is there any connection between heritage language proficiency and self-esteem, and (3) How does ethnic identity associate with selfesteem?

\section{Definition of Terms}

1. Bilingual education programs: Bilingual education programs are the programs which, in the U.S., tend to apply both English and another language other than English as language of instruction to help immigrant students learn in schools by developing their heritage language as well as English.

2. Heritage language: Heritage language is a parent's primary language one acquires and speaks in the home where the dominant language, English in this case, is not spoken or not exclusively spoken. There are many terms used 
interchangeable with heritage language, such as home language, parental language, and ancestral language.

3. Ethnic identity: Ethnic identity is dynamic and socially constructed identity of an ethnic community to which the individual belongs. In this study, I adopted Nagel's (1999) definition, which is ethnic identity "is constructed out of the material of language, religion, culture, appearance, ancestry, or regionality. The location and meaning of particular ethnic boundaries are continuously negotiated, revised, and revitalized, both by ethnic group members themselves as well as by outside observers" (p. 57).

4. Self-esteem: Self-esteem refers to an individual's overall evaluation of himself or herself such as perceptions of competence, coping skills, internal locus of control by comparing the self with others (Cheng, 2010; Haney \& Drulak, 1998; Koch, 2006). It reflects the part of self-concept, such as autonomous, individual, and separate self (Whitesell, Mitchell, Spicer, \& The Voice of Indian Teens Project Team, 2009).

5. Heritage language proficiency: Heritage language proficiency is a measurement of how well an individual has mastered in his or her heritage language. There are four sections of heritage language proficiency categorized in current study: understanding, speaking, reading, and writing, which are usually measured by a test or by self-assessment. In this study, the heritage language proficiency means Mandarin Chinese language proficiency. 


\section{Design of the Research Presentation}

This dissertation was presented in five chapters. Chapter one gave the background of the study by discussing the current immigration situation in the U.S., the issue of assimilation and bilingualism, the problem of language shift, and the maintenance of heritage language. In chapter two, more theoretical and empirical studies relevant to those issues discussed in chapter one were reviewed. Three research questions with five hypotheses were derived from the review of literature in this chapter. In the third chapter, I detailed a research method applied in this research, including research design, selection of the sample, data sources, procedures, and analysis plan of this study. In chapter four, the descriptive statistics were illustrated to show the results in accordance with the research questions, as well as the internal consistency of each measure was tested. The final chapter was a discussion of the research findings and conclusion of the research. Limitations and implications were presented in this chapter as well. 


\section{Chapter Two: Literature Review}

The rapid increase and divergent population of immigrants in the U.S. has challenged the educational policies (Garcia, 2002), and the immigrant families also encounter some difficulties in either choosing assimilation or bilingualism (Portes \& Rumbaut, 2001; Zhang, 2008). Although bilingualism and biculturalism have been suggested as a preferred way for newcomers and their offspring to accommodate themselves to the host society (Berry, 2003; Lee, 2002; Robinson, 2009), the bilingual education programs provided in the formal schools are mostly transitional, which means heritage language instruction is a strategy to help language minority students ultimately proficient in English rather than a goal to maintain their heritage language (Garcia, n.d.). Therefore, those immigrant families who choose to keep their heritage are faced with a problem, that is, how to maintain children's heritage language in an English-dominant environment and develop their bilingual skills (Zhang, 2008). In order to find out solutions for the problem and how heritage language learning benefits these children, the history of Chinese immigration, the acculturation process of the immigrants, the function of the community-based heritage language learning institutions, and the advantages of the maintenance of the heritage language are needed to be concerned and will be discussed in this section.

\section{The History of Chinese Immigration to the United States}

The number of Chinese immigrants in the U.S. had grown dramatically in over one century. In 1880, Chinese immigrants numbering 105,465 comprised only 0.21 percent of the total population in the U.S. (Lai, 2004). In 2010, there were 3,347,229 
Chinese counted in the Federal Census; they made up of 1.1 percent of the total population, which led Chinese to be one of the visible minority groups in the country (U.S. Census Bureau, 2010). The Chinese immigration history in the U.S. can be divided into three major eras: the first era started from the 1849-era California gold rush, the second era began from the passage of the Chinese Exclusion Act in 1882, and the third era happened after the legislation of the Immigrant Act of 1965 (Chang, 2003; Zhang, 2008).

The first era: the gold rush era. In the 1849-era, the gold rush in California resulted in the demand of labor from overseas. Many Chinese males from Guangdong Province migrated to California as labor for gold mining. Since then, Guangdong Province, a densely populated, poverty-stricken area along the coast in southern China, became the main source of early Chinese immigrants in the U.S. (Lai, 2004). As the calm down of the gold fever at the end of 1850s, the Chinese laborers began to be hired to construct the western section of the transcontinental railroad (Lai, Huang, \& Wong, 1980). After the transcontinental line was completed in 1869, most workers went back to California to help develop the economy in areas such as fishing, agriculture, and various light industries (Chen, 1981; Lai et al., 1980). Those able-bodied males, in fact, comprised up to one fourth of the California's physical labor force (Lai, 2004). However, the situation only lasted until the 1880s, when economic recession in the country increased job competition between white workers and Chinese laborers in California (Zhang, 2008). The anti-Chinese resentment grew and spread fast to the whole western coast, and it eventually led to the legislation of the Chinese Exclusion Law in 1882, which forbade the immigration 
of the Chinese laborers (Zhang, 2008). For the next several decades, Chinese immigration to the United States virtually stopped.

The second era: a series of Chinese exclusion policies. The Chinese Exclusion Act, which passed in 1882, renewed in 1902, and extended indefinitely in 1904, blocked the entry of Chinese laborers and prohibited the naturalization of Chinese (Lai et al., 1980). Only certain exempt classes, including teachers, students, officials, travelers, and businessmen were allowed to enter the country (Lai et al., 1980). The National Origins Law, passed in 1924, barred all aliens except the northwestern European immigrants; it even prohibited the entry of Chinese wives of the U.S. citizens (Chen, 1981). During this period of time, those Chinese who were already in the U.S. were forced to develop Chinatowns in big cities like San Francisco and Los Angeles where they stayed segregated among themselves and employed in restaurants, laundries, and garment factories (Takaki, 1989; Zhang, 2008). In brief, in the second era of Chinese immigration history, Chinese laborers were excluded from entering the U.S., and those who remained in the country formed Chinatowns. The ban of Chinese immigrants was not lifted until 1965.

The third era: great migration after 1965. In 1965, another American immigration law, the 1965 Immigration Act, was passed to reopen the gates to immigrants regardless of race and nationality (Takaki, 1989; Zhang, 2008). The new law stipulated a flat quota of 20,000 immigrants per year for every country and allowed the entry of family members on a non-quota basis (Chen, 1981; Takaki, 1989; Zhang, 2008). Thus, Chinese immigrants mainly from Mainland China, Taiwan, and Hong Kong began an influx to the U.S., which made the Chinese 
population grow dramatically from 236,000 in 1960 to 1,079,000 in 1985 (Kwong, 1996), and to 3,347,229 in 2010 (U.S. Census Bureau, 2010) in the 50 years after the new law took effect. According to the 1965 Act, two principles were emphasized as preference for admission: one was to unite the families of the American citizens; the other was to allow persons with professional skills or students who came to earn advanced degrees in the U.S. universities (Kwong, 1996). These principles eventually divided Chinese immigrants into two subgroups: the poorly educated Chinese with low English language skills who live in Chinatowns and work as lowwage labor, and the highly educated, well-spoken, financially and socially affluent middle class who usually settle in suburbs, mixing themselves with other ethnic groups (Chen, 2006; Lu, 2001).

Although a group of the Chinese immigrants from Guangdong Province of South China came to the U.S. in the gold rush era, the group was too small to be prominent in the U.S. population. Only after the 1965 immigration law did a large number of Chinese migrate to the country and became a noticeable minority group (Zhang, 2008). In addition, it was also during the 1960 s when those immigrants started to feel the pressure toward acculturation (Chen, 2006).

\section{Acculturation: Learning a Second Culture}

Acculturation is the learning of a second culture. When the minority individuals come into contact with a mainstream culture, the process of acculturation begins (Zhang, 2008). Gibson and Ogbu (1991) suggested acculturation to be understood as either additive or subtractive. Additive acculturation tends to maintain the heritage culture and language while acquiring 
the new culture and language in the dominant environment. However, subtractive acculturation aims at replacing the old culture with the new. Gibson (1995) argued that it is not subtractive acculturation but additive acculturation that helps immigrant children succeed in school. And bilingual-bicultural education may be one strategy to help reach additive acculturation (Gibson, 1988). Portes and Rumbaut (2001) also endorsed the additive acculturation, which they call selective acculturation: a preservation of native culture and language while learning English and American culture. They found that selective acculturation is linked with the preservation of the fluent bilingualism, which results in less parent-child conflict, higher self-esteem, higher educational and occupational expectation, and higher academic success. However, too often, public schools in this country adopt subtractive acculturation practices, which underline the English-only movement and many types of transitional bilingual education (Garcia, 2002; Gibson, 1995). With the conflict between research results, which support additive acculturation; and school policy in teaching language minority students, which tends to adopt subtractive acculturation, it is crucial to discuss the controversy of assimilation in education and the bilingual education in the United States.

The controversy of assimilation in education. Early in the $20^{\text {th }}$ century, acculturation was viewed as a unidirectional process, which assumed the acculturating individual should ultimately assimilate to the host culture (Pham \& Harris, 2001). Simons defines the unidirectional movement from one cultural group to another as assimilation (as cited in Teske, R. H. C., Jr. \& Nelson, B. H., 1974, p. 363). However, Portes and Rumbaut (2001) asserted that forceful assimilation may 
cause immigrant children to have limited bilingual competence, that is, they have a full command of neither their heritage language nor English. In addition, the loss of heritage culture can result in a variety of relational and psychological stresses in immigrant youth, which, as a result, leave them losing a strong sense of cultural identity (Maloof et al, 2006). These arguments were noticed during the civil rights era of the 1960s, and the federal legislation of the bilingual programs for educating the language minority students had minimized the force of assimilation agendas (Mora, 2009).

The support of assimilation was revived again in the 1980s (Crawford, 2000). An assimilationist agenda (linguistic and cultural) lead to the English-only movement, which emphasizes English as the official and only language used in the United States (Lu, 1998). The movement pushed the anti-bilingual-education ballot initiatives passed in California (1998) with Proposition 227, in Arizona (2000) with Proposition 203, and in Massachusetts (2002) with Question 2 (Mora, 2009). Proponents of the initiatives argue that new immigrants have to discard their native languages and cultural practices in order to fully assimilate into U.S. society, and the instruction in students' native language can only retard their learning of English and academic subjects (Baker, 1993; Javier, 2007; Mora, 2009), even though this view is contrary to research on the language acquisition processes (Bankston \& Zhou, 1995; Cummins \& Swain, 1986; Norton, 2000). However, the English-only initiatives do not produce significant success in terms of the academic achievement (Bratt \& Elbousty, 2010; Lee, 2002; Parrish, Pérez, Merickel, \& Linquanti, 2006; Zehr, 2008). For example, Zehr (2008), based on the data from the National Assessment of 
Educational Progress (NAEP), found the achievement gap in both reading and mathematics is wider between English-learners and non-English-learners in the 4th grade in the three above-mentioned states than in Texas and New Mexico, whose schools provide bilingual education. After examining the California English Language Development Test (CELDT) data and other achievement data, Parrish et al. (2006) argued that it will take 10 years in the public schools to reach only a 40 percent possibility of California's English language learners being reclassified as English proficient. As Lu (1998) concluded, the legislation of English-only instruction in these states, "not only threatens to inhibit the academic advancement of many language minority children, but also deprives these children of the many social advantages resulting from using their mother tongue" (p. 3).

Language minority children usually go to school with some degree of welldeveloped skills in their native language (Lu, 1998). Edelsky (1986) found that these children are willing to learn how a new language works, when they have firm background knowledge of their native languages. Even when the two written forms are obviously different, such as the Chinese characters and the English alphabet, the children can still apply the skills used in their native languages to learn English (Freeman \& Freeman, 1992). If language minority children are thrown into an English-only environment to learn unfamiliar content by using only English, their chances of success in school may be severely reduced (Lu, 1998). Similarly, Portes and Rumbaut (2006) found that while the native-born, second-generation immigrants and long-term residence of immigrant children who were foreign born increase their English skills, their grades are lowered. This concept matches Lee's 
(2002) finding that the U.S. born Chinese-American and Korean-American students who prefer additive acculturation (bilingualism) have superior academic achievement levels to those who choose subtractive acculturation (English only). With controversy over English-only instruction, policymakers and the public should view students' bilingualism as an asset which not only gives students access to knowledge, enhances social interaction and identification with their heritage cultures, but also eases their transition into the U.S. society (Mora, 2009).

Bilingual education in the United States. Bilingual education existed in the U.S. before the $20^{\text {th }}$ century. In the 1850 s, the Cherokee Nation of Oklahoma established twenty-one bilingual schools (Crawford, 2000). Across the urban and rural Midwest, some German-English programs were also created for several decades in the major cities such as St. Louis, Indianapolis, Milwaukee, and Cincinnati (Crawford, 2000; Salinas, 2006). These school systems made conscious decisions based on immigrant parents' demands. For those parents, heritage language maintenance was usually the chief goal of bilingual instruction (Crawford, 2000). It was believed that bilingual education provided a greater chance for the limitedEnglish-proficient (LEP) children to learn English and preserve their native languages at the same time (Salinas, 2006).

The federal mandate for bilingual program began in 1968, the year that the Bilingual Education Act, also known as Title VII of the Elementary and Secondary Education Act, was passed followed by five major reauthorizations in 1974, 1978, 1984, 1988, and 1994 (Garcia, 2002). It is a program that "instruction given in, and study of English and to the extent necessary to allow a child to progress effectively 
through the education system, the native language" (Schneider, 1976, p. 125). The Act is an important change in educational policy, which gives moral and legislative recognition to the assets of a person whose native language is not English (Rodriguez, 1968). According to Rodriguez (1968), the purposes of bilingual education for the child and the school are that It reduces retardation through ability to learn with the mother tongue immediately. It reinforces the relations of the school and the home through a common communication bond. It projects the individual into an atmosphere of personal identification, self-worth, and achievement. It gives the student a base for success in the world of work. It preserves and enriches the cultural and human resources of a people. (p. 7)

The program initiatives are differentiated by the way they apply a native language and English during instruction (Garcia, 2002). However, the 1978 Amendments proclaimed that the purpose of utilizing a native language in instruction was to promote English proficiency. Therefore, the ultimate goal of the bilingual program initiatives was to help children master in English rather than preserve their native languages. Those initiatives, which were designed only for the native language and culture maintenance, would be excluded from funding (Stewner-Manzanares, 1988). That is why the majority of the programs are transitional bilingual education, which offers a transition from the early-grade native-language-emphasis instruction to the later-grade English-emphasis instruction and ultimately to the English-only instruction (Garcia, 2002). In brief, the transitional bilingual education aims at a 
transition to English rather than the teaching of English alongside the maintenance of the native language (Garcia, 2002).

One of the most essential qualities of bilingualism is being able to switch languages when the situation calls for it. The ability to change language involves both the capacity to maintain the languages separately and the competence to bring them into contact when needed (Javier, 2007). Students who have competence in their home languages and in English can enjoy "the richness and values of two linguistic systems and two cultural traditions that complement and enhance each other" (Mora, 2009, p. 16). Researchers support that bilingual education can lead the minority language children to higher academic success (Baker, 1993; Bialystok \& Cummins, 2000; Crawford, 2000; Fernandez \& Nielsen, 1986; Lee, 2002; Mora, 2009; Portes \& Rumbaut, 2001), foster self-esteem, self-identity, and a positive attitude toward schooling (Baker, 1993; Lao, 2004; Oketani, 1997; Pham \& Harris, 2001; Phinney, Chavira, \& Williamson, 1992; Portes \& Rumbaut, 2001), strengthen family cohesion (Zhang, 2008), and promote respect for the ethnocultural background of self and others (Berriz, 2006; Cummins \& Swain, 1986). It is particularly appropriate and effective in schools that serve concentrations of students with a common native language (August \& Shanahan, 2006; Genesee, Lindholm-Leary, Saunders, \& Christian, 2006). In fact, Lao (2004) found that parents who send their language minority (Chinese language) children to the bilingual education programs believe that bilingual education should develop both English and their heritage language. The development of literacy in a heritage language can facilitate the development of reading and writing in English. As 
Skutnabb-Kangas (1995) wrote, "High levels of bilingualism/biculturalism benefit every child, but for minority children, bilingualism is a necessity" (p. 55). However, our nation has failed to develop or set educational policies to preserve the heritage language resources of the language minority children (Tucker, 2008).

Immigrants who speak a language other than English are increasing, owing to relatively high levels of immigration (Crawford, 2000). At the same time, the number of LEP students in public schools also increases (Garcia, 2002).

Unfortunately, funding from the national, state, and local authorities for this student population has not grown in proportion to the increase in the number of students (Garcia, 2002; Wang, 2007). Taking Chinese language as an example, according to Wang (2007), federal funding and support in teaching Chinese heritage language has been inconsistent, sporadic, and too little so that it is impossible to put a significant number of Chinese language programs in public school settings. With insufficient bilingual programs offered in the public schools for minority language children who speak different heritage languages, Lee (2002) and Ludanyi and Liu (2011) found that most children go to the community-based private schools to learn their heritage languages and cultures, including children of Chinese immigrants (McGinnis, 2008). It seems that immigrant parents care about heritage language maintenance, and the community-based heritage language schools become an alternative option for them.

\section{Learning Chinese Heritage Language in Chinese Language Schools}

A heritage language is usually spoken in the home or connected to the heritage culture (Krashen, 1998). The systematic lack of support for students' native 
languages in public schools has led to a crisis of heritage language loss (Garcia, 2002; Wong \& López, 2000; Zhang, 2008). Portes (2002) found that no second generation is proficient in its heritage language by age 17 , in terms of the ability to speak, understand, read, and write well. And Chinese is one language that literally disappeared in this second-generation sample. To maintain the heritage languages and transmit the value of the heritage cultures to their children, immigrant parents and religious organizations establish the community-based heritage language schools (Bradunas, 1988; Man, 2006). In fact, there is considerably more Chinese heritage language instruction going on at the community level than in the formal educational system (McGinnis, 2005). These community efforts are made to avoid heritage language loss.

The crisis of heritage language loss. Immigrants from linguistically different background have long faced the task of maintaining the heritage language in their children (Zhang, 2008). While many immigrant parents cherish their native language and work hard to transmit it to the next generation, their children usually resist learning the language after schooling starts; and they perceive the language useless in the dominant culture (Zhang, 2008). In some Chinese immigrant families, the American-born children cannot understand their parents' language orientation, so that there is usually conflict between parents and children of the heritage language maintenance (Zhang, 2008). Much research (Bialystok \& Miller, 1999; Flege, Yeni-Komshian, \& Liu, 1999; Jia, 2008; Jia \& Aaronson, 2003) shows that English gradually becomes the dominant language in the children of immigrants, and there is a decline at the native language proficiency. It is predictable that 
immigrants to the U.S. have typically lost their heritage languages no latter than the third generation (Crawford, 2000; Portes, 2002). A study conducted by Kuo (1974) and targeting Mandarin-speaking immigrant families in the Midwest demonstrated that the preschoolers are already shifting to English, although their parents speak Mandarin in the home. Because English is used among siblings, later-born children are losing Chinese faster than their older ones. As a result, “Chinese-Americans are faced with a lack of the most fundamental elements in forming a cultural identity, namely language, and a clear social and cultural representation recognized by the mainstream American public" (Chen, 2006, p. 100).

It was common for the second generation to speak Chinese during the 1920s (Li, 1982). However, the current generation, especially those with higher education, tend to assimilate to the mainstream society and abandon their culture of origin, so that language shift to English occurs (Wiley et al., 2008). Zhang (2008) argued that no place in the school setting for children to practice Chinese is one main reason that causes the reluctance of the second-generation Chinese children to speak Chinese. Interestingly, those who do not maintain their heritage language in their early years usually become interested in their linguistic and cultural heritage in adolescence and adulthood, as they realize the true value and benefit of knowing their heritage language and cultural identity (Lee, 2002; Tse, 1998; Wong \& López, 2000).

Researchers (Cho \& Krashen, 1998; Joseph, 2004; Norton, 2000; Portes \& Rumbaut, 2001; Wong-Fillmore, 1991) find the cost of heritage language loss is huge, especially in the estrangement from the family and community relations and 
cultural heritage. In other words, the maintenance of a heritage language has much to do with "the very fabric of family life and productive relationships between parents, children, and the wider community" (Norton, 2000, p. 459).

Why maintain Chinese heritage language? The reasons why heritage language maintenance is important to children vary. Basically, there are seven factors supported by parents and scholars: it benefits academic achievement (Cummins \& Swain, 1986; Lee, 2002; Portes, 2002; Wong-Fillmore, 1991; Zhang, 2008), it increases the career opportunities (Cho et al., 1997; Lao, 2004; Lu \& Li, 2008; Wong-Fillmore, 1991; Zhang, 2008), it helps identity formation and retention (He, 2008; Norton, 2000; Wong-Fillmore, 1991; Zanden, 1990), it reinforces family cohesion (Cho et al., 1997; Portes \& Hao, 2002; Peyton, Ranard, \& McGinnis, 2001; Zanden, 1990; Zhang, 2008), it facilitates the language acquisition skills and helps to learn another language (Bankston \& Zhou, 1995; Cummins \& Swain, 1986; Norton, 2000), it enhances self-esteem (Cummins, 1983; Lu, 2001; Wright \& Taylor, 1995; Yearwood, 2008), and it alleviates acculturation stress and leads to the positive acculturation outcomes (Cummins, 1983; Hones \& Cha, 1999; Lu, 2001; Portes \& Hao, 2002; Zhang, 2008).

Several researchers support that bilingualism and biculturalism promote positive adjustment and psychological well-being of immigrants (Baker, 1993; Lu, 2001; Pham \& Harris, 2001). As many first-generation parents (or grandparents) are limited English speakers, the heritage language becomes a bridge that enables them to reach out to their children (or grandchildren) and strengthen family ties (Zhang, 2008). Once children lack the proficiency of the heritage language, it may 
cause intergenerational conflict, which weakens family relationships, parental authority, and family unity and impedes the older generation to transmit the ethnic values (Rumbaut, 1994; Wong-Fillmore, 1991). As Portes and Hao (2002) pointed out: "It is fluent bilingualism rather than English monolingualism that is associated with the more desirable results in terms of family relations and psycho-social adjustment" (p. 907). It is also encouraged to develop the heritage languages by the increasing demand for foreign language skills in the labor market (Cho et al., 1997; Zhang, 2008). For example, Lu and Li (2008) based on the trend of globalization asserted that as China has become the world's largest market, proficiency in Chinese is more important in the West and around the globe for more job opportunities.

According to the 2010 Census, there were 2,149,620 foreign-born Chinese immigrants from China, Hong Kong, and Taiwan (age 5 and above) who resided in the U.S. and about $61 \%$ of them spoke English less than very well (U.S. Census Bureau, 2010). The data implies that Chinese heritage language is very important for the first generation in their daily life. And there will be a communication problem between two generations if the second generation cannot speak Chinese. However, in the second-generation children, the maintenance of Chinese heritage language does not happen automatically in the host country; and it usually relies on the parents and communities' efforts (Zhang, 2008). As a result, the Chinese heritage language school, a long-standing community institution, has created the potential to prevent the Chinese heritage language from erosion (Wong \& López, 2000). 
The history of Chinese language schools. A majority of school age children of immigrants who learn their heritage languages do so at the community-based heritage language schools due to the restrictive language policies at public schools (Douglas, 2005; Shin, 2005; Chao, 1996). This phenomenon has made the heritage language schools more widespread and vigorous than few decades ago in providing supplemental heritage language support $(\mathrm{Li}, 2005)$. When Chinese migrate to the U.S., they continue to speak Chinese, to practice traditions and customs, as well as to maintain their heritage for their descendants. Setting up the Chinese language schools (hereafter CLSs) comes to meet this need, especially with respect to the language (Lai, 2004). The CLSs have a history of over 125 years in the U.S. Similar to the history of Chinese immigration to the U.S., the history of CLSs in this country can be divided into three stages: initiation, reduction, and revival; and the role played by CLSs undergoes constant revision with time.

Initiation. The first CLS had been established in San Francisco in 1886 (Liu, 1976). Instruction in Chinese was supplementary to the public schools and took place daily three to four hours after school (Liu, 1976; Zhou \& Li, 2003). Providing a basic education and cultural and language proficiency was the function of CLSs at this time as well as to contribute to the development of China, because most of the immigrants planned to return to China someday, by choice or by necessity (Wong \& López, 2000; Zhou \& Li, 2003). From 1912 through the end of the World War II, the CLSs began to spread in other communities on the West Coast, the Midwest, the East Coast, and then the South (Lai, 2004). Cantonese was mainly taught in the CLSs to children of early immigrants residing in Chinatowns (Chao, 1996). With insufficient 
budgets, most of these schools could only borrow or rent space in the public or private educational institutions, or hold classes in the religious places (Lai, 2004).

Reduction. During the post World War II years, the decreasing discrimination and the opening of the employment opportunities to Chinese-Americans accelerated their integration into the mainstream society (Lai, 2004; Zhou \& Li, 2003). Following the time when the Communist Party of China took power in 1949, the preparation for return to China was no longer a prospect to these immigrants. In addition, the pressure of increasing Americanization had made learning Chinese less of a priority. These factors contributed to a decrease of CLSs between the World War II and the 1960s (Edwards, 1977; Leung, 1975; Zhou \& Li, 2003).

Revival. After the 1960s, the rapid increasing population of the Chinese immigrants resulted in an influx of numerous non-Cantonese-speaking, primarily Mandarin-speaking groups (Lai, 2004). A great number of these immigrants were middle class who resided in the suburban areas adjacent to the big cities. As the business successes of the greater China (i.e., Mainland China, Hong Kong, and Taiwan), these immigrant parents perceived bilingualism as an advantage for second-generation Chinese Americans to find better jobs in Asia and insisted that their children learn Chinese (Lao, 2004; Wong \& López, 2000). These parents began to establish CLSs with Mandarin as the language of instruction (Lai, 2004). Thus, the Mandarin-Chinese language schools became the majority in all CLSs.

There are two types of CLSs in the United States. One is for-profit, held on weekdays after regular school hours; the other is non-profit, open on weekends. The after-school Chinese classes usually run from $3 \mathrm{pm}$ to $6 \mathrm{pm}$, Monday through 
Friday, with two hours on Chinese language and other culture related activities, and one hour on regular school homework (Liu, 2010; Zhou \& Li, 2003). These kinds of schools basically opened in the big cities, such as New York, San Francisco, and Los Angeles. However, the majority of the CLSs are non-profit, held on weekends (Liu, 2010). Because parents living in the suburban areas have to drive their children to the class, which makes it impossible for working parents to do on a daily basis; they prefer to send their children to the weekend CLSs, that is, three hours at a time on weekends, either on Saturdays or on Sundays. The once-a-week classes also reduce children's study loads (Lai, 2004). The funding of non-profit Chinese language schools generally comes from the tuition and fundraising, such as sponsoring dinners, picnics, exhibits, and selling gift certificates. Most non-profit CLSs charge $\$ 70$ to $\$ 250$ per student for each semester based on the public school's academic calendar. Extra fees are charged for enrollment in the extracurricular activities offered in the schools (Chao, 1996; Zhou \& Li, 2003). In addition, two national, nonprofit organizations with political differences, both founded in 1994 were established to serve these schools. One is the National Council of Associations of Chinese Language Schools (NCACLS) which primarily consists of CLSs founded by the immigrants from Taiwan; the other is the Chinese School Association in the United States (CSAUS) whose member schools were set up by the immigrants from People's Republic of China (PRC) (Liu, 2010).

Over the 1980s, a more positive attitude of the immigrants toward CHL maintenance had developed (Wong \& López, 2000). Moreover, the rise of ethnic consciousness and cultural pride among Chinese Americans and the emphasis on 
multicultural education in the mainstream society were the additional factors that favor a revival of interest in the CHL (Wang, 1995). As for now, the weekend, oncea-week CLSs are still the most popular all over the country (Lai, 2004). Although the CLSs have made several adjustments over the years as the Chinese-American community has changed, the basic mission is always the same, namely teaching Chinese language and culture (Lai, 2004; Maloof et al., 2006).

The importance of Chinese heritage language schools. Wiley et al. (2008) conducted a survey with 766 respondents of Chinese, from Mainland China, Taiwan, and Hong Kong on their perspectives of heritage language learning and maintenance. Over $90 \%$ of the respondents find it is important for children to retain/learn their parents' languages, assuming they are already learning English. And about $92.3 \%$ of respondents feel that there should be private instruction (tutors/weekend schools) in Mandarin for the Chinese origin children if it is not available in the public schools. The prosperity of the CLSs in recent years reveals immigrant parents' commitment and enthusiasm to maintain the heritage language (Zhang, 2008). Through active parental involvement, the CLSs not only teach the language and culture values but also offer a variety of culture-related, extracurricular activities, such as Calligraphy, Chinese folk dance, martial arts, Chinese cooking, and Chinese painting (Lai, 2004; Wong-López, 2000), which are hard to do in the home (Bradunas, 1988). To stimulate students' interest in learning Chinese, many CLSs hold academic contests in vocabulary, writing (e.g., calligraphy and essays), oratory, and oral reading as well (Lai, 2004). With parents' efforts, the CLSs have become "not only a learning center for the heritage language and culture, 
but also a social center for the parents and children to share experiences, socialize and acculturate together" (Zhang, 2008, p. 220).

One most important function of CLSs is to create a sense of cultural and ethnic pride (Chuang, 1997; Lu, 2001). In the CLSs, the identity formation process is through learning Chinese, communicating with each other, and participating in the activities. Chinese cultural values and core symbols are taught through the textbooks, reinforced through the participation in the traditional events, and learned through the interaction and socialization in the CLSs. For immigrants who are immersed in the mainstream society throughout the week, the once-a-week CLSs are "an environment for cultural adjustment, identity confirmation, and social acceptance, which is essential to their psychological well-being and quality of life" (Lu, 2001, p. 203).

As aforementioned, parents and the community support the non-profit weekend CLSs. However, there are several challenges that the CLSs encounter. A major one is to find effective methods to motivate native-born Chinese to learn the CHL and culture willingly (Lai, 2004). These school-age children in their weekday public schools mostly use English and there is less chance to speak Chinese, so children usually think it unnecessary to learn Chinese (Zhang, 2008). A second challenge is that most CLSs operate on tight budgets and can only afford low remuneration to the instructors who are usually volunteers of parents, which implies a problem of teacher quality (Lai, 2004). The third challenge is how to make Chinese heritage language learning effective. Because most children go to the CLSs only for three hours once a week, some parents worry that what their children learn 
in the CLSs may be easily forgotten without reinforcement during the week (Zhang, 2008). Although it takes time and efforts for the CLSs to solve these challenges, the importance of the CLSs, such as in identity formation and confirmation and in psychological well-being promotion is undeniable (Lu, 2001). Therefore, how learning Chinese heritage language connects to children's ethnic identity and psychological well-being (e.g., self-esteem) is worth investigating.

\section{Heritage Language Proficiency, Ethnic Identity, and Self-Esteem}

The development and proficiency of the heritage language have benefited the language minority children in many aspects (Bankston \& Zhou, 1995), including strengthening their ethnic identity (He, 2008; Kim \& Chao, 2009; Wong-Fillmore, 1991) and self-esteem (Cummins, 1983; Lu, 2001; Yearwood, 2008). Inside and outside our communities, we encounter people of diverse ethnic backgrounds using their languages in communication. Language, under such circumstance, becomes a distinguishing feature to reflect one's ethnic identity (Fong, 2004). Moreover, the fluency in one's heritage language is positively related to self-esteem (Garcia, 1985). Minority children tend to display higher self-esteem when they feel positively about their own ethnic identities (Bradford, Burrell, \& Mabry, 2004). In other words, there are connections among heritage language proficiency, ethnic identity, and selfesteem, which may further affect children's school performance and attitude toward future education (Bankson \& Zhou, 1995; Portes, 2002).

Ethnic identity. Ethnic identity is dynamic and socially constructed and reflects a sense of belonging to an ethnic group with a shared heritage aspects, including language use, traditions, religious practices, values, ancestry, etc. (Hecht, 
Collier, \& Ribeau, 1993). The formation of ethnic identity is subjectively created through the interaction with others (Yep, 1998). One's ethnic identity is a composite of both one's self perception of an ethnic group and the views held by others about one's identity (Nagel, 1999). Accordingly, ethnic identity "is the result of a dialectical process involving internal and external opinions and processes, as well as the individual's self-identification and outsiders' ethnic designation-i.e., what you think your ethnicity is, versus what they think your ethnicity is" (Nagel, 1999, p. 59). After a review of more than 70 studies of ethnic identity, Phinney (1990) argued that identity development is especially difficult for those ethnic and racial minority groups who need to preserve their cultural values as well as to belong to the host culture. And language use becomes an important process to maintain a strong ethnic identity (Ting-Toomey, 1989). Moreover, the formation of ethnic identity is a key to the development of self-esteem (Phinney, 1992).

Self-esteem. Self-esteem is one of a larger constellation of self-related emotions and cognitions such as internal locus of control, perceptions of competence, persistence in the face of challenges, coping skills, and social support that potentially influence school performance (Baumeister, Campbell, Krueger, \& Vohs, 2003; Haney \& Durlak, 1998; Koch, 2006; Whitesell et al., 2009). It is often used to assess well-being among youth (Perez, 2011). Grolnick and Beiswenger (2006) argued that "one constructs a self-view through significant others' appraisals of the self. These 'reflected appraisals' become the basis for self-esteem" (p. 231). Children with more positive self-esteem are believed to be better adjusted, be more 
successful in school, and have close, trusting relationships with their parents (Gove, Style, \& Hughes, 1990).

Although there is evidence that positive self-esteem is a predictor of academic achievement (Marsh, Byrne, \& Yeung, 1999; Stalikas \& Gavaki, 1995; Whitesell et al., 2009), negative self-esteem is one key element that may indicate children's psychological and social problems (Hosogi, Okada, Fujii, Noguchi, \& Watanabe, 2012). Rosenberg and his colleagues (1989) found that there is a bidirectional, negative causal relationship between self-esteem and depression. And negative selfesteem can be a predictor of depression (Haugen \& Lund, 2002; Nguyen, Rawana, \& Flora, 2011). Moreover, a lack of self-esteem may be one of the major causes of disaffection that can cause student disengagement from school (Kinder, Harland, Wilkin, \& Wakefield, 1995). In brief, positive self-esteem is one factor, which may help children's academic performance and negative self-esteem is one key element that may be associated with their psychological and social problems (Hosogi et al., 2012).

Self-esteem measures have often been applied to evaluate levels of well-being by psychologists and sociologists on immigrants (Berry, Phinney, Sam, \& Vedder, 2006). And researchers such as Altschul, Bybee, and Oyserman (2008) and Beiley (2000) suggested that the additive acculturation, with strong retention of heritage language benefits the development of self-esteem. Therefore, it is interesting to explore the relationships among heritage language learning, ethnic identity, and self-esteem of immigrants and their offspring. 


\section{Research on heritage language proficiency, ethnic identity, and self-}

esteem. Language is one of the most important factors in the maintenance of a strong ethnic identity for all ethnic groups, particularly the minority ones (Bailey \& Oetzel, 2004; Edwards, 1997; Joseph, 2004; Ting-Toomey, 1989). In fact, heritage language is probably the most frequently cited contributor to ethnic identity (Bankston \& Zhou, 1995; Hurtado \& Gurin, 1995), although few researchers find no correlation between heritage language learning and ethnic identity (e.g., Kim \& Chao, 2009; Ng, 1999). Giles and Noels explain that language serves to classify and unite people as members of a particular ethnic group (ingroup), as well as to exclude outgroup members from interacting with people who belong to the ingroup (as cited in Chuang, 2004, p. 58). The more proficient one is in his or her heritage language; the stronger ethnic identity and affiliation he or she has with the ethnic group (Bankston \& Zhou, 1995; Cho, 2000). As in several studies of Chinese, Korean, Vietnamese, Mexican, French, and Indian children with immigrant parents support, those who maintain their heritage languages and ethnic identities have more possibilities of succeeding in school than those who assimilate to the mainstream culture (Lee, 2002; Lucas, 1997; Portes, 2002).

Heritage language maintenance should be an advantage rather than a problem regarding self-esteem development (Portes, 2002; Stalikas \& Gavaki, 1995). Garcia (1985) found that there is a positive relationship between fluency in the heritage language and self-esteem of 1,500 Chicano college students. Portes (2002) also demonstrated higher self-esteem and educational aspirations among the children of immigrants from 77 nationalities who are fluent in their heritage languages. 
However, on the contrary, some studies reveal that English language use rather than heritage language use attributes to higher self-esteem (Ortiz \& Arce, 1984;

Rumbaut, 1994; Schnittker, 2002). Schnittker (2002) suggested that adult Chinese immigrants who speak mostly English have higher self-esteem than those who speak primarily Chinese. Those who speak English and Chinese equally, however, do not show higher self-esteem than those who speak primarily Chinese, no matter the amount of neighborhood Chinese composition in the community they live.

Studies examining the relationship between ethnic identity and self-esteem have shown inconsistency as well. Some studies report a positive relationship between ethnic identity and self-esteem (Allen, Howard, \& Grimes, 1997; Lee, 2005; Phinney, 1992; Smith, 1991). For example, when the minority children have strong feelings toward their own ethnic identities, they tend to display higher self-esteem and psychological well-being (Bradford et al., 2004; Stalikas \& Gavaki, 1995). Some studies demonstrate no association between ethnic identity and self-esteem (Hovey, Kim, \& Seligman, 2006; Rumbaut, 1994; Schnittker, 2002). For example, Hovey et al.'s (2006) research focusing on 133 Korean American college students concluded that a strong sense of ethnic identity and the maintenance of heritage language have little to do with protecting against psychological difficulties.

There are a great number of studies on heritage language proficiency, ethnic identity, and self-esteem. However, the major participants in these studies are adolescents and college students. Relevant research that involves children is scarce. In the existing studies, the relationships among heritage language proficiency, ethnic identity, and self-esteem show mixed results. Some researchers support that 
learning heritage language helps form one's ethnic identity (Bailey \& Oetzel, 2004; Cho, 2000; Pease-Alvarez, 2002). Some find that heritage language proficiency has nothing to do with the formation of ethnic identity (Kim \& Chao, 2009; Ng, 1999). Some studies show a positive relationship between heritage language development and self-esteem (Cho et al., 1997; Garcia, 2002; Portes, 2002); while some reveal no connection between each other (Ortiz \& Arce, 1994; Schnittker, 2002). Some research demonstrates that ethnic identity is associated with self-esteem (Lee, 2005; Phinney, 1992); still some research has opposite conclusion (Hovey et al., 2006; Rumbaut, 1994). These results imply that there is still a room for such research to be done with different populations (e.g., research on early adolescents and children) to collect more literature.

\section{Summary}

The diverse demographic population in the United States challenges all institutions to respond in ways that take advantage of this increasing diversity. Educational institutions in particular will be attacked the hardest for it's the early contact institutions with people (Severns, 2012). Immigrant parents in the U.S. usually must decide whether to raise their children as bilingual speakers or as English-only speakers in terms of acculturation (Jeon, 2008). Gibson and Ogbu (1991) divided acculturation into two categories: additive acculturation and subtractive acculturation. Researchers who support additive acculturation demonstrate that additive acculturation can benefit the children of immigrants in school performance, parent-child relationship, and self-esteem (Gibson, 1995; Portes \& Rumbaut, 2001). Lee (2002) suggested that public schools look at the 
significant contribution of the educational programs promoting both heritage language and culture for ethnic minority students. The systematic lack of support for students' native languages in public schools has led to a crisis of heritage language loss (Garcia, 2002; Wong \& López, 2000; Zhang, 2008), because the pressure of assimilation is currently prevalent in the U.S. public schools such as with the English-only movement in some states (Lu, 1998; Mora, 2009) and the popular transitional bilingual programs (Garcia, 2002).

To maintain heritage language and transmit the value of the heritage culture to their offspring, immigrant parents and religious organizations establish the community-based heritage language schools (Bradunas, 1988; Man, 2006). Chinese immigrants are one active ethnic group that endeavors to retain their heritage language (Li, 2006), as shown by the history of the Chinese language schools (CLSs), which have been in existence for over 125 years. In fact, there is considerably more Chinese heritage language (CHL) instruction going on at the community level than in the formal educational system (McGinnis, 2005). "At their best, Chinese language schools inculcated the fundamentals of the Chinese ancestral heritage in younger Chinese Americans, enriching their lives, proving useful in their later careers, and thus contributing to the emergence of a multicultural America" (Lai, 2004. p. 339).

Research on the relationships among the maintenance of the heritage language, ethnic identity, and self-esteem has been conducted in different places with people from different ethnic groups (Bailey \& Oetzel, 2004; Edwards, 1997; Portes, 2002; Rumbaut, 1994). However, the research findings are inconsistent, which leaves much still to be explored. Although the existing research 
demonstrates inconsistent results on the relationships among heritage language proficiency and ethnic identity, heritage language proficiency and self-esteem, and ethnic identity and self-esteem, the mixed results potentially increase the value of current study on challenging the results by using different sample. Based on the literature review, there were three research questions I planed to explore in this study: (1) What is the relationship between Chinese heritage language proficiency and ethnic identity, (2) Is there any connection between heritage language proficiency and self-esteem, and (3) How does ethnic identity associate with selfesteem? Five hypotheses were incorporated in these questions. The first hypothesis stated that there is a positive relationship between Chinese heritage language proficiency and ethnic identity. The second hypothesis stated that there is a significant difference in the relationship between Chinese heritage language proficiency and ethnic identity when comparing the two subgroups: the Americanborn Chinese with at least one parent from Taiwan and the American-born Chinese with at least one parent from other countries where Mandarin Chinese is spoken. The third hypothesis stated that the relationship between heritage language proficiency and self-esteem is positive. The fourth hypothesis stated the relationship between heritage language proficiency and self-esteem is significant on the two subgroups. And the fifth hypothesis stated that ethnic identity and selfesteem are positively correlated with each other. 


\section{Chapter Three: Methodology}

A review of literature in chapter two addressed the background of Chinese immigration and foreign language policy in the U.S. educational system. In addition, the review stated the importance of the maintenance of the Chinese heritage language (CHL) to the children of immigrants and the function of the Chinese language schools (CLSs) as a learning and social center. Finally, the review examined research about the relationships among heritage language learning, ethnic identity, and self-esteem. In this chapter, I detail the research design, selection of the sample, data sources, procedures, and analysis plan of this study.

\section{Research Design}

The purpose of this study was to explore the relationships among heritage language proficiency, ethnic identity, and self-esteem on the American-born Chinese (ABC) children who went to the Chinese language schools for Chinese language learning on weekends. The ABCs, in this study, were American-born children with at least one parent who was born in greater China (including Mainland China and Taiwan) or other countries (i.e., Singapore, Philippines, and Malaysia) in the Southeast Asia with Mandarin Chinese as the parent's native language. Participants of the ABCs were required to be current 4th grade to 8th grade students in the CLSs. I examined the relationships among heritage language proficiency (including understanding/speaking abilities and reading/writing abilities), ethnic identity, and self-esteem by conducting a survey study.

The tools used for this analysis included: a collected survey data from the Parents' Demographic Questionnaire and the Children's Self-Perception of Chinese 
Language Learning Survey, which consisted of a Demographic Questionnaire, the Self-Evaluated Chinese Language Fluency Questionnaire (CLFQ), the 12-item Multigroup Ethnic Identity Measure (MEIM) (Roberts et al., 1999), and Rosenberg's Self-Esteem Scale (RSE) (Rosenberg, 1989). Below is an introduction of these questionnaires.

Parents' Demographic Questionnaire. The purpose of this questionnaire was to get general information of parents' background and their cultural orientation. The questionnaire primarily included closed-ended questions, such as birthplace, time of residency in the U.S., highest education obtained, language use at home, and the reason they send their children to the Chinese language schools. The information was used to identify if the student participants are descendants of Mandarin-speaking Chinese immigrants and help to categorize student participants into two subgroups. Descriptive statistics of the questionnaire was provided in results section.

Demographic Questionnaire. The Demographic Questionnaire consisted of several questions to generate student participants' general information, such as sex, age, and the length he or she had been studied Chinese in the CLS. This information helped further discussion beyond research questions. Descriptive statistics was used to analyze the demographic information of the participants.

Self-Evaluated Chinese Language Fluency Questionnaire (CLFQ). Selfassessment of language proficiency has been found to be a reliable and valid indicator by several studies, comparing to real test scores or interview ratings of language ability (Hakuta, 1986; Lopez, 1982; Marian, Blumenfeld, \& Kaushanskaya, 
2007; Portes \& Hao, 2002; Smith \& Baldauf, 1982; Wilson, 1999). For example, Wilson (1999) found the correlation between self-ratings and Test of English for International Communication (TOEIC) scores was around .7 indicating a high level of consistency. In addition, the reliability of self-rated language proficiency was previously calculated at a Cronbach's alpha levels of .89 (Hovey et al., 2006) and .87 (Phinney, Romero, Nava, \& Huang, 2001). The items of Self-Evaluated Chinese Language Fluency Questionnaire were modified from Kim and Chao's (2009) language fluency items by the researcher, that is, the word "language" in the original items was replaced by the word "Chinese". There were three items in this questionnaire: (1) How well do you understand Chinese when others speak it to you, (2) How well do you speak Chinese, and (3) How well do you read and write Chinese? In the measure of Vietnamese literacy, Bankston and Zhou (1995) asked two questions: "How well do you read Vietnamese?" and "How well do you write Vietnamese?" to participants and found these two items were highly correlated $(\mathrm{r}=$ .944). The result was a support of why it was reasonable to apply item (3) how well do you read and write Chinese instead of separating the item into two questions: how well do you read Chinese and how well do you write Chinese. Items of this measure are rated on a 5-point Likert scale from 1 (not at all well) to 5 (extremely well). The mean item score was used as the summary score, with higher scores demonstrating a higher proficiency in Chinese. In Kim and Chao's (2009) study, the two items for understanding and speaking showed a high correlation of .86 for Chinese. Therefore, the authors combined these two items to create the understanding/speaking subscale by averaging them together. The single 
reading/writing item with the individual and combined speaking/understanding subscale revealed correlations in the range of .55 to .63 for Chinese. It demonstrated that understanding/speaking and reading/writing represented distinct aspects of language proficiency for Chinese sample.

Twelve-item Multigroup Ethnic Identity Measure (MEIM). The 12-item Multigroup Ethnic Identity Measure (MEIM) (Roberts et al., 1999) scale is used as a global assessment of ethnic identity and was applied in the current study. The instrument that deleted two items (i.e., I am not very clear about the role of my ethnicity in my life, and I really have not spent much time trying to learn about the culture and history of my ethnic group), which are difficult to interpret, is a revised version of Phinney's (1992) Multigroup Ethnic Identity Measure. An exploratory factor analysis conducted by Roberts et al. (1999) showed that the 12-item MEIM consists of 12 items evaluating two factors of ethnic identity, including (1) the affirmation, belonging, and commitment to the ethnic group (7 items) and (2) the active exploration of and involvement in group identity ( 5 items), a process which enables one to move from the lack of unawareness of the importance of one's ethnic identity, to exploration of and, furthermore, to commitment to one's ethnic identity. Items of this measure were rated on a 4-point Likert scale from 1, strongly disagree, to 4 , strongly agree. The higher mean scores indicated higher ethnic identity. Examining students from sixth through eighth grades from diverse ethnic groups, the reliabilities of the 12-item MEIM range from .81 through .89 across ethnic groups and are .84 for Chinese American. The reliability is equal to that of the Phinney's (1992) scale (i.e., 81 for the high school students and .90 for the college 
students). For the 7-item affirmation/belonging/commitment subscale, reliabilities range from .81 through .88 across 11 ethnic groups. For the 5-item exploration/involvement subscale, reliabilities are between .55 and .76 of the same sample. The correlations between the two factors are similar across groups and are $.74, .70$, and .75 for the White, African-Americans, and Mexican-Americans respectively. The validity of the 12 -item MEIM is supported by the positive correlations with measures of self-esteem (Roberts et al., 1999) and of heritage language fluency (Kim \& Chao, 2009).

Rosenberg's Self-Esteem Scale (RSE). Rosenberg's Self-Esteem Scale (RSE) (Rosenberg, 1989) was applied in this research to measure student participants' self-esteem. The one-dimensional scale includes 10 items: five positively worded items and five negatively worded items (reverse scale). A 4-point Likert scale from 1 (strongly disagree) to 4 (strongly agree) was used to calculate scores. The higher mean scores indicated higher self-esteem. The RSE has a high reliability whether the respondents are adults, high school students, or middle-school-age youth (grades five to eight) (Hagborg, 1996). The test-retest correlations are typically in the range of .82 to .90 . Internal consistency for various samples range from .75 to .88 (see Blascovich \& Tomaka, 1993; Hagborg, 1996; Hovey et al., 2006; Rosenberg, 1986; Tsai, Ying, \& Lee, 2001 for further detail). The construct validity of the RSE is supported by Rosenberg's research (1986) and by its relationship with a multidimensional self-concept measure, Self-perception Profile for Children (Hagborg, 1996). In addition, there is no significant difference by either gender or grade (Hagborg, 1996) 
In the current study, I sought to investigate three research questions through the application of a statistical, descriptive, quantitative research method:

Research question 1: What is the relationship between Chinese heritage language proficiency and ethnic identity?

The Parents' Demographic Questionnaire, the CLFQ, and the MEIM data were obtained from the returned survey of the Parents' Demographic Questionnaire and the Children's Self-Perception of Chinese Language Learning Survey. The data included where parents are from, parent's native language, students' self-reported language proficiency in understanding, speaking, and reading and writing, and the MEIM scores. I applied these data to explain the correlation between CHL proficiency and ethnic identity and the difference of the two variables between the two subgroups, that is, the American-born Chinese with at least one parent from Taiwan and the American-born Chinese with at least one parent from other countries where Mandarin Chinese is spoken in the Asia.

Research question 2: Is there any connection between heritage language proficiency and self-esteem?

To find the results, I collected the Parents' Demographic Questionnaire, the CLFQ, and the RSE data. The data included where parents are from, parent's native language, the self-rated CHL proficiency in understanding, speaking, and reading and writing and the RSE scores. These data were applied to explain the correlation between CHL proficiency and self-esteem and the difference of the two variables between the two subgroups.

Research question 3: How does ethnic identity associate with self-esteem? 
Research on the relationship between ethnic identity and self-esteem is scarce and inconsistent and mainly focus on the adolescents and college students. Although ethnic identity and self-esteem in the present study were dependent variables, I was interested in examining the relationship between ethnic identity and self-esteem in children as well. Data of the MEIM scores and the RSE scores in both questionnaires were collected and applied to explain how ethnic identity and self-esteem associate with each other.

Due to conducting survey research, the current research was a nonexperimental study, which means "research in which the independent variable is not manipulated and there is no random assignment to groups" (Johnson \& Christensen, 2000, p. 25). Through the analysis of the questionnaire data, I described how $\mathrm{CHL}$ proficiency related to the second-generation $\mathrm{ABCs}$ ' ethnic identity and self-esteem, as well as whether there was a correlation between ethnic identity and self-esteem. The application of a descriptive research design examined the relationships between CHL proficiency and ethnic identity, CHL proficiency and self-esteem, and ethnic identity and self-esteem. The selection of participants met the characteristics described in the following section.

\section{Selection of Study Participants}

Participants for the current study were required to meet the criteria, that is: (1) students must be American born and were at that time enrolled in a Chinese language school between grade level four and grade level eight, and (2) at least one of the children's parents is a Chinese immigrant from the greater China (i.e., Mainland China and Taiwan) or other countries in the Southeast Asia, and the 
parent's native language is Mandarin Chinese. One immigrant parent per family was recruited as a participant as well. In other words, this study included both student participants and parent participants. However, students were the main participants who were targeted in the current study.

In the beginning of selecting participants, an email briefly introducing the research project was sent out from me to the principals of the 12 CLSs who were members of the Midwest Chinese Language Schools Association (MCLSA) in the greater metropolitan city in the Midwest to ask for their support and assistance in this study. Three principals responded that they were willing to cooperate with the study. As a result, these three schools were selected in this study. Because these CLSs are run by Taiwanese and the majority of student population is Taiwanese offspring, I also divided the student participants into two subgroups for comparing the difference between groups. The two subgroups are: the ABCs with at least one parent from Taiwan and the ABCs with at least one parent from Mainland China or other countries in the Southeast Asia where Mandarin Chinese is spoken. If one participant's parents are both Chinese, one from Taiwan and the other from other countries, he or she was categorized into the subgroup "at least one parent is from Taiwan." The participants were from three CLSs located in the suburban area of a Midwest U.S. metropolitan city. The selection of participants and background of these CLSs were discussed below.

Sampling participants. A total of 83 students ( 42 boys and 41 girls) who attended these three CLSs between fourth and eighth grade and their parents who met the criteria received a set of forms with both English and Chinese versions, 
including an adult consent form, a parental permission form, and a child's assent form. The assent letter was for the students, and the consent letter and the permission letter were for their parents. Students had to sign on the assent letter only when they decided to participate in the study. Parents also had to sign on the permission letter to inform me if they allowed their children to be in this study and to sign on the consent letter to demonstrate their agreement to participate. All forms were put in an envelope and returned to the researcher by the students. The participation of parents was one immigrant parent per family, no matter whether there was one child or multiple children in the family participating in this current study. In addition, the children and parents were informed that only when both parent and child filled out the surveys would the survey data be effective. The rationale for selecting this age group is in accordance with several research findings, that is, children's ethnic categorization abilities are developed no earlier than the age of six (Clark \& Clark, 1947; Ng, 1999; Wright \& Taylor, 1995). Moreover, it is not until about the age of 8 that children can construct a sense of their self-esteem (Harter, 2006, pp. 145-147). Finally, 63 students (75.9\%) returned these forms and were allowed to participate in this study, and 56 parents (76.7\%) (seven families had multiple children in this study) agreed to participate as well. Student participants' ages ranged from 8 to 14 years $(M=11.19, S D=1.545)$. Among these student participants, 29 (46.0\%) were boys and $34(54.0 \%)$ were girls. In addition, 57 student participants have at least one Mandarin-speaking parent from Taiwan and 6 student participants have at least one Mandarin-speaking parent from other countries in Asia. Table 1 is a summary of the student participants. 
Table 1

The Distribution of Student Participants

\begin{tabular}{|c|c|c|c|c|c|c|c|c|}
\hline \multicolumn{2}{|c|}{$\begin{array}{c}\text { \# of } \\
\text { students } \\
\text { (A) }\end{array}$} & \multicolumn{2}{|c|}{$\begin{array}{l}\text { \# of } \\
\text { participan } \\
\text { ts } \\
\text { (B) }\end{array}$} & \multicolumn{2}{|c|}{$\begin{array}{l}\text { \# of non- } \\
\text { participants }\end{array}$} & \multirow[t]{3}{*}{$\begin{array}{c}\# \text { of } \\
\text { subgroup } \\
1^{\text {a }}\end{array}$} & \multirow[t]{3}{*}{$\begin{array}{c}\text { \# of } \\
\text { subgroup } \\
2^{\text {b }}\end{array}$} & \multirow{3}{*}{$\begin{array}{c}\% \text { of } \\
\text { participation } \\
\text { (response } \\
\text { rate) } \\
\text { B/A } \times 100 \%\end{array}$} \\
\hline Boy & Girl & Boy & Girl & Boy & Girl & & & \\
\hline \multicolumn{2}{|c|}{ Total } & \multicolumn{2}{|c|}{ Total } & \multicolumn{2}{|c|}{ Total } & & & \\
\hline 42 & 41 & 29 & 34 & 13 & 7 & \multirow[t]{2}{*}{57} & \multirow[t]{2}{*}{6} & \multirow[t]{2}{*}{$75.9 \%$} \\
\hline & & \multicolumn{2}{|c|}{63} & \multicolumn{2}{|c|}{20} & & & \\
\hline
\end{tabular}

Note. \# denotes to numbers

a: participants with at least one Mandarin-speaking parent from Taiwan; b: participants with at least one Mandarin-speaking parent from countries in Asia except Taiwan

Background of the Chinese schools. In order to protect the privacy of these schools, school names in this research were pseudonyms. Schools involved in this research were Jian Kang Chinese School (JKCS), Min Zhu Chinese School (MZCS), and Ai Guo Chinese School (AGCS). Although these schools have their own history, they have some background in common. For example, each school borrows and uses local school's facilities. Language classes offered in these schools are about two to three hours long on Sundays from late August to mid-May. In addition to Chinese language classes, culture-related programs, such as Chinese yo yo, Chinese folk dance, Chinese Calligraphy, Tai-Chi, etc. are offered as the extracurricular activities as well. The student populations in these schools are diverse, with both Chinese as native language families and non-Chinese speaking families. However, the majority of the student population in these schools is second-generation children whose parents (either father or mother or both parents) were born in Taiwan. All 
students, based on their background, are assigned to different kinds of classes such as the regular Chinese language classes and the Chinese as a second language classes. These schools are non-profit organizations supported by the voluntary services of administrative staff, Board of Trustees, consultants, and teachers, most of whom are parents of enrolled students. The budgets of schools are mainly from the tuition, fundraising, donations, and subsidies from the Overseas Compatriot Affairs Commission, R.O.C. (Taiwan). The Overseas Compatriot Affairs Commission, R.O.C. (Taiwan) also provides experts to give teachers periodic in-service training.

There are usually two kinds of Mandarin Chinese taught in the U.S. regarding the character and phonetic system. One adopts simplified characters and pinyin system, which has Roman alphabets. Chinese particularly from the People's Republic of China (PRC) and Singapore use this kind of Mandarin. The other one applies traditional characters and zhuyin fuhao system made up of non-Roman Phonetic symbols and is used by Chinese from Taiwan (also known as Taiwanese) (see Table 2). The regular Chinese language classes in these selected schools teach traditional characters and zhuyin fuhao system. Because pinyin system is more popular in the U.S., and it will be more useful if you know pinyin when you have a job in China in the future, these Chinese schools also teach pinyin to their students, but starting from different grade levels. The following is the introduction of each school. 
Table 2

The Comparison of Mandarin Chinese: Characters and Phonetic Systems

\begin{tabular}{|l|l|l|}
\hline \multicolumn{1}{|c|}{ Characters } & \multicolumn{1}{|c|}{$\begin{array}{c}\text { Phonetic } \\
\text { system }\end{array}$} & \multicolumn{1}{|c|}{ Countries applying this } \\
\hline Simplified: 身体 & Pinyin: Shēnť̌ & $\begin{array}{l}\text { People’s Republic of China } \\
\text { Singapore }\end{array}$ \\
\hline Traditional: 身體 & $\begin{array}{l}\text { Zhuyin: } \\
\text { アム ム—v }\end{array}$ & Taiwan \\
\hline
\end{tabular}

Note. Both 身体 and 身體 mean "body" in English.

Jian Kang Chinese School (JKCS). Founded in 1986, JKCS is dedicated to providing opportunities for the community members to learn about Chinese language and culture. Classes from kindergarten to tenth grade are offered for the children from Mandarin speaking families. For children and adults with no background in Mandarin, Chinese as a Foreign Language classes are offered in this school as well. As of school year 2012-2013, the total student population in JKCS was 117 students.

Min Zhu Chinese School (MZCS). MZCS was founded in 1981 with the mission to provide Chinese language and culture learning for the next generation. The language courses and cultural related activities offered in the MZCS are for students ranging from kindergarten to high school as well as adults. Currently, classes are held at one community college located in a northwest suburb of the Midwest U.S. metropolitan city.

There are three kinds of Chinese programs offered in the MZCS: the regular Chinese language classes, the Chinese as a Second Language classes (CSL), and the adult Chinese language classes. The regular Chinese language classes are for 
Chinese descendants with grade levels from kindergarten to 10th grade. The total student population, as of school year 2012-2013, was 156 students. By implementing its mission through the effort of all volunteers and community sponsors, MZCS strongly believes that the school can benefit Chinese offspring as well as other community members who are interested in Chinese culture.

Ai Guo Chinese School (AGCS). AGCS was founded in 2003 to promote Chinese language and culture. In order to provide opportunities for non-Mandarin speaking families in the community to learn Chinese, Chinese as a Foreign Language (CFL) programs are offered starting from 2005. Currently, there are two distinct Chinese programs for students from different ethnic backgrounds in AGCS: the heritage program and the CFL program. A total of 92 students were enrolled in the AGCS in school year 2012-2013. The school hopes their efforts on promoting Chinese culture can help to retain and boost the Chinese culture.

\section{Data Sources}

A Parents' Demographic Questionnaire and a Children's Self-Perception of Chinese Language Learning Survey with four questionnaires were used for data collection in the current research. These four questionnaires for children are the Demographic Questionnaire, the Self-Evaluated Chinese Language Fluency Questionnaire (CLFQ), the 12-item Multigroup Ethnic Identity Measure (MEIM) developed by Roberts and his colleagues (1999), and the Rosenberg's Self-Esteem Scale (RSE) (Rosenberg, 1989). These questionnaires were applied to measure three variables: (1) Chinese language proficiency, (2) ethnic identity, and (3) selfesteem. 
The data of the Parents' Demographic Questionnaire, the scores of the CLFQ, and the scores of the 12-item MEIM were collected for research question: What is the relationship between Chinese heritage language proficiency and ethnic identity? For research question: Is there any connection between heritage language proficiency and self-esteem? The data of the Parents' Demographic Questionnaire, the scores of the CLFQ, and the RSE were applied to analyze this question. For research question-How does ethnic identity associate with self-esteem-the scores of the 12-item MEIM and the RSE were collected. The Pearson's correlation coefficient and analysis of variance (ANOVA) of SPSS, the most common statistical data analysis software used in educational research, were used to analyze these collected data to answer the research questions.

\section{Procedures}

In the beginning of the research, I went to one CLS on the first Sunday of February 2013 to meet first with the parents whose children were in between grade level four and grade level eight in the CLS and then with the 4th to 8th graders to explain the study and to discuss the consent forms. Then, I distributed a pack of documents, including an adult consent form, a parental permission form, and a Parents' Demographic Questionnaire for parents and a child's assent form and a Children's Self-Perception of Chinese Language Learning Survey for children in both English and Chinese versions in an envelope to children to bring home and pass the documents for parents to their parents. Parents who allowed their children to participate in the study had to sign on the parental permission form. In addition, parents who agreed to participate in the study had to sign on the adult consent form 
and then complete the Parents' Demographic Questionnaire. I needed only one parent who is Chinese immigrant to be in the study per family. If there was more than one child participating in this study, the parent only had to sign on the parental permission form and fill out the questionnaire, which his or her child in the lowest grade brought home. Children who themselves agreed and were allowed to participate had to sign on the child's assent form and then complete the Children's Self-Perception of Chinese Language Learning Survey. All documents were required to be put into the envelope and returned to me by the children the following Sunday. I then passed the package of documents to the students who were absent last Sunday and gave a follow-up reminder note to the students who did not return the forms and surveys. On the third and fourth Sundays, I went back to the same school to collect data (see Figure 1). The process was applied to the other two schools as well. The collected data then went into analysis process after all surveys were collected. 


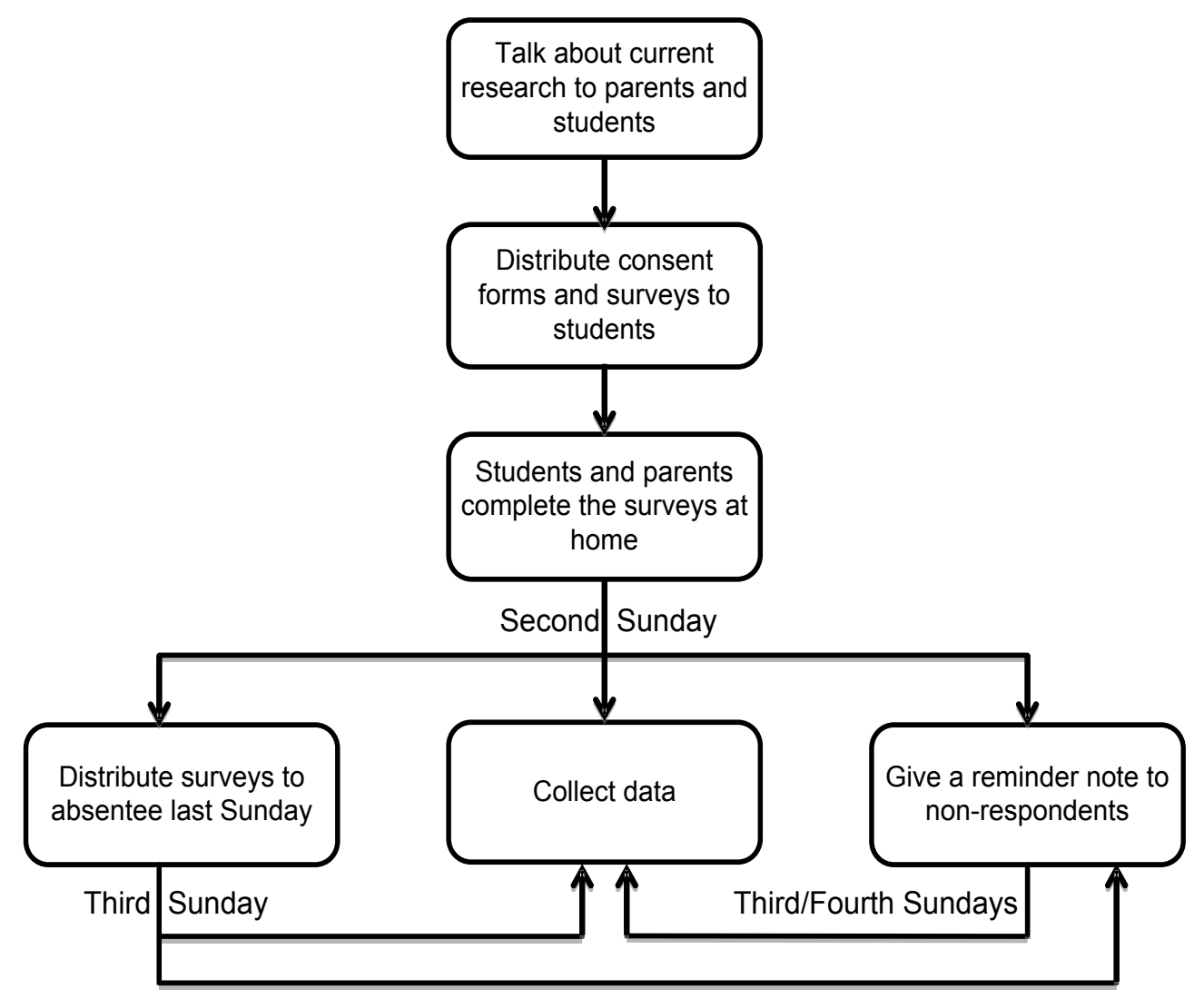

Figure 1. The procedure of survey distribution and collection. This figure illustrates how the surveys were distributed and how data were collected in each school.

\section{Analysis Plan}

There were five hypotheses in this research to reflect three research questions. Each hypothesis came with a null hypothesis $\left(\mathrm{H}_{0}\right)$ and an alternative hypothesis $\left(\mathrm{H}_{1}\right)$. The analysis plan was conducted based on these hypotheses.

The first hypothesis was $\mathrm{H}_{0}$ : There is no relationship between Chinese heritage language proficiency and ethnic identity, and $\mathrm{H}_{1}$ : There is a positive relationship between Chinese heritage language proficiency and ethnic identity. This is for question 1: What is the relationship between Chinese heritage language proficiency and ethnic identity? The Pearson's correlation coefficient was conducted to test the 
hypothesis. According to the hypothesis, the higher heritage language proficiency mean scores would accompany with the higher ethnic identity mean scores. In addition, Pearson's correlation was conducted to examine the relationships between the subscales of heritage language proficiency (i.e., understanding/speaking and reading/writing) and ethnic identity as well.

The second hypothesis was $\mathrm{H}_{0}$ : There is no significant difference in the relationship between Chinese heritage language proficiency and ethnic identity when comparing the: the American-born Chinese with at least one parent from Taiwan and the American-born Chinese with at least one parent from other countries in Asia where Mandarin Chinese is spoken, and $\mathrm{H}_{1}$ : There is a significant difference in the relationship between Chinese heritage language proficiency and ethnic identity on the two subgroups. This is also for question 1: What is the relationship between Chinese heritage language proficiency and ethnic identity? Group differences between the two subgroups: the ABCs with at least one parent from Taiwan and the ABCs with at least one parent from Mainland China or other countries in the Southeast Asia where Mandarin Chinese is spoken were tested on these two variables: heritage language proficiency and ethnic identity to get further information on how the role of Chinese from different countries played regarding heritage language fluency by applying ANOVA.

The third hypothesis was $\mathrm{H}_{0}$ : There is no connection between heritage language proficiency and self-esteem, and $\mathrm{H}_{1}$ : The relationship between heritage language proficiency and self-esteem is positive. This relates to question 2: Is there any connection between heritage language proficiency and self-esteem? To test this 
hypothesis, the Pearson's correlation coefficient was conducted to show whether the more proficient a child was in the heritage language the higher self-esteem he or she possessed. Moreover, the same ideas of the test of the first hypothesis, the Pearson's correlation was applied to examine the relationships between the subscales of heritage language proficiency and self-esteem.

The fourth hypothesis was $\mathrm{H}_{0}$ : There is no significant difference in the relationship between heritage language proficiency and self-esteem between the two subgroups: the American-born Chinese with at least one parent from Taiwan and the American-born Chinese with at least one parent from other countries in Asia where Mandarin Chinese is spoken, and $\mathrm{H}_{1}$ : The relationship between heritage language proficiency and self-esteem is significant on the two subgroups. This relates to question 2 as well. And ANOVA was conducted to examine group differences between heritage language proficiency and self-esteem.

The fifth hypothesis was $\mathrm{H}_{0}$ : There is no correlation between ethnic identity and self-esteem, and $\mathrm{H}_{1}$ : Ethnic identity and self-esteem are positively correlated with each other. This is for question 3: How does ethnic identity associate with selfesteem? The Pearson's correlation coefficient was conducted to test the hypothesis. I expected a positive correlation between ethnic identity and self-esteem. 


\section{Chapter Four: Results}

The purpose of chapter four is to present the statistical analyses of the data which were collected in this study. There are four sections in this chapter, including the descriptive statistics of sample and demographic information, the internal reliabilities of measures, the analysis of research questions and hypotheses, and summary.

\section{Descriptive Statistics of Sample and Demographic Information}

A sample of 63 fourth to eighth grades students ( 29 boys and 34 girls) who met the criteria, that is, (1) students must be American born and were at that time enrolled in a Chinese language school between grade level four and grade level eight, and (2) at least one of the children's parents is Chinese immigrant from the greater China (i.e., Mainland China and Taiwan) or other countries in the Southeast Asia and the parent's native language is Mandarin Chinese served as the participants, as well as their parents in this study. Because I required only one immigrant parent per family to participate in this study, there were 56 parents involved, which meant there were seven families with two children participating in the current study. Among these 63 students (46.0\% boys and 54.0\% girls), 14 were from JKCS, 23 were from MZCS, and 26 were from AGCS (see Table 3). The sample size of each grade was between 10 to 18 participants (see Table 4). Participants had been in the Chinese language schools for a mean of 6.26 years ranging from 1 to 10 years. 
Table 3

Crosstabulation of Gender and School

\begin{tabular}{|c|c|c|c|c|c|c|}
\hline & & & \multicolumn{3}{|c|}{ School code } & \multirow[b]{2}{*}{ Total } \\
\hline & & & JKCS & MZCS & AGCS & \\
\hline \multirow[t]{5}{*}{ Student gender } & Boy & Count & 4 & 12 & 13 & 29 \\
\hline & & $\%$ within & $28.6 \%$ & $52.2 \%$ & $50.0 \%$ & $46.0 \%$ \\
\hline & Girl & Count & 10 & 11 & 13 & 34 \\
\hline & & $\%$ within & $71.4 \%$ & $47.8 \%$ & $50.0 \%$ & $54.0 \%$ \\
\hline & & school code & & & & \\
\hline \multirow[t]{3}{*}{ Total } & & Count & 14 & 23 & 26 & 63 \\
\hline & & $\%$ within & $100.0 \%$ & $100.0 \%$ & $100.0 \%$ & $100.0 \%$ \\
\hline & & school code & & & & \\
\hline
\end{tabular}


Table 4

Crosstabulation of Gender and Grade

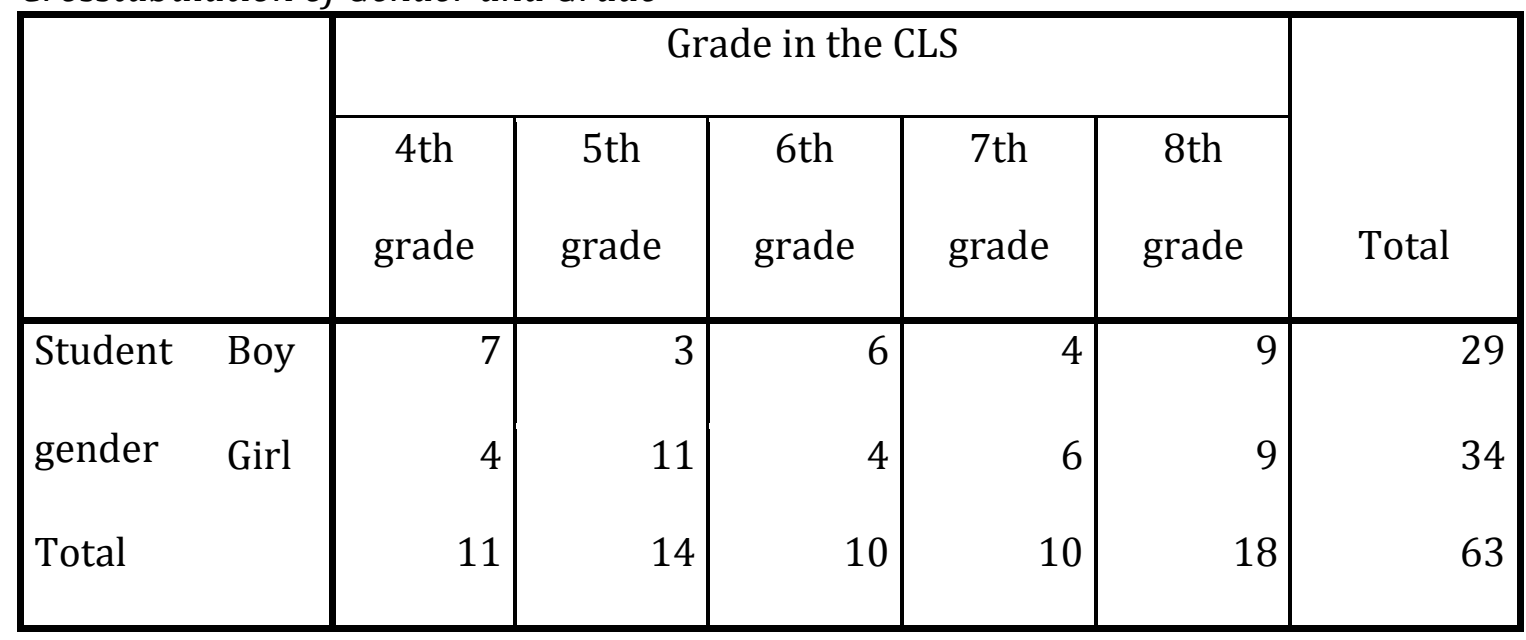

Thirty-seven out of sixty-three students spent less than two hours on doing CLS homework weekly. It is interesting that the one-way ANOVA showed that time spending on CLS homework was not related to students' Chinese language proficiency. The primary language use between parents and children varied. There were 44 parents speaking Chinese at home to their children, and 30 children speaking Chinese and 33 children speaking English to parents. However, English became the dominant language between children and their siblings (53 responses) and children and their Chinese friends (61 responses) (see Table 5). The one-way ANOVA showed that there were group differences of the primary language use (i.e., Mandarin Chinese, English, and other, e.g., Vietnamese) at home on the children's understanding/speaking abilities, no matter the language was spoken by the parents to their children $(F=4.495, p=.015)$, by the children to their parents and 
other elders $(F=7.651, p=.007)$, or by the children to their siblings $(F=5.529, p=$ .006). It implied that the language use between the parents and their children and between the children and their siblings might affect children's understanding/speaking abilities. In other words, when parents primarily spoke Mandarin Chinese to their children in the home (see Figure 2) or the children used Mandarin Chinese as the primary communication tool to their parents (see Figure 3) and their siblings (see Figure 4), the children reported higher understanding/speaking abilities. Moreover, the item means revealed that children's conversational skills (i.e., understanding and speaking) were better than their literacy skills (i.e., reading/writing) (see Table 6). And, interestingly, Figure 5 showed that children tended to choose the middle scale to represent their language ability.

Table 5

Primary Language Use: Parents and Children

\begin{tabular}{|c|c|c|c|c|c|}
\hline & & \multicolumn{4}{|c|}{ Frequency } \\
\hline & & $\begin{array}{l}\text { Parents to } \\
\text { children }\end{array}$ & $\begin{array}{c}\text { Children to } \\
\text { parents }\end{array}$ & $\begin{array}{l}\text { Children to } \\
\text { siblings }\end{array}$ & $\begin{array}{l}\text { Children to } \\
\text { Chinese friends }\end{array}$ \\
\hline \multirow[t]{5}{*}{ Valid } & Mandarin-Chinese & & & & \\
\hline & & 44 & 30 & 6 & 1 \\
\hline & English & 17 & 33 & 53 & 61 \\
\hline & Other & 2 & 0 & 4 & 1 \\
\hline & Total & 63 & 63 & 63 & 63 \\
\hline
\end{tabular}




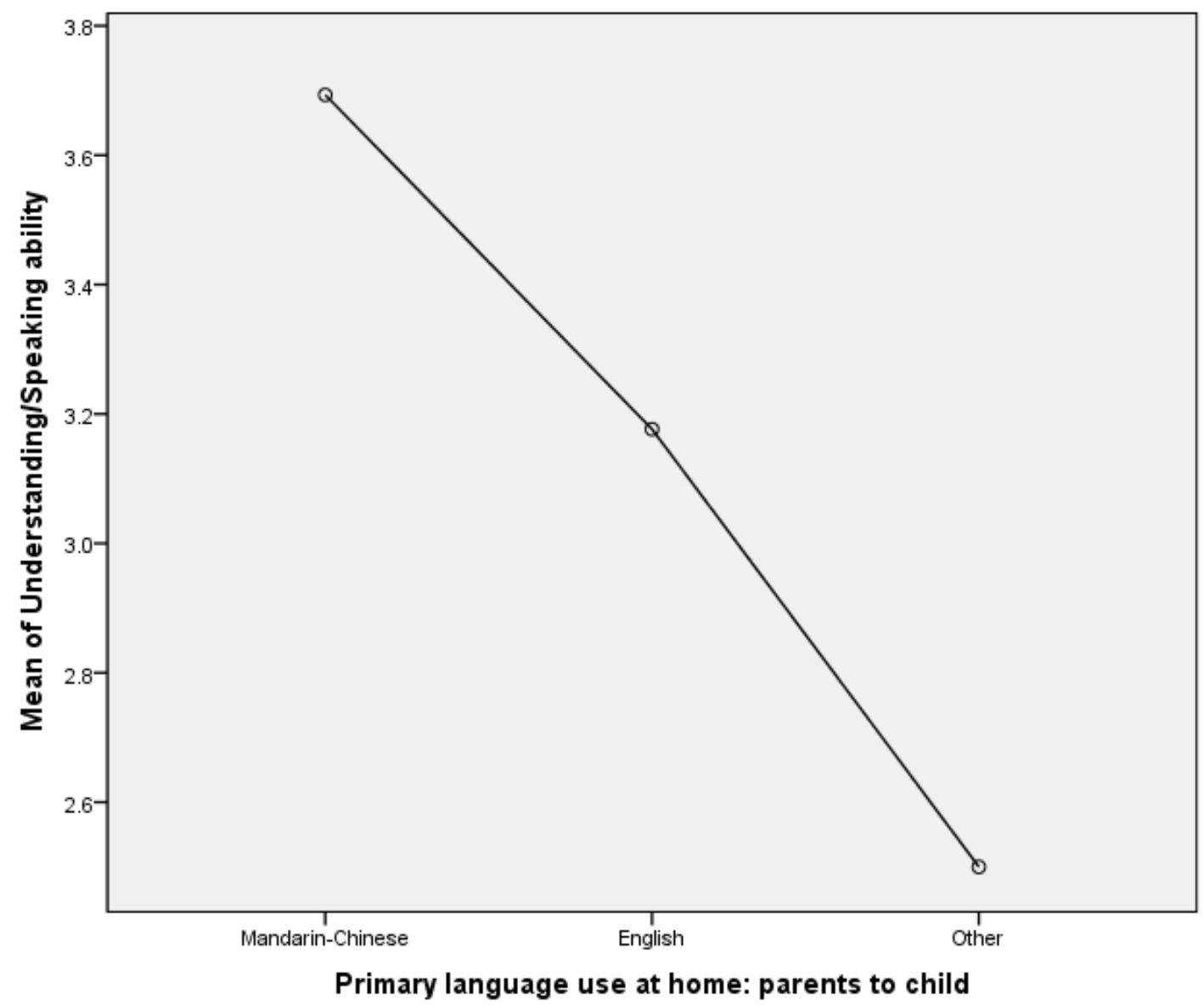

Figure 2. Primary language use at home and children's understanding/speaking abilities 1 . This figure showed the relationship between parents' primary language use at home and children's conversational abilities. 


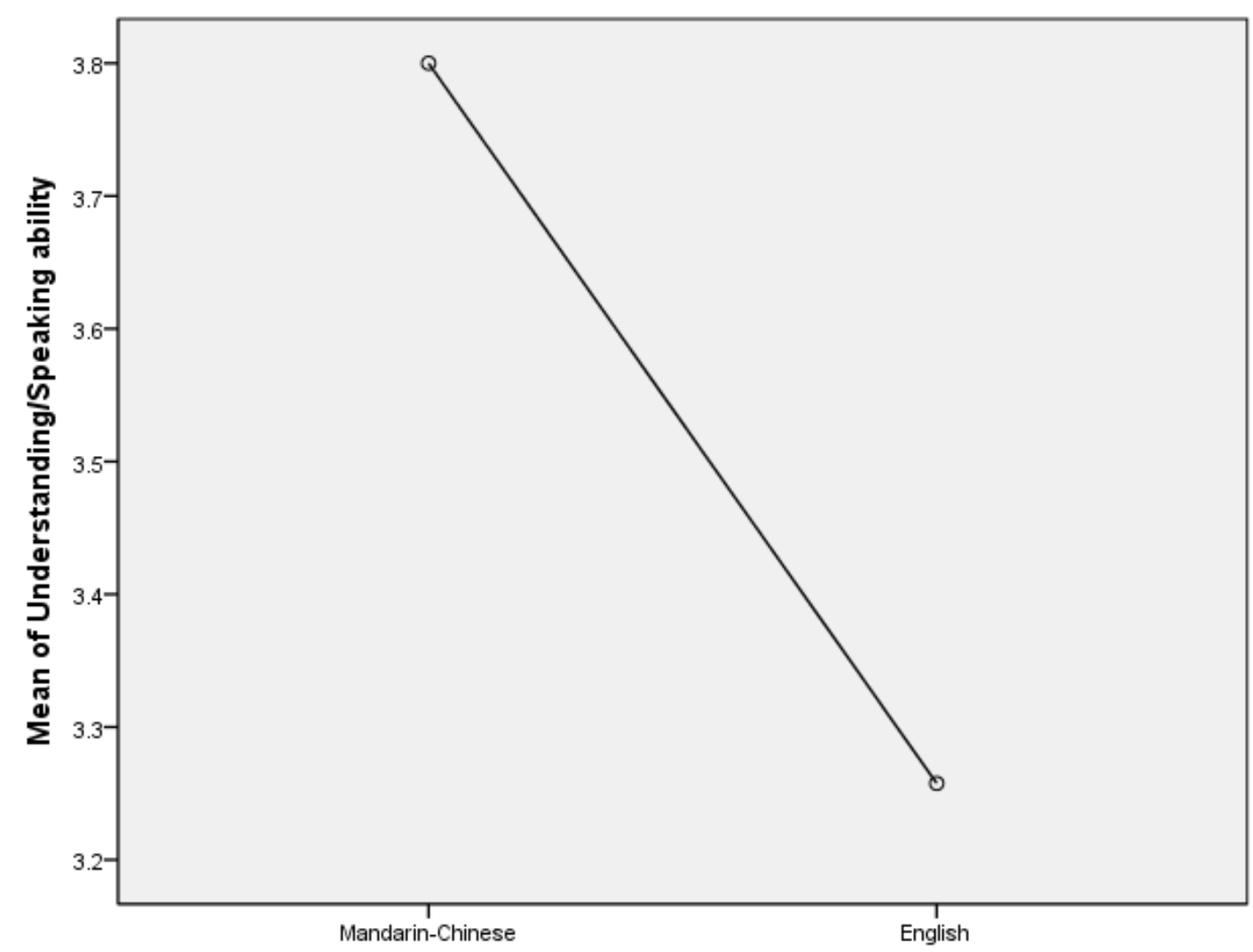

Primary language use at home: child to parents

Figure 3. Primary language use at home and children's understanding/speaking abilities 2 . This figure showed the relationship between children's primary language use at home to their parents and their conversational abilities.

Table 6

Descriptive Statistics of Chinese Language Proficiency Items

\begin{tabular}{|l|r|r|r|r|r|}
\hline & $N$ & Minimum & Maximum & Mean & Std. Deviation \\
\hline How well do you understand & 63 & 2 & 5 & 3.68 & .877 \\
Chinese? & 63 & 2 & 5 & 3.35 & .864 \\
How well do you speak & 63 & 1 & 5 & 2.89 & .764 \\
Chinese? & & & & & \\
How well do you read and & 63 & & & & \\
write Chinese? & & & & & \\
Valid N (listwise) & & & & & \\
\hline
\end{tabular}




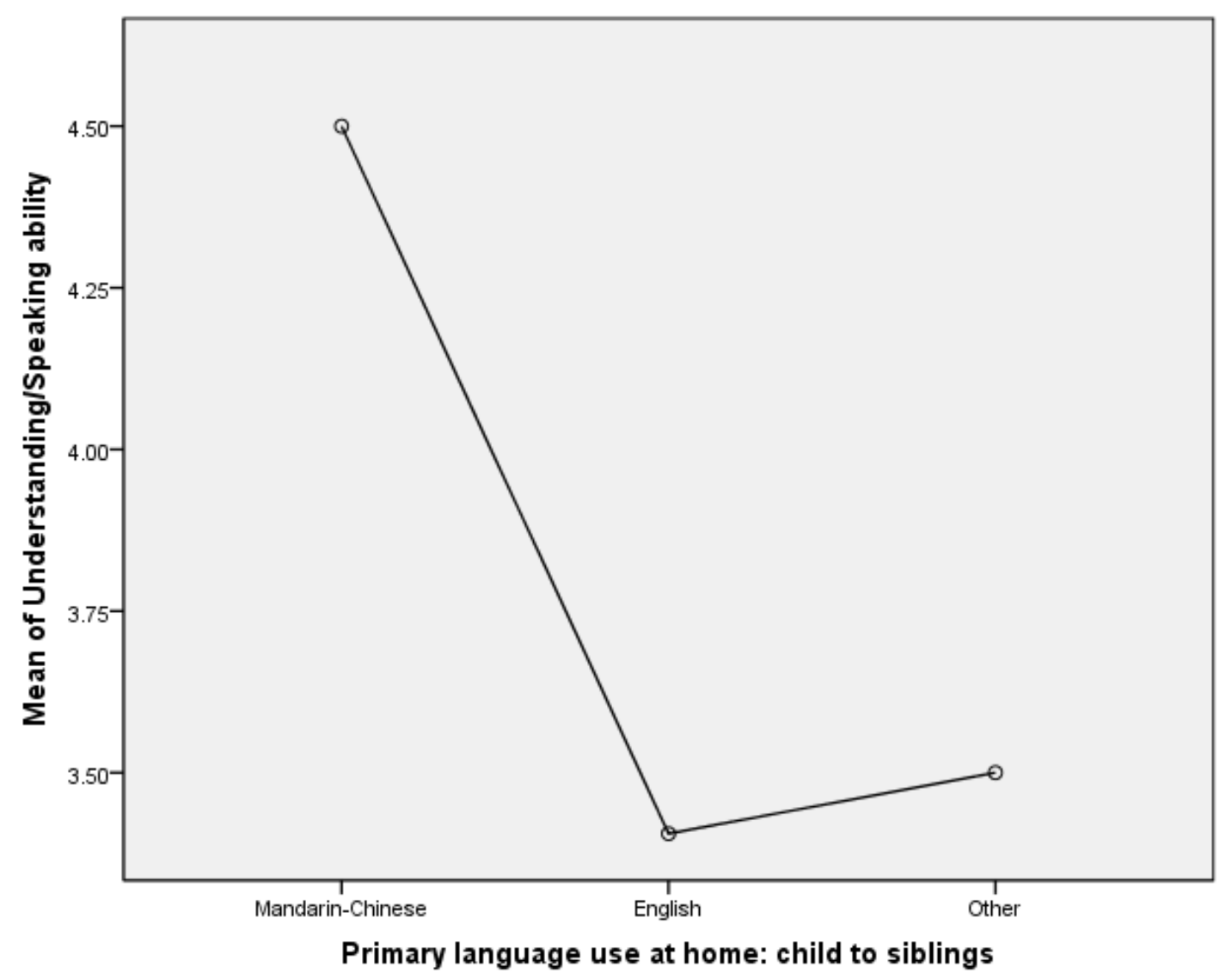

Figure 4. Primary language use at home and children's understanding/speaking abilities 3 . This figure showed the relationship between children's primary language use at home to their siblings and their conversational abilities. 


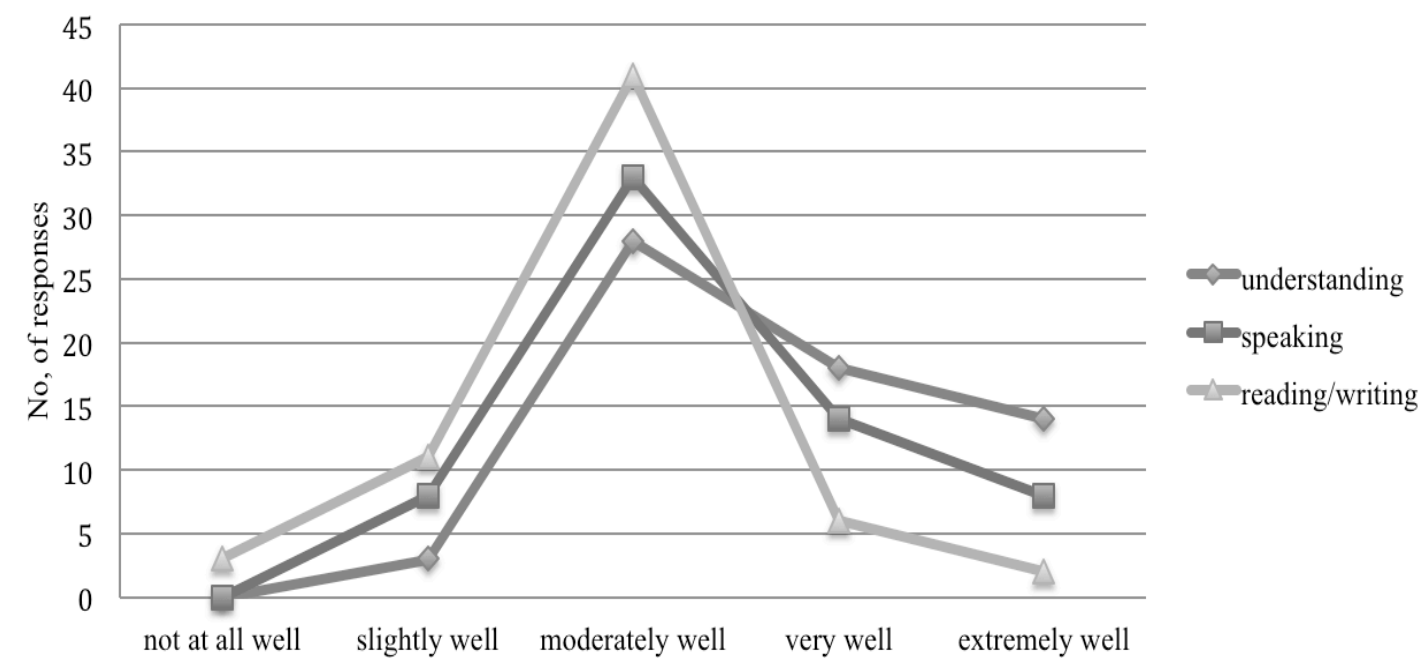

Figure 5. Self-evaluated Chinese language proficiency. This figure revealed that children tended to choose the middle scale to represent their language abilities.

According to the highest education parents obtained, the majority of these families had high educational background parents with $89.3 \%$ fathers and $92.7 \%$ mothers holding a Bachelor's degree or higher (see Table 7). Moreover, when a multiple-choice survey asked the parents the reasons why they send their children to the Chinese language schools, the data revealed that there were several reasons that parents cared about. Among these reasons, to learn and maintain Chinese, to increase future career opportunities, to learn Chinese culture, to form ethnic identity, and to make friends with Chinese children and families were the top five motives (see Table 8). 
Table 7

Distribution of Father and Mother's Highest Level of Education

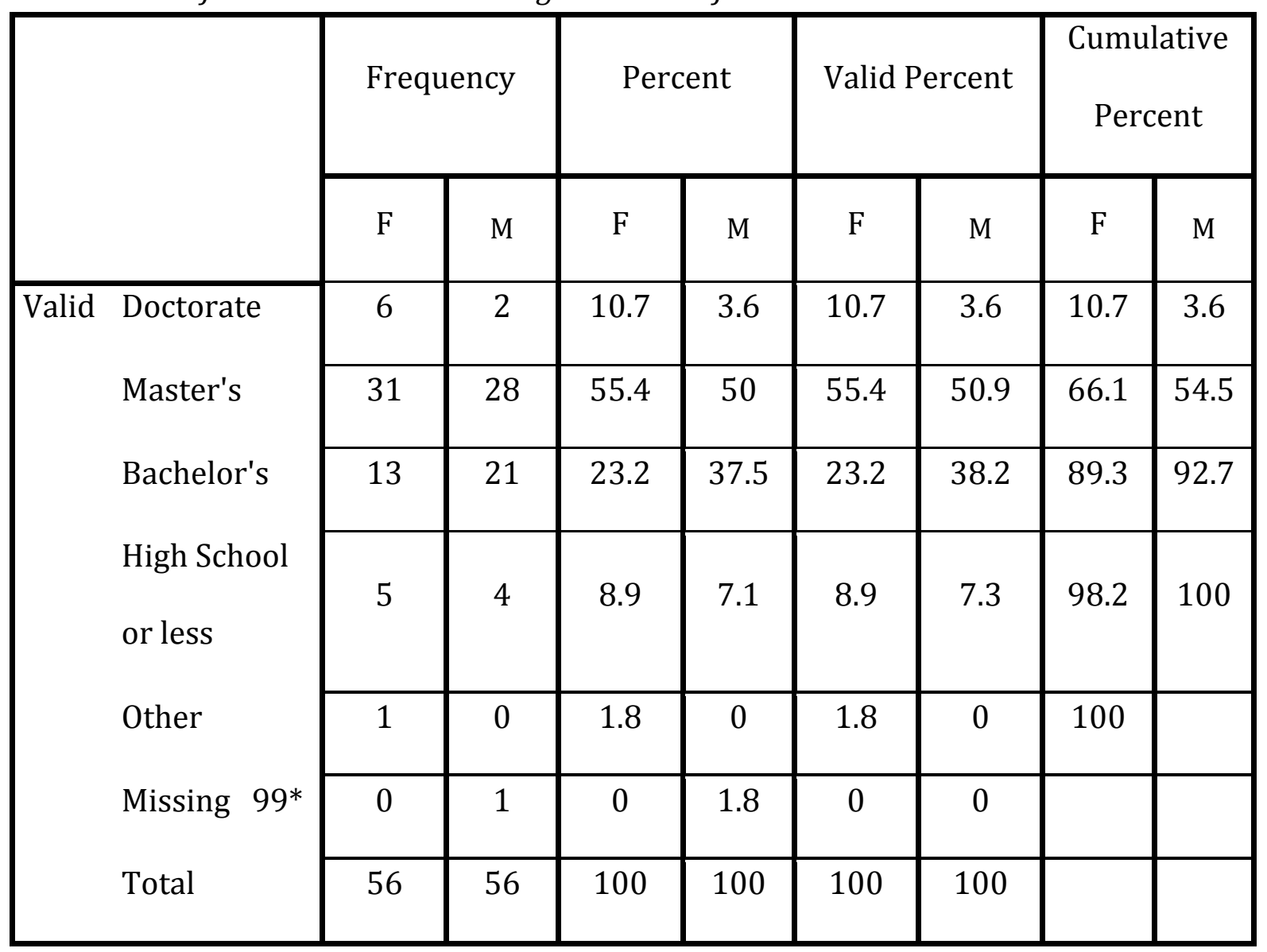

Note. $\mathrm{F}=$ Father; $\mathrm{M}=$ Mother.

*The missing data was excluded in the valid percent and cumulative percent. 
Table 8

Reasons of Sending Child to Chinese Language School

\begin{tabular}{|l|c|}
\hline \multicolumn{1}{|c|}{ Reason } & Number of Responses \\
\hline Learn and Maintain Chinese & 49 \\
\hline Increase future career opportunities & 30 \\
\hline Learn Chinese Culture & 30 \\
\hline Form ethnic identity & 24 \\
\hline Enhance self-esteem & 12 \\
\hline Reinforce family cohesion & 19 \\
\hline
\end{tabular}

\section{Internal Reliabilities of Measures}

In order to examine whether the reliabilities of these measures (CLFQ, MEIM, and RSE) in this study were consistent with the pervious studies, the mean, standard deviation, and internal reliability were assessed for each measure (see Table 9) by calculating Cronbach's alpha coefficients. In this study, two items for 
understanding and speaking of the CLFQ had a strong relationship of .77, although it was lower than that obtained in Kim and Chao's (2009) study $(r=.86)$ for the Chinese sample. The subscale of the combination of the understanding and speaking items (by averaging together) and the reading/writing item (viewed as a subscale as well) also revealed a correlation of .48, which was lower than it was in the previous study (in the range of .55 to .63 for Chinese). However, the lower correlation $(r=.48)$ between the two subscales, understanding/speaking and reading/writing, in the current study demonstrated more distinct aspects of language proficiency comparing with the correlation in Kim and Chao's study.

Overall, participants' scores on the CLFQ in this study had a mean of $3.20(S D=.68)$ and a Cronbach's alpha of .79.

Table 9

Means, Standard Deviations, and Cronbach's Alphas for Measures

\begin{tabular}{cccccc}
\hline Measure & $M$ & Minimum & Maximum & $S D$ & $\alpha$ \\
\hline CLFQ & 3.20 & 1.50 & 5.00 & .68 & .77 \\
MEIM & 2.73 & 1.00 & 3.92 & .53 & .89 \\
RSE & 3.23 & 1.70 & 4.00 & .46 & .84 \\
\hline
\end{tabular}

Note. CLFQ = Self-Evaluated Chinese Language Fluency Questionnaire; MEIM = 12-item Multigroup Ethnic Identity Measure; RSE = Rosenberg's Self-Esteem Scale; $M=$ mean scores; Minimum = minimum score in the measure; Maximum = maximum score in the measure; $S D$ $=$ standard deviation; $\alpha=$ Cronbach's alpha coefficient. 
On the 12-item MEIM measure, a mean of $2.73(S D=.53)$ and a Cronbach's alpha of .89 were obtained in the present study, which were more consistent with Roberts et al.'s (1999) findings (a range from .81 to .89 , and .84 for ChineseAmerican) and Phinney's (1992) results (.81 for the high school students and .90 for the college students) considering participants' ethnic group (Chinese-American) and age (elementary and middle school students in this case).

The RSE measure in this study had a mean of $3.23(S D=.46)$ and a Cronbach's alpha of .84. The internal consistency fell in the range of .75 to .88 for various samples (Blascovich \& Tomaka, 1993; Hagborg, 1996; Hovey et al., 2006; Rosenberg, 1986; Tsai, Ying, \& Lee, 2001). The results of the internal consistency values of the CLFQ, MEIM, and RSE showed the reliabilities of the analysis of research questions in the next section.

\section{Analysis of Research Questions and Hypotheses}

Before the analysis of the research questions and hypotheses, preliminary $t$-test and one-way ANOVAs were conducted to determine whether there were some extraneous variables that might confound the results. The potentially confounded variables being tested were gender, grade level, weekly hours spending on homework from Chinese language school, father's highest education obtained, and mother's highest education obtained. No significant difference was found, in terms of Chinese language proficiency, ethnic identity, and self-esteem. In other words, it was unnecessary to control any of the extraneous variables, which were tested for its effect. Therefore, data analysis in this section simply followed the sequence of 
the research question 1 , research question 2 , and research question 3 and was based on the hypotheses.

Research question 1. What is the relationship between Chinese heritage language proficiency and ethnic identity?

The first hypothesis: $\mathrm{H}_{0}$ : There is no relationship between Chinese heritage language proficiency and ethnic identity; $\mathrm{H}_{1}$ : There is a positive relationship between Chinese heritage language proficiency and ethnic identity.

A one-tailed Pearson's correlation was performed to assess the relationship between Chinese heritage language proficiency and ethnic identity. The exclusion of cases pairwise was selected to deal with the missing values. It was predicted that there would be a positive relationship, so as the mean scores of Chinese language proficiency increase so do the mean scores of ethnic identity. The correlation was statistically significant, $r=.316, p<.05$ (see Table 10). Furthermore, the $R$ square (.100) of the regression suggested that the correlation explained $10 \%$ of the variability in ethnic identity, which, in other words, meant that Chinese language proficiency was not only related to ethnic identity, but also could be a predictor of ethnic identity. In addition, the correlation analyses revealed a positive correlation between subscale understanding/speaking and ethnic identity $(r=.261, p<.05)$ and between subscale reading/writing and ethnic identity $(r=.282, p<.05)$ (see Table 10). 
Table 10

Correlations of Research Variables

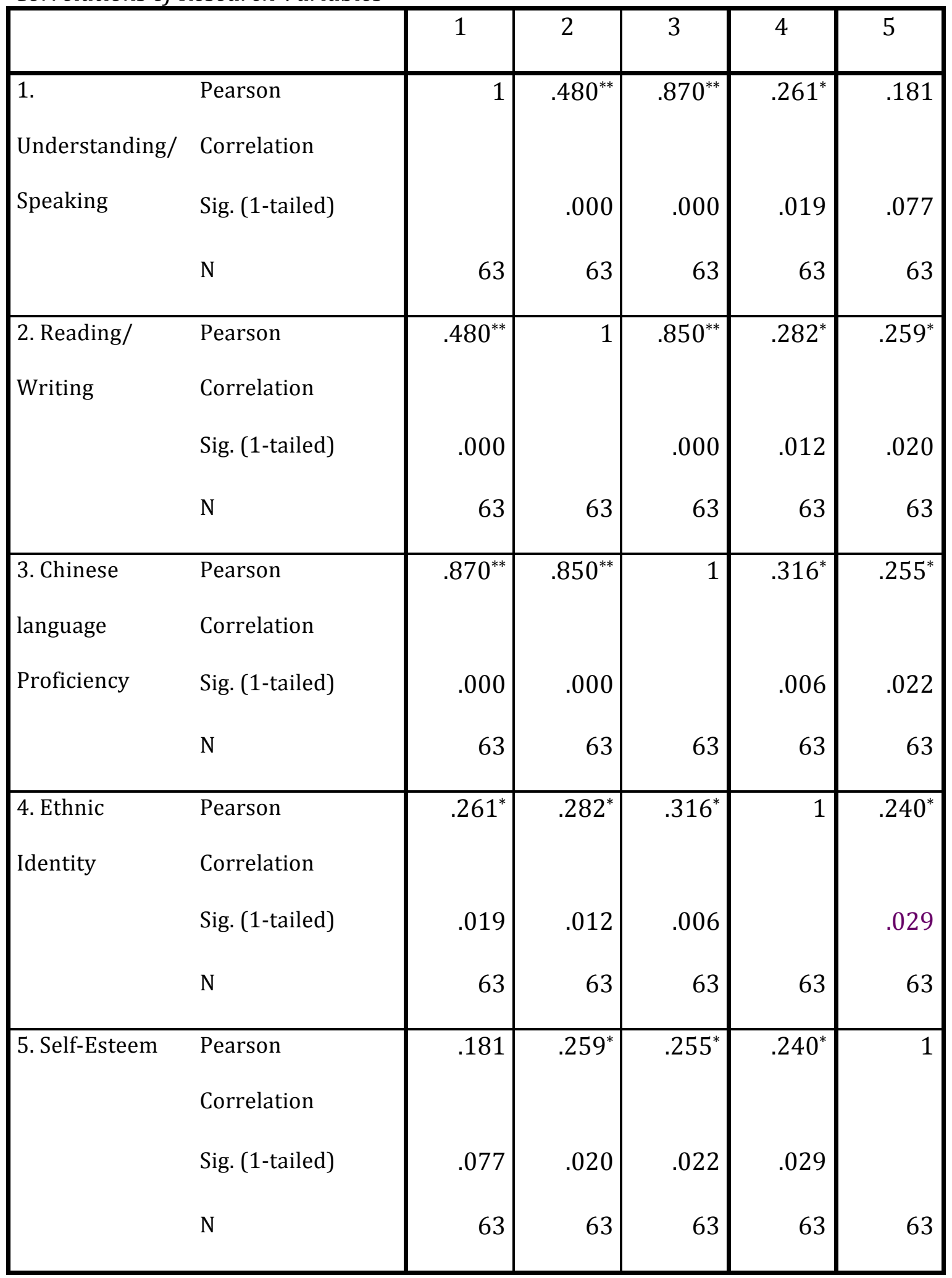

**. Correlation is significant at the 0.01 level (one-tailed); ${ }^{*}$. Correlation is significant at the 0.05 level (one-tailed). 
The second hypothesis: $\mathrm{H}_{0}$ : There is no significant difference in the relationship between Chinese heritage language proficiency and ethnic identity when comparing the two subgroups: the American-born Chinese with at least one parent from Taiwan and the American-born Chinese with at least one parent from other countries in Asia where Mandarin Chinese is spoken; $\mathrm{H}_{1}$ : There is a significant difference in the relationship between Chinese heritage language proficiency and ethnic identity on the two subgroups.

A factorial ANOVA was performed to test whether there was a significant group difference on the ethnic identity by Chinese language proficiency. The result supported the research hypothesis $(F=4.825, p<.05)$, which meant there was a significant difference in the relationship between Chinese language proficiency and ethnic identity between the two subgroups: the American-born Chinese with at least one parent from Taiwan and the American-born Chinese with at least one parent from other countries in Asia where Mandarin Chinese is spoken (see Table 11). Moreover, there was a main effect for Chinese language proficiency $(F=2.188, p=$ $.026)$, and no main effect for the two subgroups $(F=.024, p=.878)$. In addition, when examining the group differences on the ethnic identity by the subscale understanding/speaking and on the ethnic identity by the subscale reading/writing, there was a differential effect for the subscale understanding/speaking across the two subgroups $(F=4.378, p<$. 05) (see Table 12) and no differential effect for the subscale reading/writing across the two subgroups $(F=2.523, p=.089$ ) (see Table 13). The Table 14 also revealed that the subgroup one had higher item mean scores on the understanding/speaking, overall Chinese language proficiency, ethnic 
identity, and self-esteem than the subgroup two. And the subgroup two scored higher on the reading/writing than the subgroup one.

Table 11

Subgroup by Chinese Language Proficiency on Ethnic Identity

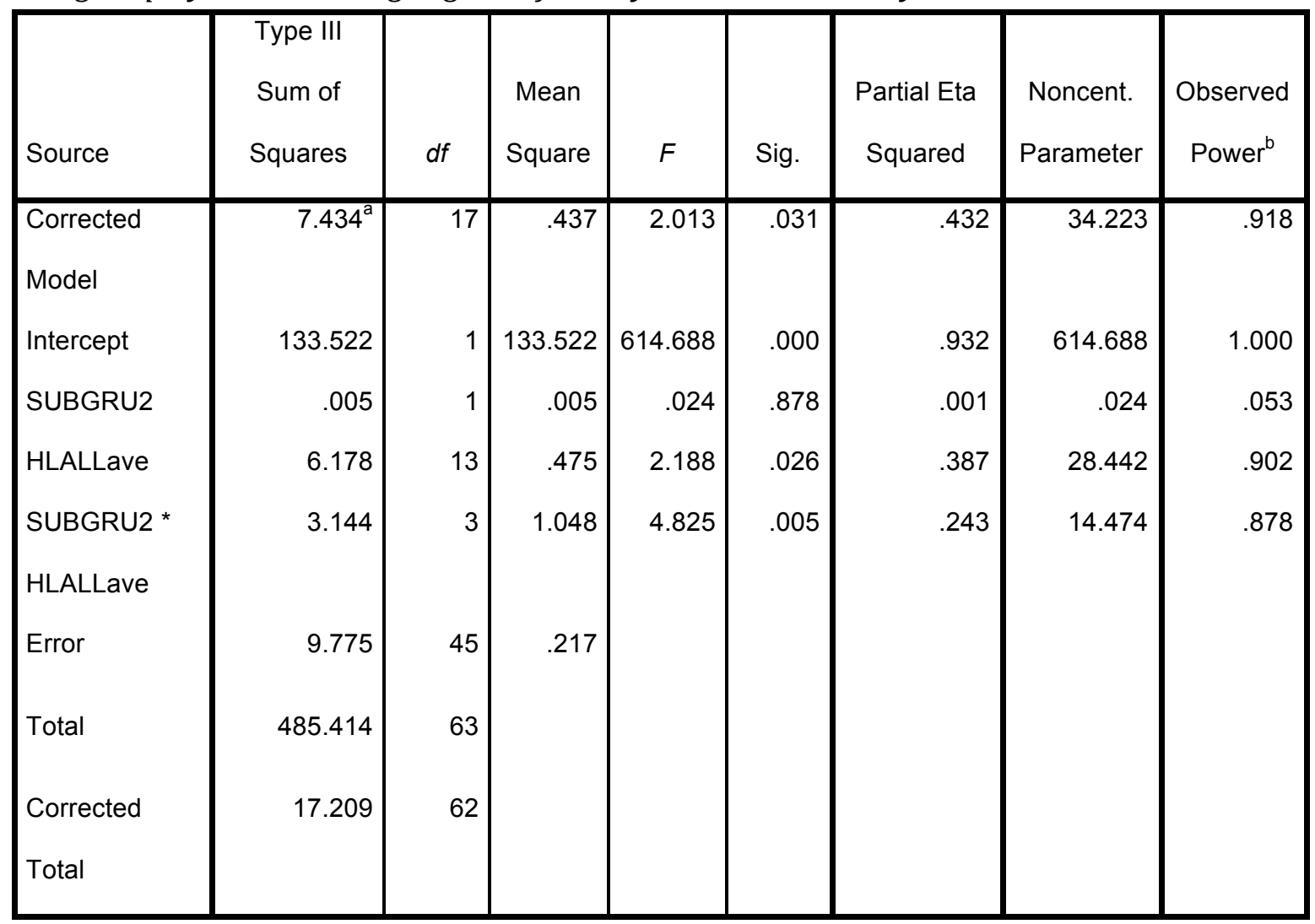

Note. SUBGRU2 = two subgruops; HLALLave = Chinese language proficiency; SUBGRU2 * HLALLave = interaction between the two subgroups and Chinese language proficiency; $d f=$ degree of freedom.

a. R Squared $=.432$ (Adjusted R Squared $=.217$ ); b. Computed using alpha $=.05$. 
Table 12

Subgroup by Subscale Understanding/Speaking on Ethnic Identity

\begin{tabular}{|c|c|c|c|c|c|c|c|c|}
\hline Source & $\begin{array}{l}\text { Type III } \\
\text { Sum of } \\
\text { Squares }\end{array}$ & df & $\begin{array}{l}\text { Mean } \\
\text { Square }\end{array}$ & $\mathrm{F}$ & Sig. & $\begin{array}{c}\text { Partial Eta } \\
\text { Squared }\end{array}$ & $\begin{array}{l}\text { Noncent. } \\
\text { Parameter }\end{array}$ & $\begin{array}{c}\text { Observed } \\
\text { Power }^{b}\end{array}$ \\
\hline $\begin{array}{l}\text { Corrected } \\
\text { Model }\end{array}$ & $5.563^{\mathrm{a}}$ & 10 & .556 & 2.484 & .016 & .323 & 24.838 & .907 \\
\hline Intercept & 152.279 & 1 & 152.279 & 679.930 & .000 & .929 & 679.930 & 1.000 \\
\hline SUBGRU2 & .010 & 1 & .010 & .044 & .835 & .001 & .044 & .055 \\
\hline HLUS & 2.386 & 6 & .398 & 1.776 & .122 & .170 & 10.654 & .615 \\
\hline $\begin{array}{l}\text { SUBGRU2 * } \\
\text { HLUS }\end{array}$ & 2.941 & 3 & .224 & 4.378 & .008 & .202 & 13.133 & .846 \\
\hline Error & 11.646 & 52 & .207 & & & & & \\
\hline Total & 485.414 & 63 & & & & & & \\
\hline $\begin{array}{l}\text { Corrected } \\
\text { Total }\end{array}$ & 17.209 & 62 & & & & & & \\
\hline
\end{tabular}

Note. HLUS = subscale understanding/speaking; SUBGRU2 $*$ HLUS = interaction between the two subgroups and understanding/speaking abilities

a. R Squared $=.323$ (Adjusted R Squared $=.193$ ); b. Computed using alpha $=.05$. 
Table 13

Subgroup by Subscale Reading/Writing on Ethnic Identity

\begin{tabular}{|c|c|c|c|c|c|c|c|c|}
\hline Source & $\begin{array}{l}\text { Type III } \\
\text { Sum of } \\
\text { Squares }\end{array}$ & df & $\begin{array}{l}\text { Mean } \\
\text { Square }\end{array}$ & $F$ & Sig. & $\begin{array}{l}\text { Partial Eta } \\
\text { Squared }\end{array}$ & $\begin{array}{l}\text { Noncent. } \\
\text { Parameter }\end{array}$ & $\begin{array}{c}\text { Observed } \\
\text { Power }^{b}\end{array}$ \\
\hline $\begin{array}{l}\text { Corrected } \\
\text { Model }\end{array}$ & $3.616^{a}$ & 7 & .517 & 2.090 & .060 & .210 & 14.629 & .748 \\
\hline Intercept & 111.595 & 1 & 111.595 & 451.528 & .000 & .891 & 451.528 & 1.000 \\
\hline SUBGRU2 & .027 & 1 & .027 & .111 & .741 & .002 & .111 & .062 \\
\hline HLRW & 2.081 & 4 & .520 & 2.105 & .093 & .133 & 8.418 & .588 \\
\hline $\begin{array}{l}\text { SUBGRU2 * } \\
\text { HLRW }\end{array}$ & 1.247 & 2 & .624 & 2.523 & .089 & .084 & 5.046 & .485 \\
\hline Error & 13.593 & 55 & .247 & & & & & \\
\hline Total & 485.414 & 63 & & & & & & \\
\hline $\begin{array}{l}\text { Corrected } \\
\text { Total }\end{array}$ & 17.209 & 62 & & & & & & \\
\hline
\end{tabular}

Note. HLRW = subscale reading/writing; SUBGRU2 * HLRW = interaction between the two subgroups and reading/writing abilities

a. R Squared $=.210$ (Adjusted R Squared $=.110$ ); b. Computed using alpha $=.05$. 
Table 14

Item Mean Scores by Subgroup

\begin{tabular}{|c|c|c|c|c|c|c|}
\hline $\begin{array}{l}\text { Subgrc } \\
\text { of sam }\end{array}$ & ups & $\begin{array}{c}\text { Understanding } \\
/ \\
\text { Speaking }\end{array}$ & $\begin{array}{l}\text { Reading/ } \\
\text { Writing }\end{array}$ & $\begin{array}{l}\text { Chinese } \\
\text { language } \\
\text { proficiency }\end{array}$ & $\begin{array}{l}\text { Ethnic } \\
\text { identity }\end{array}$ & $\begin{array}{l}\text { Self- } \\
\text { esteem }\end{array}$ \\
\hline G1 & Mean & 3.570 & 2.88 & 3.2237 & 2.7470 & 3.2444 \\
\hline & $\mathrm{N}$ & 57 & 57 & 57 & 57 & 57 \\
\hline & SD & .7930 & .709 & 65241 & .44726 & .43557 \\
\hline G2 & Mean & 3.000 & 3.00 & 3.0000 & 2.5278 & 3.1000 \\
\hline & $\mathrm{N}$ & 6 & 6 & 6 & 6 & 6 \\
\hline & SD & .9487 & 1.265 & .96177 & 1.07195 & .70993 \\
\hline Total & Mean & 3.516 & 2.89 & 3.2024 & 2.7261 & 3.2306 \\
\hline & $\mathrm{N}$ & 63 & 63 & 63 & 63 & 63 \\
\hline & SD & .8180 & .764 & .68075 & .52684 & .46242 \\
\hline
\end{tabular}

Note. G1 = at least one parent from Taiwan; G2 = at least one parent from Asian countries except Taiwan.

Research question 2. Is there any connection between heritage language proficiency and self-esteem?

The third hypothesis: $\mathrm{H}_{0}$ : There is no connection between heritage language proficiency and self-esteem; $\mathrm{H}_{1}$ : The relationship between heritage language proficiency and self-esteem is positive. 
A one-tailed Pearson's correlation with an exclusion of cases pairwise was conducted to examine the relationship between Chinese language proficiency and ethnic identity. A correlation showed that the Chinese language proficiency was correlated with self-esteem $(r=.255, p<.05)$ (see Table 10), which meant that the research hypothesis was supported. The $R$ square (.065) suggested that the correlation explained $6.5 \%$ of the variability in self-esteem, which showed a predictive ability of Chinese language proficiency on self-esteem. The positive relationship also existed between the subscale reading/writing and self-esteem ( $r=$ $.259, p<.05$ ) (see Table 10). However, there was no connection between the subscale understanding/speaking and self-esteem $(r=.181, p=.077)$ (see Table 10).

The fourth hypothesis: $\mathrm{H}_{0}$ : There is no significant difference in the relationship between heritage language proficiency and self-esteem between the two subgroups: the American-born Chinese with at least one parent from Taiwan and the Americanborn Chinese with at least one parent from other countries in Asia where Mandarin Chinese is spoken; $\mathrm{H}_{1}$ : The relationship between heritage language proficiency and self-esteem is significant on the two subgroups.

A factorial ANOVA was conducted to test the research hypothesis. There were no main effects for Chinese language proficiency $(F=1.377, p=.208)$ and for the two subgroups $(F=.725, p=.399)$. The result also revealed no significant difference between the American-born Chinese with at least one parent from Taiwan and the American-born Chinese with at least one parent from other countries in Asia where Mandarin Chinese is spoken between Chinese language proficiency and self-esteem, $F=.926, p=.436$ (see Table 15). In other words, the result could not reject the null 
hypothesis. There were also no significant differences in the relationship between the subscale understanding/speaking and self-esteem $(F=1.712, p=.176)$ (see Table 16) and between the subscale reading/writing and self-esteem $(F=2.074, p=$ .135) (see Table 17) across the two subgroups.

Table 15

Subgroup by Chinese Language Proficiency on Self-Esteem

\begin{tabular}{|c|c|c|c|c|c|c|c|c|}
\hline Source & $\begin{array}{l}\text { Type III } \\
\text { Sum of } \\
\text { Squares }\end{array}$ & df & $\begin{array}{l}\text { Mean } \\
\text { Square }\end{array}$ & $\mathrm{F}$ & Sig. & $\begin{array}{c}\text { Partial Eta } \\
\text { Squared }\end{array}$ & $\begin{array}{l}\text { Noncent. } \\
\text { Parameter }\end{array}$ & $\begin{array}{c}\text { Observed } \\
\text { Power }^{\mathrm{b}}\end{array}$ \\
\hline $\begin{array}{l}\text { Corrected } \\
\text { Model }\end{array}$ & $3.962^{\mathrm{a}}$ & 17 & .233 & 1.128 & .359 & .299 & 19.177 & .634 \\
\hline Intercept & 190.290 & 1 & 190.290 & 921.146 & .000 & .953 & 921.146 & 1.000 \\
\hline SUBGRU2 & .150 & 1 & .150 & .725 & .399 & .016 & .725 & .133 \\
\hline HLALLave & 3.698 & 13 & .284 & 1.377 & .208 & .285 & 17.903 & .679 \\
\hline $\begin{array}{l}\text { SUBGRU2 * } \\
\text { HLALLave }\end{array}$ & .574 & 3 & .191 & .926 & .436 & .058 & 2.777 & .237 \\
\hline Error & 9.296 & 45 & .207 & & & & & \\
\hline Total & 670.789 & 63 & & & & & & \\
\hline $\begin{array}{l}\text { Corrected } \\
\text { Total }\end{array}$ & 13.258 & 62 & & & & & & \\
\hline
\end{tabular}

Note. HLALLave $=$ Chinese Language Proficiency; SUBGRU2 $*$ HLALLave $=$ interaction between the two subgroups and Chinese Language Proficiency

a. R Squared $=.299$ (Adjusted R Squared $=.034$ ); b. Computed using alpha $=.05$. 
Table 16

Subgroup by Subscale Understanding/Speaking on Self-Esteem

\begin{tabular}{|c|c|c|c|c|c|c|c|c|}
\hline Source & $\begin{array}{l}\text { Type III } \\
\text { Sum of } \\
\text { Squares }\end{array}$ & df & $\begin{array}{l}\text { Mean } \\
\text { Square }\end{array}$ & $\mathrm{F}$ & Sig. & $\begin{array}{c}\text { Partial Eta } \\
\text { Squared }\end{array}$ & $\begin{array}{l}\text { Noncent. } \\
\text { Parameter }\end{array}$ & $\begin{array}{c}\text { Observed } \\
\text { Power }^{b}\end{array}$ \\
\hline $\begin{array}{l}\text { Corrected } \\
\text { Model }\end{array}$ & $2.393^{\mathrm{a}}$ & 10 & .239 & 1.146 & .348 & .181 & 11.456 & .527 \\
\hline Intercept & 250.575 & 1 & 205.575 & 983.945 & .000 & .950 & 983.945 & 1.000 \\
\hline SUBGRU2 & .070 & 1 & .070 & .335 & .565 & .006 & .335 & .088 \\
\hline HLUS & 1.841 & 6 & .307 & 1.469 & .207 & .145 & 8.814 & .521 \\
\hline $\begin{array}{l}\text { SUBGRU2 * } \\
\text { HLUS }\end{array}$ & 1.073 & 3 & .358 & 1.712 & .176 & .090 & 5.136 & .422 \\
\hline Error & 10.864 & 52 & .209 & & & & & \\
\hline Total & 670.789 & 63 & & & & & & \\
\hline $\begin{array}{l}\text { Corrected } \\
\text { Total }\end{array}$ & 13.258 & 62 & & & & & & \\
\hline
\end{tabular}

Note. HLUS = subscale understanding/speaking; SUBGRU2 $*$ HLUS = interaction between the two subgroups and understanding/speaking abilities

a. R Squared $=.181$ (Adjusted R Squared $=.023$ ); b. Computed using alpha $=.05$. 
Table 17

Subgroup by Subscale Reading/Writing on Self-Esteem

\begin{tabular}{|c|c|c|c|c|c|c|c|c|}
\hline Source & $\begin{array}{l}\text { Type III } \\
\text { Sum of } \\
\text { Squares }\end{array}$ & $d f$ & $\begin{array}{l}\text { Mean } \\
\text { Square }\end{array}$ & $F$ & Sig. & $\begin{array}{l}\text { Partial Eta } \\
\text { Squared }\end{array}$ & $\begin{array}{l}\text { Noncent. } \\
\text { Parameter }\end{array}$ & $\begin{array}{c}\text { Observed } \\
\text { Power }^{\mathrm{b}}\end{array}$ \\
\hline $\begin{array}{l}\text { Corrected } \\
\text { Model }\end{array}$ & $2.091^{\mathrm{a}}$ & 7 & .299 & 1.471 & .197 & .158 & 10.298 & .565 \\
\hline Intercept & 152.183 & 1 & 152.183 & 749.547 & .000 & .932 & 749.547 & 1.000 \\
\hline SUBGRU2 & .076 & 1 & .076 & .372 & .544 & .007 & .372 & .092 \\
\hline HLRW & 1.620 & 4 & .405 & 1.995 & .108 & .127 & 7.979 & .562 \\
\hline $\begin{array}{l}\text { SUBGRU2 * } \\
\text { HLRW }\end{array}$ & .842 & 2 & .421 & 2.074 & .135 & .070 & 4.147 & .409 \\
\hline Error & 11.167 & 55 & .203 & & & & & \\
\hline Total & 670.789 & 63 & & & & & & \\
\hline $\begin{array}{l}\text { Corrected } \\
\text { Total }\end{array}$ & 13.258 & 62 & & & & & & \\
\hline
\end{tabular}

Note. HLRW = subscale reading/writing; SUBGRU2 * HLRW = interaction between the two subgroups and reading/writing abilities

a. R Squared $=.158$ (Adjusted R Squared $=.051$ ); b. Computed using alpha $=.05$.

Research question 3. How does ethnic identity associate with self-esteem?

The fifth hypothesis: $\mathrm{H}_{0}$ : There is no correlation between ethnic identity and self-esteem; $\mathrm{H}_{1}$ : Ethnic identity and self-esteem are positively correlated with each other.

The one-tailed Pearson's correlation was conducted to examine whether there was a positive relationship between ethnic identity and self-esteem. The exclusion of cases pairwise was selected in this case as well. The report reached statistical 
significance, which meant that ethnic identity and self-esteem were positively related to each other $(r=.240, p<.05)$ and the research hypothesis was supported (see Table 10). In other words, as the mean scores of ethnic identity increase, so do the mean scores of self-esteem, and vice versa.

\section{Summary}

In this study, the participants were chosen from three Chinese language schools: JKCS, MZCS, and AGCS. Participants were 63 students and one of their parents for a total of 56 . However, students met two criteria to be considered, which were (1) students must be the American-born Chinese and were current fourth to eighth graders at that time in a Chinese language school, and (2) at least one of the students' parents is a native Mandarin-speaking Chinese immigrant from the greater China (i.e., Mainland China and Taiwan) or other countries in the Southeast Asia. Eighty-three packages of the documents, which included the consent forms and surveys were distributed. Sixty-three (29 boys and 34 girls) were completed and returned to me. Thus, the response rates were $75.9 \%$ for the students and $76.7 \%$ for the parents. Among the 63 students, 57 belonged to the subgroup one: at least one parent from Taiwan, and 6 belonged to the subgroup two: at least one parent from Asian countries other than Taiwan where Mandarin Chinese is spoken. Frequency reports showed that most parents spoke Chinese to their children at home. Only about half of the children spoke Chinese to their parents. However, English was the primary language used between the children and their siblings and the children and their Chinese friends. For those children that Chinese was primarily used in the home reported a higher understanding and 
speaking abilities than the other cases did. And according to the item mean scores, children's understanding and speaking abilities are better than their reading/writing abilities. Ninety per cent of these students' parents (both father and mother) obtained a Bachelor's degree or higher, which shows a lack of the diversity of the participants for completion of higher education.

Because some existing measures were administered in this study, the researcher examined the reliability of each measure as well. The test of the internal consistency of the measures applied in this study showed that the Cronbach's alpha values of the CLFQ, the 12-item MEIM, and the RSE were .77, .89, and .84 respectively. The values were close or higher than those in the previous studies.

There were three research questions along with five hypotheses in this study. The parents' demographic information and the mean scores of each measure were calculated to answer these questions. For research hypothesis one: There is a positive relationship between Chinese heritage language proficiency and ethnic identity, a one-tailed Pearson's correlation was conducted and revealed that the relationship between these two variables were positive, $r=.316, p<.05$.

Furthermore, the correlations were statistically significant when the independent variable was replaced by the subscale understanding/speaking $(r=.261, p<.05)$ and by the subscale reading/writing $(r=.282, p<.05)$. For hypothesis two: There is a significant difference in the relationship between Chinese heritage language proficiency and ethnic identity on the two subgroups, the result of the factorial ANOVA showed a significant difference between the two subgroups $(F=4.825, p<$ .05). There were also group differences on the ethnic identity by the subscale 
understanding/speaking $(F=4.378, p<.05)$ and no difference on the ethnic identity by the subscale reading/writing $(F=2.523, p=.089)$. For hypothesis three: The relationship between heritage language proficiency and self-esteem is positive, the hypothesis was supported $(r=.255, p<.05)$. The subscale reading/writing was related to self-esteem as well $(r=.259, p<.05)$. However, there was no connection between the subscale understanding/speaking and self-esteem $(r=.181, p=.077)$. For hypothesis four: The relationship between heritage language proficiency and self-esteem is significant on the two subgroups, the factorial ANOVA reported no group difference, no matter the factor was the overall Chinese language proficiency $(F=.926, p=.436)$, the subscale understanding/speaking $(F=1.712, p=.176)$, or the subscale reading/writing $(F=2.074, p=.135)$. And for hypothesis five: Ethnic identity and self-esteem are positively correlated with each other, the result was significant $(r=.240, p<.05)$, which meant ethnic identity was connected to selfesteem.

After all research questions were answered, the discussion and conclusion were demonstrated in the next chapter based on the research results. 


\section{Chapter Five: Discussion}

This chapter discusses the results of the survey study to address the research questions set forth in chapter one and the chapter is divided into three sections. First, there is a summary and interpretation of the research findings associated with the previous studies. Second, the limitations of the study are explained. Finally, the implications of the findings for each of the stakeholders are provided. The stakeholders include the Chinese language schools and parents, $\mathrm{K}-12$ educators and policymakers. Implications for future research are discussed.

\section{Summary and Interpretation of the Research Findings}

The purpose of this study was to investigate the relationships among heritage language proficiency, ethnic identity, and self-esteem in the American-born Chinese (ABC) children who went to the Chinese language schools for Chinese language learning on weekends. Students who were targeted were current 4 th to 8 th grade enrollees with at least one parent who is a Chinese immigrant whose native language is Mandarin Chinese. A total of 63 students and their parents participated in this study. The student participants were viewed as a group and were divided into two subgroups for group comparison, as well. The two subgroups were (1) students with at least one parent from Taiwan and (2) students with at least one parent from any Asian countries, except Taiwan, where Mandarin Chinese is spoken. There were two questionnaires, the Parents' Demographic Questionnaire and the Children's Self-Perception of Chinese Language Learning Survey, for the participants to complete. The Children's Self-Perception of Chinese language Learning Survey included the Demographic Questionnaire, the Self-Evaluated Chinese Language 
Fluency Questionnaire (CLFQ), the 12-item Multigroup Ethnic Identity Measure (MEIM), and the Rosenberg's Self-Esteem Scale (RSE). The data of parents' demographic information, the CLFQ, the MEIM, and the RSE were analyzed to answer three research questions along with five hypotheses.

\section{The relationship between Chinese heritage language proficiency and}

ethnic identity. The first question in this research was: What is the relationship between Chinese heritage language proficiency and ethnic identity? Phinney (1990) argued that identity development is especially difficult for those ethnic and racial minority groups who, on the one hand, need to preserve their cultural values and, on the other hand, have to belong to the host culture. Under this circumstance, heritage language use becomes an important process to maintain a strong ethnic identity (Pease-Alvarez, 2002). In addition, according to Phinney et al.'s (2001) observation, heritage language fluency is one key component of ethnic identity among the adolescents from immigrant families. The test of the relationship between Chinese heritage language proficiency and ethnic identity in this study revealed that Chinese language proficiency was positively related to ethnic identity. In addition, the tests of the relationships of the subscale understanding/speaking abilities and subscale reading/writing abilities with ethnic identity also showed positive connections. The findings matched the majority of existing studies on ethnic identity, that is, language is one crucial factor in the maintenance of a strong ethnic identity for minority groups (Bailey \& Oetzel, 2004; Edwards, 1997; Joseph, 2004; Pease-Alvarez, 2002). The more proficient one is in his or her heritage language, the stronger the ethnic identity and affiliation he or she has with the 
ethnic group (Oh \& Fuligni, 2010). The evidence of the positive relationship between Chinese heritage language proficiency and ethnic identity also indicated the validity of the 12-item MEIM on measuring language proficiency for the children of Chinese immigrants. Moreover, there were group differences across the two Chinese subgroups in overall Chinese language proficiency and the understanding/speaking abilities on ethnic identity. No group difference was found across the two Chinese subgroups in the reading/writing abilities on ethnic identity. However, no similar research regarding the subgroups in the same ethnic group had been done to date. More studies on the comparison of the subgroups within the ethnic groups are required to get more general ideas.

\section{The connection between Chinese heritage language proficiency and}

self-esteem. The second research question being tested in this study was: Is there any connection between heritage language proficiency and self-esteem? The findings demonstrated that Chinese language proficiency and the reading/writing abilities showed a correlation with self-esteem. These results add to the existing literature (Altschul et al., 2008; Lee, 2008; Portes, 2002) on the self-esteem by providing evidence that heritage language fluency and self-esteem were positively significant, which, furthermore, indicated the validity of the RSE on measuring language proficiency. In other words, the findings supported that a strong retention of a heritage language could benefit the development of self-esteem (Altschul et al., 2008; Beiley, 2000). Self-esteem may influence students' academic performance. In their research, Alves-Martins, Peixoto, Gouveia-Pereira, Amaral, and Pedro (2002) found that there is a significant difference between the self-esteem felt by students 
with high levels and those with low levels of academic achievement in the seventh grade. With the finding of the positive relationship between Chinese language proficiency and self-esteem, it provides the children of the Chinese immigrants optimistic information that their learning on the heritage language may ultimately help better their school performance. However, neither connection was found between the understanding/speaking abilities and self-esteem, nor were group differences found between the subgroups in the overall language proficiency, the understanding/speaking skills, and the reading/writing skills on self-esteem.

The association between ethnic identity and self-esteem. The final research question examined was: How does ethnic identity associate with selfesteem? Previous studies regarding the exploration of the relationship between these two variables, ethnic identity and self-esteem, have shown inconsistency. Some studies show that there is a positive relationship between ethnic identity and self-esteem (Allen et al., 1997; J. Lee, 2008; R. Lee, 2005; Phinney, 1992); some reveal no connection between these two variables (Hovey et al., 2006; Rumbaut, 1994; Schnittker, 2002). In this study, the result supported with Allen et al. (1997), J. Lee (2008), R. Lee (2005), and Phinney's (1992) findings that ethnic identity was significantly related to self-esteem. Phinney (1990) argued: "Ethnic identity is central to the psychological functioning of members of ethnic and racial minority groups" (p. 499). A study on examining ethnic and American identity as predictors of self-esteem among the American-born high school students: Latinos, African Americans, and Whites shows that ethnic identity is a significant predictor of selfesteem for these three groups of students, but only White students show that 
American identity is a strong predictor of self-esteem (Phinney, Cantu, \& Kurtz, 1997). It implies that ethnic identity is especially important for the children of immigrants and the racial minority groups regarding the psychological functioning. Therefore, the development of ethnic identity becomes essential for the ethnic minority groups to foster their psychological well-being.

Additional findings in the present study. In the analyses of the relationships between Chinese language proficiency and ethnic identity and between Chinese language proficiency and self-esteem, the subscale reading/writing showed positive correlations with both ethnic identity and self-esteem. The subscale understanding/speaking was only positively related to ethnic identity. Comparing to the degree of the correlation with ethnic identity, the subscale reading/writing was slightly higher than the subscale understanding/speaking. The results echoed Imbens-Bailey's (1997) research findings on 66 Armenian-American children (age from 8 to 15 years), that is, children's level of literacy skills significantly predicts ethnic identity more than oral proficiency does. On the other hand, research suggests that higher literacy abilities in the heritage language may not only contribute to academic achievement (Bankston \& Zhou, 1995; Kim \& Chao, 2009) but also increase self-esteem (Yearwood, 2008), which was supported by this current study as well. Kern (2000) argued that literacy is a "cognitive process that involves creating links between our knowledge and textual forms" (p. 37). To reach the proficiency in literacy is to reach the higher level of language ability. However, the participants in this study showed a lower mean scores of literacy skills than the mean scores of conversational skills, which, in other words, meant that participants' 
reading/writing abilities were not as good as their understanding/speaking abilities. Why are literacy skills difficult to master? In fact, the second-generation Chinese-American children are faced with the salient challenges of maintaining their heritage language, because the structure of Chinese is different from the structure of English. Chinese characters are based on pictographs rather than consisted of alphabets (e.g., “再見”[Zàijiàn] in Chinese characters means "goodbye” in English.), which make the reading and writing abilities more difficult to develop. In addition, the American-born Chinese-American children have more limited opportunities to learn their heritage language than their counterparts born in countries where Chinese is the native language (Kim \& Chao, 2009). Therefore, a primary concern of the Chinese language schools became how to improve students' reading and writing abilities.

Several studies on the second-generation children of immigrants support that those who maintain their heritage languages and ethnic identities have more possibility to succeed in school than those who assimilate to the mainstream culture (Lee, 2002; Lucas, 1997; Portes, 2002). And the more positive self-esteem children have, the better adjusted they are, the more successful they are in school, and the closer relationships they have with their parents (Alves-Martins et al., 2002). With the suggestions stated in the existing studies, it is very important to find that there were positive relationships among Chinese language proficiency, ethnic identity, and self-esteem in the second-generation children of the Chinese immigrants, especially those immigrants who are from Taiwan, for no research so far has particularly focused on the population of Chinese from Taiwan. 


\section{Limitations of the Study}

Because of the research design and the small sample size, there were several limitations in this research, which limit the ability to generalize the research results to a larger population:

1. The non-experimental research design caused the lack of manipulation and control of variables. As a result, the research could only answer the general relationship questions between variables and could not conclude the causality of each other. It impeded the exploration of the in-depth questions, for example, were students' ethnic identity and self-esteem formed during the learning of the Chinese language; if so, how were ethnic identity and selfesteem developed in the process of Chinese language learning; why did the connections happen among Chinese language fluency, ethnic identity, and selfesteem; and how?

2. Although purposive sampling with a small sample size made the participants in this research meet $100 \%$ of the criteria for qualification, the sample was so small when considering other second-generation children of immigrants from the same or different ethnic groups with different ages who were learning their heritage languages at the same time in the Midwest metropolitan city and in the United States.

3. Self-reported survey might cause potential response biases. For example, the use of a rating scale could reflect a tendency for respondents to respond consistently using the particular sections of the scale or avoiding the extremes of a rating scale, thus shrinking its range. The phenomenon was found in this 
study, because the majority of the participants tended to choose the middle of the scale of each item of the CLFQ, the 12-item MEIM, and the RSE.

Furthermore, the self-report questionnaire might also lead the respondents to provide fake answers instead of their true perspectives to produce a desirable outcome.

4. Another limitation of the self-reported survey was that it might cause inconsistent rating with the same item among participants. For example, when both participants with the same age and in the same grade responded they were "very well" in understanding Chinese, it did not necessary mean that these two participants reached the same ability level of Chinese in understanding.

5. About $90 \%$ parents (both father and mother) of the participating families held a degree of Bachelor's or higher. Although the sample might be representative of those families whose children attended these Chinese language schools (JKCS, MZCS, and AGCS), the sample lacked diversity in terms of the highest education parents had obtained, which might not be representative of all of the children who attend other Chinese language schools.

6. There was a wide gap between the sample sizes of the two subgroups with 57 participants in the subgroup one and only 6 participants in the subgroup two. The gap might affect the analyzed results with regard to the test of group difference. 


\section{Implications for Education and Future Research}

The research findings showed that Chinese language proficiency is positively related to ethnic identity and self-esteem. The results, thus, explained that Chinese language learning is significant in the identity formation and the self-esteem development for Chinese-American children. There are several implications gained from this research. These implications are discussed in three categories: implications for Chinese language schools and parents, implications for educators and policymakers, and implications for future research.

Implications for the Chinese language schools and parents. Zhang (2008) argued that it usually relies on the parents and the communities' efforts to maintain the Chinese heritage language in the second-generation children in the host country. Because participants in this this study lived in non-Chinese communities, going to Chinese language school became an important way to learn Chinese outside their homes. In this case, the parents and Chinese language schools play an important role in the second-generation children's Chinese language learning. In this research, parents reported that the reasons they send their child to a Chinese language school are mainly to learn and maintain Chinese, to increase future career opportunities, to learn Chinese culture, to form ethnic identity, and to make friends with Chinese children and families. Chinese language schools, as for these parents and children, are not only the places to learn their heritage language and culture and develop identity, but also the places to build social networks. These reasons suggest that Chinese language schools have irreplaceable functions that cannot be found in the home and in the mainstream schools. More attention should 
be paid to such heritage language schools, because the volunteer parents devote much time to maintain their heritage languages and to make Chinese language schools better. The maintenance of the heritage languages also helps preserve the valuable linguistic resources to this country. However, the public usually does not realize that these schools work very hard to preserve the linguistic resources or may not know that such schools exist.

Another implication for Chinese language schools to consider is that students reported lower mean scores on literacy skills, than on conversational skills. It is not surprising that students' oral skills are usually better than literacy skills in language learning. However, we should put more efforts on figuring out what causes students' weak literacy skills and how to fix it. Simply being fluent in understanding and speaking abilities is not enough to maintain a heritage language. Reading and writing skills need to be reinforced as well. Therefore, more professional development regarding how to improve students' reading and writing skills for teachers may provide Chinese language school teachers information on latest professional pedagogical techniques, which in turn will facilitate students progress. In addition, school administrators, teachers, and parents should work together to examine whether the textbooks provide more focus more on conversation than on literacy, whether the classroom practice emphasizes too much listening and speaking skills, and whether there are very few chances or no chance to practice reading and writing at home. If so, Chinese language schools need to adjust the content of the curriculum, teachers' teaching in the classroom, and the homework assigned to students to make sure that the conversational skills and 
literacy skills are both emphasized in Chinese language learning. If the problem is that students have no motivation to learn due to their busy schedules or feelings of relevance regarding the learning or other factors, then that is another serious issue to be explored.

One more implication for the Chinese language schools is that there is a need to schedule at least one time per school year for teachers to get together to share their teaching experience. The majority of the Chinese language school teachers are volunteer parents who have no teaching experience in the beginning. It will help improve the teaching and classroom management skills if they can have a chance to share their experience and materials with each other or to learn from other teachers' experience. Although the Midwest Chinese Language Schools Association (MCLSA) periodically holds a variety of workshops for Chinese language teachers on weekends (usually for both the mainstream schoolteachers and the Chinese language schoolteachers), not every teacher is able to participate in the workshops. The in-school teacher gathering, therefore, would provide another opportunity for those teachers who attend the workshops to pass on the information they get and to share the experience they learn to other teachers who miss the workshops.

The last one is an implication for parents. The parental support of the heritage language is the key to facilitate Chinese children's heritage language proficiency (Park, Tsai, Liu, \& Lau, 2012). For these students, home is the primary context for Chinese speaking. Results showed that those students whose families spoke Chinese as their primary language in the home had higher Chinese language proficiency than other students whose families primarily spoke a language other 
than Chinese at home. Parents who want their children to be fluent in Chinese and would like to avoid the conflict in communication with their children should keep speaking Chinese to their children, as well as encourage their children to speak Chinese in the home.

Implications for the $\mathrm{K}$ - 12 educators and policymakers. The current study, once again, supported that heritage language proficiency is important to the ethnic minority students. However, the lack of place in the mainstream school settings for students to practice their heritage language, Chinese in this case, can cause the reluctance of the second-generation students to speak and learn Chinese (Zhang, 2008). With more and more immigrant children going to public schools, educators ought to aware and accept the diversity, as well as allow and encourage languages other than English spoken in the school, especially when students need to use their heritage languages to help them study in the school. Schools should create an environment for the language minority students to speak their heritage languages. As Garcia (1995) argued that additive acculturation helps immigrant children succeed in school; bilingual-bicultural education may be one strategy to help reach additive acculturation (Gibson, 1988). Rolstad, Mahoney, and Glass (2005) approved Garcia and Gibson's assertion by reviewing more than 300 studies published in 1985 and later program effectiveness research on the language minority students. Their findings show that bilingual education is consistently superior to English-only instruction and is effective in promoting academic achievement. 
Immigrants who speak a language other than English are increasing. When they immigrate to the U.S., they bring in their native languages, which are precious linguistic resources to this country. Polinsky and Kagan (2007) suggested that heritage language speakers are a severely underutilized national resource; with proper instruction, they are likely to achieve near-native language proficiency, which meet the need for the corporate and government employees who represent our nation to work with other countries that politically and economically tie with the U.S. Once these heritage languages are lost, it will be enormous waste of the resources. Policymakers should rethink the importance of the maintenance of the heritage languages and bilingual education and realize that bilingual programs can benefit not only the English language learners but also this country as a whole. If this is the budget issue that causes the reduction of bilingual programs, policymakers can look for other possibilities, and to collaborate with the heritage language schools is one feasible way to consider. There are many heritage language schools like Chinese language schools existing in the U.S. These schools are well organized with a principal, other school officers, and teachers in each school, although these schools are usually community-based, nonprofit organizations, and teachers are mostly the voluntary parents without teaching experience before they teach in the language schools. Taking these Chinese language schools in this study as an example, they apply textbooks to teach students and have several professional development sessions periodically for teacher training. Moreover, these schools are supported by the Overseas Compatriot Affairs Commission, R.O.C. (Taiwan), which means that these schools also have resources from their homeland and dedicate to 
preserve the Chinese heritage language. If public schools collaborate with the heritage language schools, they can, on the one hand, help train those teachers in the heritage language schools to improve teaching quality, and on the other hand, borrow the resources these heritage language schools already have to better the bilingual programs in the mainstream schools. I believe that the collaboration may create a win-win situation for both public schools and the heritage language schools.

Implications for future research. This study has indicated the positive relationships among Chinese language proficiency, ethnic identity, and self-esteem. It also points to directions for future research. First, the current study only collected participants' self-reported Chinese language proficiency at the point of the time these participants were surveyed. A longitudinal study of the current sample will help investigate the participants' Chinese language learning process and their language ability to find out whether their language ability improves or declines; and how their language proficiency, then, connects to ethnic identity and self-esteem as they grow older. Secondly, the present study targeted students in three Chinese language schools in the Midwest; the research design can only reveal the heritage language situation in this small area. Therefore, to enlarge the sample size and to extend the diversity of the sample based on the participants' socioeconomic status, as well as to include the examination of other ethnic groups to identify the important factors common to the heritage language situation in this country are suggested for further research. Thirdly, the present study focused only on the second-generation children. Future research is suggested to incorporate the first generation and the later generations to compare the differences among generations 
in terms of heritage language proficiency, ethnic identity, and self-esteem; and to explore whether there is a fairly consistent decline in the later generations on heritage language proficiency, and how does it affect the relationships with ethnic identity and with self-esteem? Finally, this study gained only the general idea of the second-generation Chinese Americans' Chinese language learning and touched the surface of the interaction of Chinese language proficiency, ethnic identity, and selfesteem. In-depth, qualitative investigation on how students strengthen their heritage language ability, how students develop their ethnic identity and self-esteem and what the developmental trajectories are, how heritage language proficiency connects to ethnic identity and self-esteem, and whether and how heritage language proficiency affects students' academic performance are needed for future research.

Language plays an important role in linking with the past, with national origins; it is an indispensable tool for communication (Joseph, 2004). With the trend toward globalization and the continual change of the ethnic composition of the U.S. population, there is increasing awareness in the U.S. that not every child is raised in an English-only family. In fact, the population of school-age (age 5-17) children who spoke a language other than English at home rose from 4.7 million to 11.2 million, which grew $138.84 \%$ between 1980 and 2009 (The Condition of Education, 2011). This phenomenon appears that heritage languages are crucial for the children of immigrants to communicate with their parents. In addition, as De Vos (1995) states, "Language is often cited as a major component in the maintenance of a separate ethnic identity...language undoubtedly constitutes the single most characteristic feature of ethnic identity" (p. 23). And the ability of 
bilingualism may contribute to the self-esteem, which ultimately increases the schooling success of the minority children (Lee, 2008). The present study adds to the existing literature by showing that Chinese language proficiency is positively related to ethnic identity and to self-esteem, and ethnic identity is connected to selfesteem. The researcher hopes the results of this study can shed some light on the importance of the maintenance of heritage languages and help justify educational reforms and correct existing problems. 


\section{References}

Allen, M., Howard, L., \& Grimes, D. (1997). Racial group orientation and self-concept: Examining the relationship using meta-analysis. The Howard Journal of Communications, 8, 371-386.

Altschul, I., Bybee, D., \& Oyserman, D. (2008). Racial-ethnic self-schemas and segmented assimilation: Identity and the academic achievement of Hispanic youth. Social Psychology Quarterly, 71, 302-320.

Alves-Martins, M., Peixoto, F., Gouveia-Pereira, M., Amaral, V., \& Pedro, I. (2002). Self-esteem and academic achievement among adolescents. Educational Psychology, 22, 51-62.

Ambert, A. N. \& Melendez, S. E. (1985). Bilingual education: A sourcebook. New York: Garland.

August, D. \& Shanahan, T. (Eds.). (2006). Developing literacy in second-language learners: Report of the National Literacy Panel on language-minority children and youth. Mahwah, NJ: Erlbaum.

Bailey, C. L. \& Oetzel, J. (2004). Tighten me up: Reflecting and maintaining ethnic identity through daily interactions in an African American-owned beauty salon. In M. Fong \& R. Chuang (Eds.), Communicating ethnic and cultural identity (pp. 217-229). Lanham, MD: Rowman \& Littlefield Publishers, Inc.

Baker, C. (1993). Foundations of bilingual education and bilingualism. England: Multilingual Matters Ltd. 
Bankston, C. L., III \& Zhou, M. (1995). Effects of minority-language literacy on the academic achievement of Vietnamese youths in New Orleans. Sociology of Education, 68, 1-17.

Baumeister, R. F., Campbell, J. D., Krueger, J. I., \& Vohs, K. D. (2003). Does high selfesteem cause better performance, interpersonal success, happiness, or healthier lifestyles? Psychological Science in the Public Interest, 4, 1-44.

Beiley, B. (2000). Language and negotiation of ethnic/radical identity among Dominican Americans. Language in Society, 29, 555-582.

Berriz, B. R. (2006). Unz got your tongue: What have we lost with the English-only mandates? The Radical Teacher, 75, 10-15.

Berry, J. W. (2003). Conceptual approaches to acculturation. In K. Chun, P. BallsOrganista, \& G. Marin (Eds.), Acculturation: Advances in theory, measurement and applied research (pp. 17-37). Washington, DC: American Psychological Association.

Berry, J. W., Phinney, J. S., Sam, D. L., \& Vedder, P. (2006). Immigrant youth in cultural transitions: Acculturation, identity, and adaptation across national contexts. Mahwah, NJ: Erlbaum.

Bialystok, E. \& Cummins, J. (2000). Language, cognition, and education of bilingual children. In E. Bialystok (Ed.), Language processing in bilingual children (pp. 222-232). New York: Cambridge University Press.

Bialystok, E. \& Miller, B. (1999). The problem of age in second language acquisition: Influences from language, structure and task. Bilingualism: Language and Cognition, 2, 127-145. 
Blascovich, J. \& Tomaka, J. (1993). Measures of self-esteem. In J. P. Robinson, P. R. Shaver, \& L. S. Wrightsman (Eds.), Measures of personality and social psychological attitudes (3rd ed.) (pp. 115-160). Ann Arbor: Institute for Social Research.

Bosher, S. (1997). Language and cultural identity: A study of Hmong students at the postsecondary level. TESOL Quarterly, 31, 593-603.

Bradford, J., Burrell, N. A., \& Mabry, E. A. (2004). Negotiating cultural identity: Strategies for belonging. In M. Fong \& R. Chuang (Eds.), Communicating ethnic and cultural identity (pp. 313-327). Lanham, MD: Rowman \& Littlefield Publishers, Inc.

Bradunas, E. (1988). Introduction. In E. Bradunas \& B. Topping (Eds.), Ethnic heritage and language schools in America (pp. 13-27). Washington, DC: Library of Congress.

Bratt, K. R. \& Elbousty, Y. (2010). On dangerous grounds: Bilingual teachers of bilingual students in English-only schools on the daily risks of exercising one's professional judgment. Retrieved from http://www.eric.ed.gov/PDFS/ED510701.pdf.

Camarota, S. A. (2012). Immigrants in the United States: A profile of America's foreign-born population. Retrieved from http://cis.org/2012-profile-ofamericas-foreign-born-population\#population.

Chang, I. (2003). The Chinese in America: A narrative history. New York: The Penguin Group. 
Chao, T. (1996). Chinese heritage community language schools in the United States. In X. Wang (Ed.), A view from within: A case study of Chinese heritage community language schools in the United States (pp. 7-14). Washington, DC: The National Foreign Language Center at the John Hopkins University.

Cheatham, G. A., Santos, R. M., \& Ro, Y. E. (2007). Home language acquisition and retention for young children with special needs. Young Exceptional Children, 11, 27-39.

Chen, L. L. (2006). Writing Chinese: Reshaping Chinese cultural identity. New York: Palgrave Macmillan.

Chen, J. (1981). The Chinese of America. San Francisco: Harper \& Row.

Cheng, R. (2010). Evaluating the effect of heritage language on the well-being of Chinese-American youth. (Unpublished master thesis). Southern Connecticut State University, New Haven, Connecticut.

Cho, G. (2000). The role of heritage language in social interactions and relationships: Reflections from a language minority group. Bilingual Research Journal, 24, 369384.

Cho, G., Cho, K., \& Tse, L. (1997). Why ethnic minorities want to develop their heritage language: The case of Korean-Americans. Language, Culture, and Curriculum, 10, 106-112.

Cho, G. \& Krashen, S. (1998). The negative consequences of heritage language loss and why we should. In S. D. Krashen, L. Tse, \& J. McQuillan (Eds.), Heritage language development (pp. 31-39). Culver City, CA: Language Education Associates. 
Chuang, G. (1997). A survey of Chinese school teachers in suburban New York. (Unpublished manuscript), New York University, New York.

Chuang, R. (2004). Theoretical perspectives: Fluidity and complexity of cultural and ethnic identity. In M. Fong \& R. Chuang (Eds.), Communicating ethnic and cultural identity (pp. 51-68). Lanham, MD: Rowman \& Littlefield Publishers, Inc.

Clark, K. B. \& Clark, M. P. (1947). Racial identification and preference in Negro children. In T. M. Newcomb \& E. L. Harley (Eds.), Readings in social psychology (pp. 169-179). New York: Holt.

Crawford, J. (2000). At war with diversity: US language policy in an age of anxiety. Buffalo, NY: Multilingual Matters Ltd.

Cummins, J. (1983). Language proficiency, biliteracy and French immersion. Canadian Journal of Education, 8, 117-137.

Cummins, J. \& Swain, M. (1986). Bilingualism in education: Aspects of theory, research, and practice. London: Longman.

De Vos, G. A. (1995). Ethnic pluralism: Conflict and accommodation. In L. Romanucci-Ross \& G. A. De Vos (Eds.), Ethnic identity: Creation, conflict, and accommodation (3rd ed.) (pp. 15-47). Walnut Creek, CA: Alta Mira Press.

Douglas, M. O. (2005). Pedagogical theories and approaches to teach young learners of Japanese as a heritage language. Heritage Language Journal, 3, 60-82.

Edelsky, C. (1986). Writing in a bilingual program: Haba una vez. Norwood, NJ: Ablex. 
Edwards, J. R. (1977). Ethnic identity and bilingual education. In H. Giles (Ed.), Language, ethnicity and intergroup relations (pp. 253-282). New York: Academic Press ING.

Fernandez, R. \& Nielsen, F. (1986). Bilingualism and Hispanic scholastic achievement: Some baseline results. Social Science Research, 15, 43-70.

Feuerverger, G. (1991). University students' perceptions of heritage language learning and ethnic identity maintenance. The Canadian Modern Language Review, 47, 660-676.

Fishman, J. A. (1985). Mother-tongue claiming in the United States since 1960: Trends and correlates. In J. A. Fishman, M. H. Gertner, E. G. Lowy, \& W. G. Milan (Eds.), The rise and fall of the ethnic revival: Perspectives on language and ethnicity (pp. 107-194). Berlin, Germany: Mouton.

Flege, J. E., Yeni-Komshian, G. H. \& Liu, S. (1999). Age constraints on secondlanguage acquisition. Journal of Memory and Language, 41, 78-104.

Fong, M. (2004). Ethnic and cultural identity: Distinguishing features. In M. Fong \& R. Chuang (Eds.), Communicating ethnic and cultural identity (pp. 35-50). Lanham, MD: Rowman \& Littlefield Publishers, Inc.

Freeman, Y. S. \& Freeman, D. (1992). Whole language for second language learners. Portsmouth, NH: Heinemann.

Garcia, E. (2002). Student cultural diversity: Understanding and meeting the challenge (3rd ed.). New York: Houghton Mifflin Company.

Garcia, G. (n. d.). Bilingual education. Retrieved from http://www.education.com/reference/article/bilingual-education/. 
Garcia, H. (1985). Family and offspring language maintenance and their effects of Chicano college students' confidence and grades. In E. Garcia \& R. Padilla (Eds.), Advances in bilingual education research (pp. 226-243). Tucson: University of Arizona Press.

Genesee, F., Lindholm-Leary, K., Saunders, W., \& Christian, D. (Eds.). (2006).

Educating English language learners: A synthesis of research evidence. Cambridge, UK: Cambridge University Press.

Gibson, M. A. (1988). Accommodation without assimilation. Ithaca, NY: Cornell University Press.

Gibson, M. A. (1995). Promoting additive acculturation in schools. Multicultural Education, 3, 10-12, 54.

Gibson, M. A. \& Ogbu, J. (Eds.). (1991). Minority status and schooling: A comparative study of immigrant and involuntary minorities. New York: Garland.

Gove, W. R., Style, C. B., \& Hughes, M. (1990). The effect of marriage on the wellbeing of adults: A theoretical analysis. Journal of Family Issues, 11, 4-35.

Grolnick, W. S. \& Beiswenger, K. L. (2006). Facilitating children's self-esteem: The role of parents and teachers. In M. H. Kernis (Ed.), Self-esteem issues and answers: A source book of current perspectives (pp. 230-237). New York: Psychology Press.

Guthrie, G. P. (1985). A school divided: An ethnography of bilingual education in a Chinese community. Hillsdale, NJ: Erlbaum.

Hagborg, W. (1996). Scores of middle-school-age students on the Rosenberg selfesteem scale. Psychological Reports, 78, 1071-1074. 
Hakuta, K. (1986). Mirror of language: The debate on bilingualism. New York: Basic Books.

Haney, P. \& Durlak, J. A. (1998). Changing self-esteem in children and adolescents: A meta-analytical review. Journal of Clinical Child Psychology, 27, 423-433.

Harter, S. (2006). The development of self-esteem. In M. H. Kernis (Ed.), Self-esteem issues and answers: A sourcebook of current perspectives (pp. 144-150). New York: Psychology Press.

Haugen, R. \& Lund, T. (2002). Self-concept, attributional style and depression. Educational Psychology, 22, 305-315.

He, A. W. (2008). An identity-based model for the development of Chinese as a heritage language. In A. W. He \& Y. Xiao (Eds.), Chinese as a heritage language: Fostering rooted world citizenry (pp. 109-121). Honolulu: University of Hawaii Press.

Hecht, M. L., Collier, M. J., \& Ribeau, S. A. (1993). African American communication: Ethnic identity and cultural interpretation. Newbury Park, CA: SAGE.

Hones, D. F. \& Cha, S. C. (1999). Educating new Americans: Immigrants' lives and learnings. Mahwah, NJ: Lawrence Erlbaum Associates.

Hornberger, N. H. (2004). Nichols to NCLB: Local and global perspectives on US language education policy. Presentation at $14^{\text {th }}$ Annual Nessa Wolfson Colloquium Graduate School of Education, University of Pennsylvania.

Hosogi, M., Okada, A., Fujii, C., Noguchi, K., \& Watanabe, K. (2012). Importance and usefulness of evaluating self-esteem in children. BioPsychoSocial Medicine, 6, 914. 
Hovey, J. D., Kim, S. E., \& Seligman, L. D. (2006). The influences of cultural values, ethnic identity, and language use on the mental health of Korean American college students. The Journal of Psychology, 140, 499-511.

Humes, K. R., Jones, N. A., \& Ramirez, R. R. (2011). Overview of race and Hispanic origin:2010. United States Census Bureau.

Hurtado, A. \& Gurin, P. (1995). Ethnic identity and bilingualism attitudes. In A., Padilla (Ed.), Hispanic psychology: Critical issues in theory and research (pp. 89103). Thousand Oaks, CA: SAGE.

Imbens-Bailey, A. L. (1997). Oral proficiency and literacy skills in an ancestral language: Implications for ethnic identity. Paper presented at the Biennial Meeting of the Society for Research in Child Development, Washington, DC. Javier, R. A. (2007). The bilingual mind: Thinking, feeling and speaking in two languages. New York: Springer.

Jeon, M. (2008). Korean heritage language maintenance and language ideology. Heritage Languages Journal, 6, 54-71.

Jia, G. (2008). Heritage language development, maintenance, and attrition among recent Chinese immigrants in New York City. In A. W. He \& Y. Xiao (Eds.), Chinese as a heritage language: Fostering rooted world citizenry (pp. 189-203). Honolulu, HI: University of Hawai'i, National Foreign Language Resource Center.

Jia, G. \& Aaronson, D. (2003). A longitudinal study of Chinese children and adolescents learning English in the US. Applied Psycholinguistics, 24, 131-161. 
Jo, H. (2001). 'Heritage' language learning and ethnic identity: Korean Americans' struggle with language authorities. Language, Culture, and Curriculum, 14, 2641.

Johnson, B. \& Christensen, L. (2000). Educational research: Quantitative and qualitative approaches. Needham Heights, MA: Allyn and Bacon.

Joseph, J. E. (2004). Language and identity: National, ethnic, religious. New York: Palgrave Macmillan.

Kern, R. (2000). Literacy and language teaching. Oxford: Oxford University Press.

Kim, S. Y. \& Chao, R. K. (2009). Heritage language fluency, ethnic identity, and school effort of immigrant Chinese and Mexican adolescents. Cultural Diversity and Ethnic Minority Psychology, 15, 27-37.

Kinder, K., Harland, J., Wilkin, A., \& Wakefield, A. (1995). Three to remember: Strategies for disaffected pupils. Slough, Berkshire: National Foundation for Educational Research.

Koch, E. J. (2006). Examining the role of self-esteem in psychological functioning and well-being. In M. H. Kernis (Ed.), Self-esteem issues and answers: A sourcebook of current perspectives (pp. 260-266). New York: Psychology.

Krashen, S. (1998). Heritage language development: Some practical arguments. In S. D. Krashen, L. Tse, \& J. McQuillan (Eds.), Heritage language development (pp. 313). Culver City, CA: Language Education Associates.

Kuo, E. C. Y. (1974). Bilingual pattern of a Chinese immigrant group in the United States. Anthropological Linguistics, 16, 128-140.

Kwong, P. (1996). The new Chinatown. New York: Hill and Wang. 
LaFromboise, T., Coleman, H. L. K., \& Gerton, J. (1993). Psychological impact of biculturalism: Evidence and theory. Psychological Bulletin, 114, 395-412.

Lai, H. M. (2004). Becoming Chinese American: A history of communities and institutions. Walnut Creek, CA: AltaMira Press.

Lai, H. M., Huang, J., \& Wong, D. (1980). The Chinese of America: 1785-1980. San Francisco: Chinese Culture Foundation.

Landry, R. \& Allard, R. (1992). Ethnolinguistic vitality and bilingual development of minority and majority group students. In W. Face, K. Jaspaert, \& S. Kroon (Eds.), Maintenance and loss of minority languages (pp. 171-186). Amsterdam: John Benjamins.

Lao, C. (2004). Parents' attitudes toward Chinese-English bilingual education and Chinese-language use. Bilingual Research Journal, 28, 99-121.

Lee, J. W. (2008). The effect of ethnic identity and bilingual confidence on Chinese youth's self-esteem. The Alberta Journal of Educational Research, 54, 83-96.

Lee, R. M. (2005). Resilience against discrimination: Ethnic identity and other-group orientation as protective factors for Korean Americans. Journal of Counseling Psychology, 52, 36-44.

Lee, S. K. (2002). The significance of language and cultural education on secondary achievement: A survey of Chinese-American and Korean-American Students. Bilingual Research Journal, 26, 327-338.

Leung, E. C. (1975). A sociological study of the Chinese language schools in the San Francisco Bay area. (Unpublished doctoral dissertation). University of Missouri, Columbia. 
Li, G. (2006). The role of parents in heritage language maintenance and development: Case studies of Chinese immigrant children's home practices. In K. Kondo-Brown (Ed.), Heritage language development: Focus on East Asian immigrants (pp. 15-31). Philadelphia: John Benjamins North America.

Li, M. (2005). The role of parents in Chinese heritage-language schools. Bilingual Research Journal, 29, 197-207.

Li, W. L. (1982). The language shift of Chinese-Americans. International Journal of the Sociology of Language, 38, 109-124.

Liu, N. (2010, November). Chinese heritage language schools in the United States. Heritage Briefs Collection.

Liu, P. C. (1976). [In Chinese] A history of the Chinese in the United States of America. Taipei: Liming.

Lopez, D. E. (1982). Language maintenance and shift in the United States today: The basic patterns and their social implications, Volume 1-4. Los Alamitos, CA: National Center for Bilingual Research.

Lu, M. (1998). English-only movement: Its consequences on the English of language minority children. ERIC Clearinghouse on Reading English and Communication Bloomington IN.

Lu, X. (2001). Bicultural identity development and Chinese community formation: An ethnographic study of Chinese schools in Chicago. The Howard Journal of Communications, 12, 203-220.

Lu, X. \& Li, G. (2008). Motivation and achievement in Chinese language learning: A comparative analysis. In A. W. He \& Y. Xiao (Eds.), Chinese as a heritage 
language: Fostering rooted world citizenry (pp. 89-108). Honolulu, HI:

University of Hawai'i, National Foreign Language Resource Center.

Lucas, T. (1997). Into, through, and beyond secondary schools: Critical transitions for immigrant youths. Washington, DC and McHenry, IL: Center for Applied Linguistics and Delta Systems.

Ludanyi, R. \& Liu, N. (2011). German heritage language schools in the United States. Heritage Briefs Collection. Retrieved from http://www.cal.org/heritage/pdfs/briefs/german-heritage-language-schoolsin-the-united-states.pdf.

Maloof, V. M., Rubin, D. L., \& Niller, A. N. (2006). Cultural competence and identity in cross-cultural adaptation: The role of a Vietnamese heritage language school. The International Journal of Bilingual Education and Bilingualism, 9, 255-273.

Man, E. Y. (2006). First language use and language behavior of Chinese students in Toronto, Canada. In K. Kondo-Brown (Ed.), Heritage language development: Focus on East Asian immigrants (pp. 209-241). Philadelphia: John Benjamins North America.

Marian, V., Blumenfeld, H. K., \& Kaushanskaya, M. (2007). The Language Experience and Proficiency Questionnaire (LEAP-Q): Assessing language profiles in bilinguals and multilinguals. Journal of Speech, Language, and Hearing Research, 50, $940-967$.

Marsh, H., Byrne, B., \& Yeung, A. (1999). Causal ordering of academic self-concept and achievement: Reanalysis of a pioneering study and revised recommendations. Educational Psychologist, 34, 155-167. 
McGinnis, S. (2005). More than a silver bullet: The role of Chinese as a heritage language in the United States. The Modern Language Journal, 89, 592-594.

McGinnis, S. (2008). From mirror to compass: The Chinese heritage language education sector in the United States. In D. M. Brinton, O. Kagan, \& S. Bauckus (Eds.), Heritage language education: A new field emerging (pp. 229-242). New York: Routledge.

Mora, J. K. (2009). From the ballot box to the classroom. Educational Leadership, 66, 14-19.

Nagel, J. (1999). Constructing ethnicity: Creating and recreating ethnic identity and culture. In N. R. Yetman (Ed.), Majority and minority: The dynamics of race and ethnicity in American life (6th ed.) (pp. 57-71). Needham Heights, MA: Allyn and Bacon.

Ng, E. (1999). The impact of heritage education on self-esteem and ethnic identity. (Unpublished doctoral dissertation ). Pace University, New York.

Nguyen, H., Rawana, J. S., \& Flora, D. B. (2011). Risk and protective predictors of trajectories of depressive symptoms among adolescents from immigrant backgrounds. Journal of Youth Adolescence, 40, 1544-1558.

Norton, B. (2000). Investment, acculturation, and language loss. In S. L. McKay \& S. C. Wong (Eds.), New immigrants in the United States (pp. 443-461). New York: Cambridge University Press.

Oh, J. S. \& Fuligni, A. J. (2010). The role of heritage language development in the ethnic identity and family relationships of adolescents from immigrant backgrounds. Social Development, 19, 202-220. 
Oketani, H. (1997). Japanese-Canadian youths as additive bilinguals: A case study. MOSAIC, 42, 14-18.

Ortiz, V. \& Arce, C. H. (1984). Language orientation and mental health status among persons of Mexican descent. Hispanic Journal of Behavioral Sciences, 6, 127-143.

Ovando, C. J. (2003). Bilingual education in the United States: Historical development and current issues. Bilingual Research Journal, 27, 1-24.

Park, H., Tsai, K., Liu, L., \& Lau, A. (2012). Transactional associations between supportive family climate and young children's heritage language proficiency in immigrant families. International Journal of Behavioral Development, 36, 226236.

Parrish, T. B., Pérez, M., Merickel, A., \& Linquanti, R. (2006). Effects of the implementation of Proposition 227 on the education of English learners, $K-12$ : Findings from a five-year evaluation. Final Report submitted to California Department of Education, Sacramento: America Institutes for Research/WestEd.

Pease-Alvarez L. (2002). Moving beyond linear trajectories of language shift and bilingual language socialization. Hispanic Journal of Behavioral Sciences, 24, 114-137.

Perez, R. M. (2011). Linguistic acculturation and context on self-esteem: Hispanic youth between cultures. Child Adolescent Social Work Journal, 28, 203-228.

Peyton, J., Ranard, D. A., \& McGinnis, S. (Eds.). (2001). Heritage languages in America: Preserving a national resource. McHenry, IL: Center for Applied Linguistics. 
Pham, T. B. \& Harris, R. J. (2001). Acculturation strategies among VietnameseAmericans. International Journal of Intercultural Relations, 25, 279-300.

Phinney, J. S. (1990). Ethnic identity in adolescents and adults: Review of research. Psychological Bulletin, 108, 499-514.

Phinney, J. S. (1992). The multigroup ethnic identity measure: A new scale for use with adolescents and young adults from diverse groups. Journal of Adolescent Research, 7, 156-176.

Phinney, J. S., Cantu, C. L., \& Kurtz, D. A. (1997). Ethnic and American identity as predictors of self-esteem among African American, Latino, and White adolescents. Journal of Youth and Adolescence, 26, 165-185.

Phinney, J. S., Chavira, V., \& Williamson, L. (1992). Acculturation attitudes \& selfesteem among high school \& college students. Youth \& Society, 23, 299-312.

Phinney, J.S., Romero, I., Nava, M., \& Huang, D. (2001). The role of language, parents, and peers in ethnic identity among adolescents in immigrant families. Journal of Youth and Adolescence, 30, 135-153.

Polinsky, M. \& Kagan, O. (2007). Heritage languages in the 'wild' and in the classroom. Language and Linguistic Compass, 1, 368-395.

Portes, A. (2002). English-only triumphs, but the costs are high. Contexts, 1, 10-15.

Portes, A. \& Hao, L. (2002). The price of uniformity: Language, family and personality adjustment in the immigrant second generation. Ethnic and Racial Studies, 25, 889-912.

Portes, A. \& Rumbaut, R. G. (2001). Legacies: The story of the immigrant second generation. Berkeley and Los Angeles: University of California Press. 
Portes, A. \& Rumbaut, R. G. (2006). Immigrant America (3rd ed.). Berkeley and Los Angeles: University of California Press.

Robinson, L. (2009). Cultural identity and acculturation preferences among South Asia adolescents in Britain: An exploratory study. Children \& Society, 23, 442454.

Roberts, R. E., Phinney, J. S., Masse, L. C., Chen, Y. R., Roberts, C. R., \& Romero, A. (1999). The structure of ethnic identity of young adolescents from diverse ethnocultural groups. Journal of Early Adolescence, 19, 301-332.

Rodriguez, A. (1968). Bilingual education. Paper presented at National Conference on Education Opportunities for the Mexican-American, Austin, Texas.

Rolstad, K., Mahoney, K., \& Glass, G. (2005). The big picture: A meta-analysis of program effectiveness research on English language learners. Educational Policy, 19, 572-594.

Rosenberg, M. (1986). Conceiving the self (reprint ed.). Malabar, FL: Robert E. Krieger Publishing Company.

Rosenberg, M. (1989). Society and the adolescent self-image (revised ed.). Middletown, CT: Wesleyan University Press.

Rosenberg, M., Schooler, C., \& Schoenbach, C. (1989). Self-esteem and adolescent problems: Modeling reciprocal effects. American Sociological Review, 54, 10041018.

Rossell, C. H. (2003). The near end of bilingual education. Education Next, 3, 44-52. 
Rumbaut, R. G. (1994). The crucible within: Ethnic identity, self-esteem, and segmented assimilation among children of immigrants. International Migration Review, 28, 748-794.

Ryan, E. B. \& Carranza, M. A. (1997). Language and ethnicity. In H. Giles (ed.), Language ethnicity and intergroup relations (pp. 59-82). New York: Academic Press ING.

Salinas, R. A. (2006). All children can learn...to speak English. National Forum of Educational Administration and Supervision Journal, 23, 20-24.

Schneider, S. G. (1976). Revolution, reaction, or reform: The 1974 Bilingual Education Act. New York: Las Americas.

Schnittker, J. (2002). Acculturation in context: The self-esteem of Chinese immigrants. Social Psychology Quarterly, 65, 56-76.

Severns, M. (2012). Starting early with English language learners: First lessons from Illinois. New America Foundation.

Shin, S. J. (2005). Developing in two languages: Korean children in America. Clevedon, England: Multilingual Matters.

Skutnabb-Kangas, T. (1995). Multilingualism and the education of minority children. In O. Garcia \& C. Baker (Eds.), Policy and practice in bilingual education: Extending the foundations (pp. 40-62). Philadelphia: Multilingual Matters.

Smith, E. J. (1991). Ethnic identity development: Toward the development of a theory within the context of majority/minority status. Journal of Counseling and Development, 70, 181-188. 
Smith K. F. \& Baldauf, R. B. (1982). The concurrent validity of self-rating with interviewer rating on the Australian Second Language Proficiency Ratings Scale. Educational and Psychological Measurement, 42, 1117-1124.

Stalikas, A. \& Gavaki, E. (1995). The importance of ethnic identity: Self-esteem and academic achievement of second-generation Greeks in secondary school. Canadian Journal of School Psychology, 11, 1-9.

Stewner-Manzanares, G. (1988). The Bilingual Education Act: Twenty years later. New Focus, 6, 1-8.

Suárez-Orozco, M. M., Suárez-Orozco, C., \& Qin, D. B. (Eds.). (2004). The new immigration: An interdisciplinary reader. New York: Taylor \& Francis Group.

Takaki, R. (1989). Strangers from a different shore: A history of Asian Americans. Boston: Little, Brown and Company.

Tannenbaum, M. (2005). Viewing family relations through a linguistic lens: Symbolic aspects of language maintenance in immigrant families. The Journal of Family Communication, 5, 229-252.

Teske, R. H. C., Jr. \& Nelson, B. H. (1974). Acculturation and assimilation: A clarification. American Ethnologist, 1, 351-367.

The Condition of Education. (2011). Children who spoke a language other than English at home. U.S. Department of Education.

Ting-Toomey, S. (1989). Identity and interpersonal bonding. In M. K. Asante \& W. B. Gudykunst (Eds.), Handbook of international and intercultural communication (pp. 117-144). Newbury Park, CA: SAGE. 
Tsai, J. L., Ying, Y., \& Lee, P. A. (2001). Cultural predictors of self-esteem: A study of Chinese American female and male young adults. Cultural Diversity and Ethnic Minority Psychology, 7, 284-297.

Tse, L. (1998). Affecting affect: The impact of heritage language programs on student attitudes. In S. D. Krashen, L. Tse, \& J. McQuillan (Eds.), Heritage language development (pp. 51-72). Culver City, CA: Language Education Associates.

Tucker, G. R. (2008). Learning other languages: The case for promoting bilingualism within our educational system. In D. M. Brinton, O. Kagan, \& S. Bauckus (Eds.), Heritage language education: A new field emerging (pp. 39-51). New York: Routledge.

U.S. Census Bureau. (2010). American factor finder. Retrieved from http://factfinder2.census.gov/faces/nav/jsf/pages/index.xhtml.

Veltman, C. (2000). The American linguistic mosaic. In S. L. McKay \& S. C. Wong (Eds.), New immigrants in the United States (pp. 58-93). New York: Cambridge University Press.

Wang, L. C. (1995). Integration or separation in a shrinking world: Overseas Chinese education policies and strategies in the Post-Cold War era. In Proceedings on Chinese Education in Southeast Asia (pp. 352-372). National Pingtung Teachers College.

Wang, S. C. (2007). Building societal capital: Chinese in the US. Language Policy, 6, 27-52. 
Whitesell, N. R., Mitchell, C. M., Spicer, P., \& The Voice of Indian Teens Project Team. (2009). A longitudinal study of self-esteem, cultural identity, and academic success among American Indian adolescents. Cultural Diversity and Ethnic Minority Psychology, 15, 38-50.

Wiley, T. G. et al., (2008). Attitudes toward Mandarin, heritage languages, and dialect diversity among Chinese immigrants and international students in the United States. In A. W. He \& Y. Xiao (Eds.), Chinese as a heritage language: Fostering rooted world citizenry (pp. 67-87). Honolulu, HI: University of Hawai'i, National Foreign Language Resource Center.

Wilson, K. M. (1999). Validity of global self-ratings of ESL speaking proficiency based on an FSI/ILR-Reference Scale. ETS, Statistics \& Research Division.

Wong, A. (1980, October). Chinese bilingual education: Current status and issues. Paper presented at the National Conference on Chinese American Studies, San Francisco.

Wong, S. C. \& López, M. G. (2000). English language learners of Chinese background. In S. L. McKay \& S. C. Wong (Eds.), New immigrants in the United States (pp. 264305). New York: Cambridge University Press.

Wong-Fillmore, L. (1991). When learning a second language means losing the first. Early Childhood Research Quarterly, 6, 323-346.

Wright, S. C. \& Taylor, D. M. (1995). Identity and the language of the classroom: Investigating the impact of heritage versus second language instruction on personal and collective self-esteem. Journal of Educational Psychology, 87, 241252. 
Yearwood, E. (2008). Psychosocial implications for heritage language maintenance. Journal of Child and Adolescents Psychiatric Nursing, 21, 62-63.

Yep, G. A. (1998). My three cultures: Navigating the multicultural identity landscape. In J. M. Martin, T. K. Nakayama, \& L. A. Flores (Eds.), Readings in cultural contexts (pp. 79-85). Mountain View, CA: Mayfield.

Zehr, M. A. (2008). NAEP scores in states that cut bilingual Ed. fuel concern on ELLs. Education Week, 27, 10.

Zanden, V. (1990). American minority relations. New York: McGraw-Hill.

Zhang, D. (2008). Between two generation: Language maintenance and acculturation among Chinese immigrant families. El Paso, TX: LFB Scholarly Publishing LLC.

Zhou, M. \& Li, X. (2003). Ethnic language schools and the development of supplementary education in the immigrant Chinese community in the United States. New Directions for youth Development, 100, 57-73. 